\title{
Mushrooms do not contain flavonoids
}

\author{
Alicia Gil-Ramírez ${ }^{a^{*}}$, Cristina Pavo-Caballero $^{a}$, Esther Baeza $^{\mathrm{a}}$, Nieves Baenas ${ }^{\mathrm{b}}$, \\ Cristina Garcia-Viguerab, Francisco R. Marín ${ }^{\text {a }}$, Cristina Soler-Rivas ${ }^{\text {a }}$ \\ ${ }^{a}$ Department of Production and Characterization of Novel Foods. CIAL-Research Institute in Food \\ Science (UAM-CSIC). Madrid. Spain. \\ ${ }^{b}$ Department of Food Science and Technology. CEBAS-CSIC, Murcia, Spain \\ *Corresponding author: aliciagilramirez@gmail.com/alicia.gil@uam.es \\ Running title: Mushrooms do not contain flavonoids. \\ Keywords: mushrooms, flavonoids, chalcone synthase, chalcone isomerase, phenylalanine \\ ammonia-lyase. \\ Chemical compounds studied in this article: Quercetin (PubChem CID: 5280343); Hesperidin \\ (PubChem CID: 3594); Luteolin (PubChem CID: 5280445); Luteolin-7-O-glucoside (PubChem \\ CID: 5280637); Gallic acid (PubChem CID: 370); Caffeic acid (PubChem CID: 689043); L-3,4- \\ dihydroxyphenylalanine (PubChem CID: 6047) and ergosterol (PubChem CID: 444679). \\ Abbreviations: phenylalanine ammonia-lyase (PAL), chalcone synthase (CHS) and chalcone \\ flavanone isomerase $(\mathrm{CHI})$.
}




\section{ABSTRACT}

A literature and database review and several experiments were carried out because of the perturbing increase and exponential spreading of a major mistake thought scientific publications. Up to October 2015, more than 136 reports ensured that mushrooms contain flavonoids. However, 91\% of the publications used an unspecific colorimetric method that was developed to quantify them in plants. However, no sequences encoding chalcone synthase or chalcone isomerase (key enzymes involved in the flavonoid biosynthetic pathway) were found in genomic databases even in completely sequenced mushrooms indicating that they do not have the enzymes needed for their production. Fruiting bodies obtained from substrates containing onion wastes and mycelia grown on media supplemented with specific flavonoids showed no flavonoid content after HPLC DAD/MS determinations indicating that they were also unable of absorbing them. 


\section{Introduction}

Flavonoids are already for decades intimately associated with plant kingdom, particularly with land plants (Harborne, 1994; Robards \& Antolovich, 1997; Winkel, 2006) and it is widely accepted by the scientific community that flavonoids are plant secondary metabolites. Although edible mushrooms belong to a completely different kingdom than plants, since 2005 an exponential increase in the number of publications has been noticed measuring these compounds that are almost restricted to the vegetal word in mushrooms. The fast spreading of this mistake is alarming since many other publications and even reviews are giving it for granted and justifying fungal bioactivities due to the action of these compounds (Fernandes, Antonio, Oliveira, Martins, \& Ferreira, 2012; Guillamón et al., 2010; Jayakumar, Thomas, Sheu, \& Geraldine, 2011).

Flavonoids are compounds derived from the secondary metabolism in plants from precursors originated via two different pathways of primary metabolism, phenylpropanoid derivatives and malonyl-CoA Malonyl-CoA is synthesised by carboxylation of acetyl-CoA, a central intermediate in the tricarboxylic acid cycle. Coumaroyl-CoA is synthesised from the amino acid phenylalanine by three enzymatic steps initiated by phenylalanine ammonia-lyase (PAL) within the so called phenylpropanoid pathway, involved in the biosynthesis of many other compounds besides flavonoids (lignans, coumarins, stilbenes etc.). Flavonoid synthesis starts by condensation of 4-coumaroyl-CoA with three molecules of malonylCoA yielding naringenin chalcone. This reaction is catalyzed by chalcone synthase (CHS). The generated chalcone is subsequently isomerised by chalcone flavanone isomerase $(\mathrm{CHI})$ to yield a flavanone. From these central intermediates the pathway diverges into several side branches, each yielding a different class of flavonoids, isoflavones, anthocyanins etc. (Winkel, 2006).

Nowadays, flavonoid biosynthesis is considered as a classical example of a pathway that evolved gradually by genetic change through specialization of a duplicate gene and also through the evolution of the regulatory control on such gene. The climax of complexity may be exemplified in anthocyanin synthesis where six sequential biochemical reactions enabled by six different enzymes are involved (Winkel, 2006). Land plants are believed to have evolved from organisms like green algae (Charales) and although extensive surveys were conducted, flavonoids were not found in algae (Markham, 1988). Furthermore, chalcone 
synthase (the entry point to flavonoid byosintesis) was not described in green algae (Charales) but it was in

liverworts (Marchantiophyta) and mosses (Bryophyta) until more complex organisms such as flowering plants (Angiosperma). The complexity of the flavonoid pathways and the synthetized compounds fit with this evolutionary model (Rausher, 2006).

Mushrooms share with plants similarities in the biosynthetic pathways to generate phenolic compounds as precursors of melanins. The melanogenesis starts with the shikimate pathway derived from the Krebs cycle (as initial steps of the phenylpropanoid pathway) when the fungal hyphae are damaged or infected (SolerRivas, Jolivet, Arpin, Olivier, \& Wichers, 1999). Then, phenolic compounds are substrates of polyphenol oxydases or peroxidases that catalyse oxidative reactions yielding diphenols, quinones and further intermediate complexes that spontaneously generate GHB-, DOPA-derivative melanins or other specific compounds.

The reported presence of flavonoids in mushrooms could be due to the facility of these organisms to absorb many nutrients and compounds from the substrate where they grow or from neighbouring plants by spreading their hyphae or forming mycorrhizae. Certain flavonoids are released by some plants to regulate these symbiotic plant-microbe interactions defining the species tolerated to grow on their roots (Grotewold, 2006). Although in taking of these compounds might negatively affect fungal growth because flavonoids are frequently produced by plant as protection against fungal infections indeed, they were widely reported as antifungal compounds (Grotewold, 2006).

Thus, in this work a detailed review of the literature was carried out to elucidate how this mistake might have appeared and evolved until its fast spreading acceptance. The methodological mistake was reproduced in order to explain the causes of the pitfall and other experiments and searches were carried out to confirm that mushrooms cannot synthetize flavonoids neither absorb them from neighbouring plants.

\section{Experimental Section}

\subsection{Biological material}

Mushroom strains used in this investigation were Lentinus edodes, Pleurotus ostreatus, Pleurotus eryngii, Pleurotus pulmonarius, Agaricus bisporus, Agaricus blazei, Amanita ponderosa, Amanita caesarea, Lactarius 
deliciosus, Craterellus cornucopioides, Cantharellus cibarius, Lyophyllum shimeji, Agrocybe aegerita,

Auricularia judea, Calocybe gambosa, Ganoderma lucidum, Hydnum repandum, Lepiota procera, Grifola frondosa, Pholiota nameko, Hericium erinaceus, Boletus edulis, and Morchella conica. Fruiting bodies from wild mushrooms were purchased on season from the local market in Madrid (Spain). The cultivable strains were grown at $\mathrm{CTICH}$ (Centro Tecnológico de Investigación del Champiñón de La Rioja, Autol, Spain). Fruiting bodies were frozen at $-20^{\circ} \mathrm{C}$ and freeze-dried. Dehydrated samples were ground into fine powder as described in Gil-Ramírez et al. (2013) and stored at $-20^{\circ} \mathrm{C}$ until further use.

Commercial fully grown spawn of Pleurotus ostreatus K8 was kindly donated by Micelios Fungisem S.A. (Autol, La Rioja, Spain) and was used to obtain fruiting bodies or mycelium subcultures.

\subsection{Reagents}

Malt extract agar (MEA), sodium hydroxide, quercetin, hesperidin, gallic, cafeic and formic acids, sodium nitrite, L-3,4-dihydroxyphenylalanine (L-DOPA) and Folin-Ciocalteu's reagent were purchased from SigmaAldrich (Madrid, Spain). Luteolin and luteolin-7-O-glucoside were obtained from Extrasynthese (Lyon Nord, France). $\mathrm{AlCl}_{3} \cdot \mathrm{H} 2 \mathrm{O}$ was purchased at Panreac (Barcelona, Spain), ergosterol hydrate at Alfa Aesar Gmbh \& CoKG (Karlsruhe, Germany) and methanol (HPLC grade) at LAB-SCAN (Gliwice, Poland).

\subsection{Systematic review of the literature}

A quantitative and systematic search of the literature was carried out using the key words 'mushroom' and 'flavonoid' in the Web of Science ${ }^{\mathrm{TM}}$ (Thomson Reuters) by selecting 'all years' (system start searching from 1864 up to now). The search included listed records up to October 2015.

Records were reviewed one by one and selected only if the abstract or title was indicating that flavonoids (as total flavonoids or as specific identified flavonoid) were determined in mushrooms. Selected references were listed extracting the publication year, Impact factor (IF) of the journal that year (except for those articles published in 2015 where the indicated IF is from 2014), name of flavonoid identified (or total flavonoid determination), methodology utilized for their determination and detection device used, mushroom species analysed, type of extract (where indicated) and other considerations (see the Supplementary Table 1). 


\subsection{In silico search for enzymes involved in the flavonoid biosynthesis}

A protein search was carried out using Pfam (http://pfam.xfam.org/) and Blast ${ }^{\circledR}$ (Basic local alignment search tool) (http://blast.ncbi.nlm.nih.gov/Blast.cgi) looking for specific sequences of enzymes involved in the biosynthesis of phenolic compounds and flavonoids. The selected key enzymes were phenylalanine ammonia-lyase (PAL), chalcone synthase (CHS) and chalcone isomerase (CHI). The taxonomic distribution of the enzymes through the Eukaryote organisms was monitored using the Sunburst species distribution of Pfam. Afterwards, the CHS amino acid sequence (393 aa) from Vitis vinifera was obtained from Genebank (ref. seq. NP_001267879.1) (http://www.ncbi.nlm.nih.gov/genbank/) and utilized in Blastp as sequence to search for homologies (alignments) within model organisms, different plant and fungi families and certain specific species.

\subsection{Lab scale production of fruiting bodies on flavonoid rich substrates}

Specific substrate mixtures were prepared in triplicate as described by Ruiz-Rodriguez, Soler-Rivas, Polonia, \& Wichers (2010) with a few modifications: wheat straw and onion waste (leftovers after peeling onions) were chopped $(2-5 \mathrm{~cm})$ and left overnight soaking up tap hot water. The excess of water was drained on a sieve during 20 min. Afterwards, the soaked lignocellulosic substrates were mixed and homogenized with $0 \%$ (control) and $14 \%(\mathrm{w} / \mathrm{w})$ onion waste. Homogenized substrates $(500 \mathrm{~g})$ were placed in plastic bags and sterilized in autoclave $\left(120^{\circ} \mathrm{C}\right)$ during 15 minutes.

The sterilized substrates were inoculated with $10 \%(w / w)$ of fully colonized spawn and left incubated in dark at $24^{\circ} \mathrm{C}$. When substrates were fully colonized temperature was changed to $16^{\circ} \mathrm{C}$ and high humidity in the presence of light, in a day/night cycle to induce fructification. One hole (approx. $2 \mathrm{~cm}$ diam.) was made in one side of each bag. After few days (depending on substrate) pinheads were eye visible. Mushrooms obtained from the first flush were harvested, weighed and lyophilized. Afterwards, dried fruiting bodies were ground in a mortar with liquid nitrogen and stored at $-20^{\circ} \mathrm{C}$ for further analysis.

\subsection{Mycelium cultivation on Petri dishes supplemented with flavonoids}

Mycelia obtained from mother cultures generated from one grain of the $P$. ostreatus spawn were inoculated on Petry plates containing MEA medium $\left(50 \mathrm{~g} \mathrm{~L}^{-1}\right.$ of malt extract agar, Sigma-Aldrich, (Madrid, Spain)) and sterilized cellophane circles at the top of the semi-solid medium following the procedure 
described by Ruiz-Rodríguez, Polonia, Soler-Rivas, \& Wichers (2011). To test the effect of flavonoids or a

phenolic compound, MEA medium was supplemented with increasing concentrations of luteolin, luteolin-7O-glucoside (Extrasynthese, Lyon, France), quercetin, hesperidin or caffeic acid (Sigma-Aldrich) (from 0.25 up to 2 or $4 \mathrm{mg} / \mathrm{mL}$ depending on their saturation level) dissolved in ethanol (or MilliQ water for those water-soluble). Plates were inoculated in triplicate and incubated at $25^{\circ} \mathrm{C}$.

\subsection{Determination of fungal growth}

Several cultivation parameters were evaluated during $P$. ostreatus cultivation on control substrates (containing only wheat straw) and on substrates including onion waste. The incubation time required before pinning (pinhead appearance) and for harvesting of the first flush was recorded. Yield, biological efficiency and productivity were monitored as described by Ruiz-Rodriguez et al. (2010).

Mycelial growth (minor and major diameters) was measured once a day until mycelia reached the plates edge (Ruiz-Rodríguez et al., 2011). Growth was later expressed as $\mathrm{cm} /$ day using the slope at the linear growth phase of the fungi. Mycelial biomass was also quantified by weighting the produced mycelia scratched from the cellophane when they reached the plate edges. Afterwards, fresh mycelia were frozen, freeze-dried and weighted again to calculate their dry weight. They were later ground in a mortar with liquid nitrogen and stored at $-20^{\circ} \mathrm{C}$ for further analysis.

\subsection{Determination of total phenol content}

The total phenol concentration was determined by the Folin-Ciocalteu's phenol reagent method according to the procedure of Ramírez-Anguiano, Santoyo, Reglero, \& Soler-Rivas (2007) using directly the powdered fruiting bodies or mycelia (10 mg) prepared as previously described. Gallic acid was used as standard for quantification.

\subsection{Spectrophotometric determination utilized by literature as method to measure 'total flavonoid'}

The colorimetric determination was carried out as described by Choi, Lee, Chun, Lee, \& Lee (2006) since it was one of the first recorded publications that determined flavonoids in mushrooms using a modified protocol previously utilized to measure flavonoids in mulberry (Zhishen, Mengcheng, \& Jianming, 1999). Briefly, powdered fruiting bodies $(100 \mathrm{mg}$ ) were mixed with $10 \mathrm{ml}$ methanol and stirred for $1 \mathrm{~h}$ at room 
temperature. Afterwards, solution was centrifuged (35000 rpm $15 \mathrm{~min}$ ) and resulting supernatant filtered

and dried until dryness. Two hundred fifty microliters of obtained mushroom extracts (diluted up to 15 $\mathrm{mg} / \mathrm{mL}$ with methanol) were mixed with $1.25 \mathrm{~mL}$ of distilled water and $75 \mu \mathrm{L}$ of a $5 \% \mathrm{NaNO}_{2}$ solution. After $5 \min , 150 \mu \mathrm{L}$ of a $10 \% \mathrm{AlCl}_{3} \cdot \mathrm{H}_{2} \mathrm{O}$ was added. After $6 \min , 500 \mu \mathrm{L}$ of $1 \mathrm{M} \mathrm{NaOH}$ and $275 \mu \mathrm{L}$ of distilled water were added to the mixture. The solution was mixed and the intensity of red-pink color was measured at 415 and $510 \mathrm{~nm}$. Quercetin was used as standard for quantification and ergosterol (ergosta-5,7,22-trien-3 $\beta$ ol, $0.7 \mathrm{mg} / \mathrm{mL}$ ) and L-Dopa (L-3,4-dihydroxyphenylalanine, $0.1 \mathrm{mg} / \mathrm{mL}$ ) were solubilized in ethanol and treated as mushroom extracts but not only its absorbance at those wavelengths were recorded but the complete spectrum from 300 to $600 \mathrm{~nm}$ to compare with results from Pękal \& Pyrzynska (2014).

\subsection{Flavonoid detection and quantification by HPLC-DAD}

The presence of flavonoids in mushrooms was determined by HPLC in two different labs using two different devices and methods.

In the first one, powdered fruiting bodies or mycelia were mixed with methanol and treated as previously described for the spectrophotometrical methods. Dried extracts were dissolved in $100 \mu \mathrm{L}$ methanol and filtered (0.45 $\mu \mathrm{m}$ PVDF filter (Millex HV13, Millipore, Bedford, MA, USA)) before HPLC analysis.

Mushroom extracts $(10 \mu \mathrm{L})$ were injected in a Varian liquid chromatograph, model 920-LC Galaxy, with a diode array (PAD) and fluorescence detectors (range scanned $=200-600 \mathrm{~nm}$ ). Reverse phase chromatographic separation was performed with an AquaTM C18 analytical column ( $250 \times 4.6 \mathrm{~mm}$ i.d. with an average particle size of $5 \mu \mathrm{m})$ after a precolum AquaTM C18 $(4 \times 3 \mathrm{~mm})$ both from Phenomenex (Madrid, Spain). As solvent (A) $2 \%$ formic acid ( $v / v$ ) and (B) acetonitrile was used with the following gradient profile: from 0 to $20 \mathrm{~min}, 0$ to $30 \% \mathrm{~B}$, from 20 to $25 \mathrm{~min}, 30$ to $60 \% \mathrm{~B}$, from 25 to $26 \mathrm{~min}, 60 \% \mathrm{~B}$, from 26 to 27,60 to $100 \% \mathrm{~B}$ and 27 to 35 min washing with $100 \% \mathrm{~B}$. The flow rate was $1 \mathrm{~mL} / \mathrm{min}$ at $35^{\circ} \mathrm{C}$. The absorbance changes were recorded in the vis-UV DAD and simultaneously at 2 wavelengths for the different types of flavonoids: $280 \mathrm{~nm}$ for flavanones, $350 \mathrm{~nm}$ for flavones but the complete spectral range was visualized to identify any possible flavonoid-related spectrum. 


\subsection{Flavonoid identification and quantification by HPLC-MS}

The presence of flavonoids in mushrooms was also evaluated at the other lab by an HPLC-DADESI/MS device using as starting material the same mushroom samples that above indicated. Firstly, powdered mushrooms $\left(50 \mathrm{mg}\right.$ ) were extracted with $1 \mathrm{~mL}$ of the extracting mixture $\mathrm{MeOH}: \mathrm{H}_{2} \mathrm{O}: \mathrm{HCOOH}$ (25:24:1), homogenized using a vortex and sonicated in an ultrasonic bath for $60 \mathrm{~min}$. Then, samples were kept overnight at $4^{\circ} \mathrm{C}$ and sonicated again for $60 \mathrm{~min}$. The supernatant for analysis was separated using a centrifuge $(9500 \times \mathrm{g}, 5 \mathrm{~min}$ ) (model EBA 21, Hettich Zentrifugen) and filtered through a $0.45 \mu \mathrm{m}$ PVDF filter (Millex HV13, Millipore, Bedford, MA, USA) before the analyses were performed.

A chromatographic separation was performed using an HPLC system equipped with an Agilent 1200 series (Agilent Technologies, Waldbronn, Germany) and coupled to a mass detector in series. The HPLC system consisted of a binary capillary pump (G1376A), a degasser (G1379B), an autosampler (G1377A), a sample cooler (control temperature $\left.4^{\circ} \mathrm{C}\right)(\mathrm{G} 1330 \mathrm{~B})$, and a photodiode array detector (G1315D) controlled by Chemstation software (v.B.0103-SR2). The mass detector was a Bruker, model UltraHCT (Bremen, Germany) ion trap spectrometer equipped with an electrospray ionisation (ESI) system and controlled by Bruker Daltonics Esquire software (v.6.1).

The separation was performed using C18 Kinetex 100A (150 × $4.6 \mathrm{~mm}$ i.d.) column, $5 \mu \mathrm{m}$ particle size. The flow rate was $0.8 \mathrm{~mL} / \mathrm{min}$. Chromatographic separation was achieved using a binary gradient consisting of (A) $1 \%$ formic acid and (B) acetonitrile as HPLC grade solvents. The elution profile started with $10 \%$, reaching $30 \%$ B at 20 minutes, $60 \%$ B at $25 \mathrm{~min}$ and maintained up to $26 \mathrm{~min}$. The injection volume was 8 $\mu \mathrm{L}$. Chromatograms were recorded from 240 to $400 \mathrm{~nm}$ (set $340 \mathrm{~nm}$ for flavonoids).

The mass spectrometer settings were as follows: the pressure and flow rate of the dryer gas were set at $11 \mathrm{psi}$ and $5 \mathrm{~L} / \mathrm{min}$ respectively. The full-scan mass spectrum was from $\mathrm{m} / \mathrm{z} 300$ to 1400 . Collision-induced fragmentation experiments were performed in the ion trap using He as collision gas, with voltage ramping cycles from 0.3 to $2 \mathrm{~V}$. The heated capillary and voltage were maintained at $350^{\circ} \mathrm{C}$ and $4275 \mathrm{~V}$, respectively. Other parameters for the detection were as follows: skimmer, $40 \mathrm{~V}$; capillary exit, $108.5 \mathrm{~V}$; octopole $1 \mathrm{DC}$, $12 \mathrm{~V}$; octopole $2 \mathrm{DC}, 1.7 \mathrm{~V}$; octopole RF, $138.8 \mathrm{Vpp}$; lens 1, $-5 \mathrm{~V}$; lens 2, $-60 \mathrm{~V}$. The mass spectrometry data were acquired in the negative ionization mode for flavonols. 


\section{Results}

\subsection{Systematic literature review}

After the literature search, a total of 136 scientific works were found determining specific or total flavonoids in mushrooms, although a few more (including reviews i.e. Fernandes et al. (2012); Guillamón et al. (2010); Jayakumar et al. (2011)) were noticed where flavonoid presence was assumed because it was described elsewhere. Attempts to detect flavonoids were carried out already in 2001 using HPLC (Mattila, et al., 2001) however, authors did not detect them. It was in 2005 when a report was firstly published indicating their presence (Y. M. Choi, Ku, Chang, \& Lee, 2005)(see the Supplementary Table 1). The work was included in a low-indexed journal but at the following year, the same group managed to publish a similar work in a highly indexed journal (high for the area of Food Science and Technology)(Choi et al. 2006). Authors utilized a colorimetric method that was previously utilized to detect flavonoids in mulberry (Zhishen et al. 1999) and referred the determination of 'total flavonoids' as 'free and bound flavonoids'. The same procedure was then followed in 2007 by several groups to detect flavonoids in mushrooms pointing as 'method of reference' that utilized for mulberry or another used for propolis analysis (Park, Koo, Ikegaki, \& Contado, 1997). Despite others, three of these works were published in journals with IF (Impact factor) $>3$ and 3 others in journals with IF $>2$ (Figure 1) promoting an exponential use of the colorimetric method to determine flavonoids in mushrooms. The increase was such that from 5 works published in 2008 it doubled the number in 2009 and raised up to 18 publications in 2010 and 2012 and even 22 in 2013 and 2014. Although most of the reports through all these years were published in journals with $\mathrm{IF}<1(35 \%)$, many of them were also published in journals with IF $>2(21 \%)$ or IF $>3(11 \%)$ and even 4 of them were published in journals with IF>4 (3\%) in 2008, 2009 and 2012.

When a close look was given to the methodologies utilized to determine flavonoids in mushrooms, $91 \%$ of the reports were based on colorimetric determinations utilizing $\mathrm{AlCl}_{3}\left(\right.$ or $\left.\mathrm{Al}\left(\mathrm{NO}_{3}\right)_{3}\right)$ as reactive agent and a spectrophotometer. Only $9.3 \%$ of the reports used more advanced systems such as HPLC (UV/DAD only two used MS as detection devices) (Leal et al. 2013; Liu, Jia, Kan, \& Jin, 2013), UPLC-ESI-MS/MS (Özyürek, Bener, Güçlü, \& Apak, 2014) and surprisingly, one manuscript indicated that these polyphenols and other triterpenic acids were determined by GC-MS (Kalogeropoulos, Yanni, Koutrotsios, \& Aloupi, 2013). 
Moreover, the amounts of flavonoids found in the mushrooms also differed in the range of $\mu \mathrm{g} / \mathrm{g} d w$ (Babu

\& Rao, 2013; Karaman, Stahl, Vulić, Vesić, \& Čanadanović-Brunet, 2014) or mg/g (Kumari, Upadhyay, \& Atri, 2013; Yongcai, Xin, \& Yaung-lee, 2013) levels of $67.3 \mathrm{mg} / \mathrm{g}$ (Zhang et al. 2015) or $349.6 \mathrm{mg} / \mathrm{g}$ (Jeong et al. 2013) meaning that 6.7 or $34.9 \%$ of the mushroom dry weight were flavonoids. These levels were found in extracts obtained using different solvents including all polarities such as water, ethanol, methanol, chloroform, ethyl acetate, butanol, petroleum ether, acetone, mixtures of indicated solvent and other specific extracts (when it is well known that many flavonoids are virtually insoluble in some of the listed solvents).

In addition to the 'flavonoid method' some of the works also included a colorimetric method to determine 'anthocyanins'(Tevfik, Cihan, Oznur, \& Ibrahim, 2011) or 'anthocyanidins' (Sharma \& Gautam, 2015) in mushrooms such as i.e. Agaricus arvensis or Cantharellus cibarius, although their fruiting bodies did not show the red-violet-blue discoloration characteristic from berries and other food products containing these pigments. Mushroom colors are due to different compounds depending on the considered species but they have completely different molecular structures than antocyanins such as i.e. red terphenylquinones related to orange-red grevillins, yellow-orange pulvic or pulvinic acids and styrylpyrones, red-violet betacyanins or variegatic, xerocomic or atromentic acids or anthraquinones (Velísek \& Cejpek, 2011).

\subsection{Systematic search in molecular databases for flavonoid-related gene homologies}

In plants, the flavonoid biosynthesis required the presence of many enzymes but three of them play an essential role: the phenylalanine ammonia-lyase (PAL), chalcone synthase (CHS) and chalcone isomerase (CHI)(Winkel, 2006). The presence of these proteins through the Eukaryote organisms was investigated using the taxonomical distribution of Pfam 'Sunburst' species distribution. Results indicated that the 3 enzymes were mostly distributed through the Viridiplantae kingdom (Table 1), particularly the chalcone synthase and isomerase where respect. 93 and $87 \%$ of the known sequences were found in plant species being the rest still uncategorized.

PAL-like proteins were found in 12 fungal species belonging to the phylla Basidomycota and Ascomycota where the macrofungi and most of the edible mushrooms are included (Table 1). In fact commonly 
consumed mushrooms such as Agaricus bisporus (white button mushroom) and Pleurotus eryngii (king

trumpet mushroom) expressed at least one sequence that match with the lyase aromatic family but no protein related to the PF02797 or PF02431 families (where respect. CHS and CHI are included) have been described so far.

Another attempt to try to find sequences encoding flavonoid-related enzymes was carried out using BLAST as search tool. The CHS sequence from Vitis vinifera obtained from Genebank was used as example to look for homologies within other Eukaryote organisms such as berries, citrus etc. as well as many fungal species. CHS sequences within plant species showed high homologies (Table 2) and most of them were identified as chalcone synthases including only one or several isoforms. However, homology with fungal sequences dropped down to $17-3 \%$ in completely sequenced mushrooms such as $A$. bisporus and Pleurotus ostreatus and no significant similarities were found in other edible mushrooms (although their genomes are still not completely sequenced). However, the sequence of the proteins that slightly matched grape CHS was not identified as CHS or any known enzyme, they were only hypothetical proteins.

Homologies with the $V$. vinifera chalcone synthase were also investigated through the known sequences of all the mushroom genera where flavonoids were reported using methods different than the colorimetric determination (Lactarius, Morchella, Lepista, Chantarelle, Pholliota, Tremella, Boletus, Amanita, Russula, Gyromitra, Suillus, Cynomorium, Marasmius, Craterellus, Helvela, Clitocibe, Catathelasma, Stropharia, Laccaria, Auricularia, Calocybe, Hygrophorus and truffles genus such as Tuber and Terfezia sp.) and no significant similarities were found.

\subsection{Spectrophotometric determinations and HPLC analysis of mushroom fruiting bodies}

The total phenolic content of several mushroom species was determined using a commonly utilized colorimetric method (Figure 2). Values ranged from 1 to more than $14 \mathrm{mg} / \mathrm{g}$ mushroom powder depending on the strain being Boletus edulis the specie with the highest phenol content followed by others such as Amanita ponderosa, Agrocybe aegerita or Calocybe gambosa. These values were in concordance with other authors (Barros, Dueñas, Ferreira, Baptista, \& Santos-Buelga, 2009; Del Signore, Romeo, \& Giaccio, 1997; Ramírez-Anguiano et al. 2007). 
Similarly, the protocol used by several publications to determine "total flavonoid" was applied to the same

mushroom species for comparison. Except for Lactarius deliciosus, most of the determined values were similar or lower than the phenolic compounds ranging from 0.1 to $6.7 \mathrm{mg} / \mathrm{g}$. The profile did not correlate with the phenolic content since for instance Amanita cesarea showed similar phenolic composition than $P$. ostreatus or Hericium erinaceus but it doubled the values obtained using the method utilized to determine 'total flavonoid' in mushrooms.

On the other hand, when an ergosterol standard solution was prepared and treated as indicated to determine 'total flavonoids' it positively reacted with the protocol showing absorbance at both 415 and 510 $\mathrm{nm}$ (Figure 3). Ergosterol is the major sterol from fungal hyphae but its structure is completely different from a flavonoid. Other compounds typical for mushrooms such as L-Dopa showed similar spectrum than those indicated by Pękal \& Pyrzynska (2014) for some flavonoids, confirming that 0 -diphenols might also induce false flavonoid-positives.

Moreover, when the selected mushroom species were prepared following typical methods to extract flavonoids in plants (as described in M\&M) and injected in HPLC-DAD/MS, no flavonoid peaks were detected or identified in any of the 24 tested species.

\subsection{Flavonoid absorption by fruiting bodies from the cultivation substrate}

Pleurotus ostreatus was cultivated in wheat straw as control and straw supplemented with onion waste in order to test whether the latter mycelium could partially absorb any of the flavonoids present in the onion waste during its growth. Addition of the flavonoid-containing waste slightly increased 1 day the time for pinning (inducing 1 day delay in harvesting) but did not reduce significantly fruiting bodies yield (15.7\% w/w) nor quality (90.4-85.6\% water content). No significant differences were noticed in the levels of total phenols $(2.6-3.4 \mathrm{mg} / \mathrm{g})$ neither in the values determined with the method utilized to measure 'total flavonoids' in mushrooms cultivated with or without onion supplementation (respect. $1.8-2.2 \mathrm{mg} / \mathrm{g}$ ).

The flavonoids present in the onion waste were extracted and analysed by HPLC/DAD-MS together with the substrate after mycelial colonization and the fruiting bodies obtained from both control and supplemented substrates. Some of the peaks detected in substrate (Figure 4a) were identified as flavonoids (quercetin 3,7 or 3,4' diglucoside, quercetin 3-glucoside, isorhamnetin 3-diglucoside and 
isorhamnetin 3-glucoside) and they practically disappeared after mushrooms were grown in it, leaving only

traces of some of them detected, such as quercetin 3- glucoside ( $t_{R}: 16,02 \mathrm{~min}$ ) (Figure $\left.4 \mathrm{~b}\right)$. Their disappearance from the substrate during the mycelial growth might be explained by transformation into a different chemical (i.e. degradation) or by fungal absorption. However, the latter possibility is unlikely since the HPLC chromatograms obtained after fruiting bodies analysis showed no peaks at any of the wavelengths used to monitor flavonoids nor spectrum or mass which might resemble them (Figure 4c).

\subsection{Flavonoid absorption by mycelium from culture medium}

Pleurotus ostreatus mycelium was grown on Petri plates supplemented with increasing concentrations of several flavonoids (quercetin, hesperidin, luteolin and luteolin-7-glucoside) and caffeic acid (as control) in order to enhance or force their absorption if that was possible. Quercetin or hesperidin addition up to $2 \mathrm{mg} / \mathrm{ml}$ did not influence significantly mycelial growth, the slightly extended lag phase (4 days) and the growth reduction noticed (from 1.2 to approx. $0.5 \mathrm{~cm} /$ day in the exponential phase) was mostly due to the ethanol utilized to solubilize the flavonoids because it was also observed in control samples were only ethanol was added $(0.4 \mathrm{~cm} /$ day). Ethanol (with or without flavonoid addition) induced larger biomass production and water retention capacity by the mycelium since they showed higher fresh and dry weights than the control.

Additions of luteolin or its glucosylated derivative to the cultivation medium resulted in inhibition of the mycelial growth correlating with the flavonoids concentration utilized. The inhibition was more drastic when the aglycone was used (Figure 5a) that when luteolin-7-glucoside was applied at similar concentrations. However, addition of the simple phenolic compound did not significantly influenced mycelial growth or biomass production except for a slight reduction noticed when applied at the highest concentration tested $(4 \mathrm{mg} / \mathrm{mL})$ (Figure $5 b)$.

No significant differences were found when the total phenolic compounds were determined in the mycelia obtained from plates supplemented with any of the selected flavonoids or concentrations. Control samples with or without ethanol contained approx. $4.4-4.8 \mathrm{mg} / \mathrm{g} \mathrm{dw}$. Only caffeic acid addition induced a significant increase (up to $7.3 \mathrm{mg} / \mathrm{g} \mathrm{dw}$ ) but only when a low concentration was applied $(0.25 \mathrm{mg} / \mathrm{mL}$ ). However, when the samples were injected in HPLC-DAD and developed using a solvent gradient that 
differently eluted the selected flavonoids and caffeic acid, none of the compounds were detected in the

mycelia grown at any of the selected flavonoid concentrations.

\section{Discussion}

The literature review carried out indicated that, at the present, approximately 136 scientific publications are worldwide available ensuring that they can determine flavonoids in mushrooms. Moreover, during the citations compilation many other articles were found (more than 50) were authors indicated in their introduction section or under specific sub-headings (in reviews) that mushrooms contain flavonoids because previous reports demonstrated their presence. However, in a more detailed observation of the methodologies utilized to demonstrate their presence, almost $91 \%$ of the publications utilized an unspecific colorimetric method developed to determine them in plants or plant products. The method involved the measurement at $410-430 \mathrm{~nm}$ (some authors used other wavelengths such as $510 \mathrm{~nm}$ ) of a colorimetric reaction that take place after addition of $\mathrm{AlCl}_{3}$ which selectively reacts only with certain flavonoids depending on the reaction medium utilized. The analytical method was proposed in the 60s (Christ \& Müller, 1960) and it was already indicated that was not accurate enough to determine 'total flavonoids' neither in plants (Pękal \& Pyrzynska, 2014). The method is based on the nitration of any aromatic ring bearing a catechol group with its 3 or 4 positions unsubstituted or sterically blocked. After addition of $\mathrm{Al}(\mathrm{III})$, a yellow complex is formed that turn red in the presence of $\mathrm{NaOH}$ and can be quantified at $510 \mathrm{~nm}$. However, if $\mathrm{AlCl}_{3}$ is added in neutral or acidic media (without $\mathrm{NaNO}_{2}$ ) it should only be used to determine flavonols (queretin, rutin, galangin etc.) and luteolin. In the presence of $\mathrm{NaNO}_{2}$ in alkaline medium seems to react with rutin, luteolin and catechins but, also with other phenolic acids bearing catecholic moieties such as chlorogenic acid, in fact in the past, this method was used for the determination of o-diphenols (Barnum, 1977). Most of the protocols followed by authors that indicated the presence of flavonoids in mushrooms used $\mathrm{NaNO}_{2}$ and therefore, the more unspecific test. Moreover, mushrooms contain not only chlorogenic acid but many other hydroxycinnamic acids (Puttaraju, Venkateshaiah, Dharmesh, Urs, \& Somasundaram, 2006), o-diphenols (i.e. glutaminyl-3,4dihydroxybenzene) and molecules including catechol residues such as pigments (i.e. variegatorubin, 
hispolon, 3,4',4-trihydroxypulvinone, inoscavin A etc) or melanin-precursors (i.e. 5,6-dihydroxyindole,

leucodopachrome)(Soler-Rivas et al. 1999; Velísek \& Cejpek, 2011), even ergosterol (with a completely different chemical structure from a flavonoid or a phenolic compound) showed a positive response in the $\mathrm{AlCl}_{3}$-test. This molecule is only partially soluble in methanol however; it might also contribute together with the other phenolic compounds to the absorbance determined as 'total flavonoids'. This might also explain the lack of linear correlation noticed between the amount of total phenolic compounds and the absorbances quantified as 'total flavonoids'.

Nevertheless, 13 publications identified specific flavonoids by HPLC/UPLC/GC using UV, DAD or MS as detection devices (although in one of them no device or method was described, HPLC was assumed because authors were able of quantifying quercetin (Zhishen et al. 1999)). These reports indicated the presence of compounds such as quercetin, luteolin, myricetin, naringenin, naringin, hesperetin, rutin, morin, kaempferol, chrysin and derivatives, genistein, apigenin or catechin in commonly consumed mushrooms i.e. P. ostreatus, A. bisporus, B. edulis, C. cibarius, L. deliciosius, and other less popular (see the Supplementary Table 1). The presence of these compounds in mushrooms could be due to two possibilities: that mushroom can synthetize them or absorb them from neighbouring plants or from those that establish symbiotic interactions via mycorrhizae (although not all the mushrooms species establish them).

In order to synthetize flavonoids, mushrooms should contain in their genome at least a copy of the three key enzymes within their biosynthetic pathway, phenylalanine ammonia-lyase (PAL), chalcone synthase (CHS) and chalcone isomerase $(\mathrm{CHI})$ and nowadays only PAL has been reported in mushrooms according to genomic databases. No gene encoding $\mathrm{CHS}$ or $\mathrm{CHI}$ have been identified so far suggesting that they were not yet studied or not found because they were neither detected in those mushrooms that are, at the present, completely sequenced (Agaricus bisporus and Pleurotus ostreatus). These results indicate that mushrooms can generate phenolic compounds using their PAL but they cannot further transform them into flavonoids because the lacked the necessary enzymes.

Fungi evolved separately from plants long before the enzymatic mechanism specifically designed to produce most of the primitive flavonoids appeared. Moreover, although it is possible that, initially, 
flavonoids were a metabolic by-product, nature found function for them in plants. For instance, they are

signals for pollen tube formation, for bacteria attraction (nitrification), pest and plagues repellents etc. But, what do they do in fungi? Is there any single report informing about their role in fungal biology? Then, if they do not synthetize them, the second possibility might be that they could absorb them from their substrate or from plants. However, when P. ostreatus was cultivated on onion waste containing flavonoids the obtained fruiting bodies lacked quercetin- or isorhamnetin-derivatives or any other flavonoid. Therefore, the flavonoids described at least in P. ostreatus (i.e. Huang, Cai, Xu, \& Zhao (2012), Palacios et al. (2011) or Sapozhnikova, Byrdwell, Lobato, \& Romig (2014)) cannot be explained by an absorption mechanism and as all fungi share a similar biology, these conclusions could be extended to the rest of species, or at least to those 24 strains analysed in is study since no trace of flavonoid was found using HPLC.

When P. ostreatus mycelium was forced to grow on semi-synthetic media with increasing concentrations of certain flavonoids no absorption was also noticed on the contrary, some of them inhibited the fungal growth confirming the fungicide properties that have been described for flavonoids in many other publications (Orhan, Özçelik, Özgen, \& Ergun, 2010; Winkel, 2006). In several reports flavonoids were found in the range of micrograms per gram mushroom ( $\mathrm{dw}$ ) however in many others, they were present in $\mathrm{mg} / \mathrm{g}$ reaching levels of $349.6 \mathrm{mg} / \mathrm{g}$ flavonoids (Jeong et al. 2013), where it seems unlikely that mushrooms could absorb that amount of toxic compounds ( $35 \% \mathrm{dw}$ ) without significant changes in the fruiting bodies quality and metabolism. If this was the case, mushrooms could have an extremely interesting commercial application as flavonoid source since in plants, they are present in large concentrations only under specific physiological conditions such as in the earliest developmental stages (Jourdan, McIntosh, \& Mansell, 1985). When citrus fruits such as sour orange are still immature (diameter $<10 \mathrm{~mm}$ ), values of i.e. neohesperidin are still below $30 \%$ dry matter and they are being used as raw material for industrial extraction processes (Ortuño et al. 1997).

\section{Conclusions}

Edible mushrooms cannot synthesise flavonoids because they do not have the main enzymes involved in their metabolic pathway and no significant absorption was noticed from fruiting bodies cultivated in 
flavonoid-enriched substrates or from mycelia grown of flavonoid-supplemented lab media. Thus, spectrophotometric methods for 'total flavonoids' determination should not be applied to fungal samples. The flavonoids identified in several mushroom species using advance identification devices such as DAD and MS might be due to sample contaminations or other pitfalls within the utilized protocols. Scientists should be more careful when planning experiments to avoid the exponential spreading of large mistakes such as considering fungi as plants.

\section{Conflict of interest}

The authors declare that they have no conflict of interest.

\section{Acknowledgments}

This review was supported by AGL2010-21537 and AGL2014-56211-R projects financed by the national R+D program from the Spanish Ministry of Science and Innovation and ALIBIRD-C M S2009/AGR-1469 regional program from the Community of Madrid (Spain).

\section{Appendix}

Supplementary Table 1

\section{References}

Babu, D., \& Rao, G. N. (2013). Antioxidant properties and electrochemical behavior of cultivated commercial Indian edible mushrooms. Journal of Food Science and Technology, 50, 301-308.

Barnum, D. W. (1977). Spectrophotometric determination of catechol, epinephrine, dopa, dopamine and other aromatic vic-diols. Analytica Chimica Acta, 89, 157-166.

Barros, L., Dueñas, M., Ferreira, I. C. F. R., Baptista, P., \& Santos-Buelga, C. (2009). Phenolic acids determination by HPLC-DAD-ESI/MS in sixteen different Portuguese wild mushrooms species. Food and Chemical Toxicology, 47, 1076-1079.

Choi, Y., Lee, S. M., Chun, J., Lee, H. B., \& Lee, J. (2006). Influence of heat treatment on the antioxidant activities and polyphenolic compounds of Shiitake (Lentinus edodes) mushroom. Food Chemistry, 99, 381-387. 
Choi, Y. M., Ku, J. B., Chang, H. B., \& Lee, J. S. (2005). Antioxidant activities and total phenolics of ethanol extracts from several edible mushrooms produced in Korea. Food Science and Biotechnology, 14, 700-703.

Christ, B., \& Müller, K. H. (1960). Zur serienmäßigen Bestimmung des Gehaltes an Flavonol-Derivaten in Drogen. Archiv der Pharmazie, 293, 1033-1042.

Del Signore, A., Romeo, F., \& Giaccio, M. (1997). Content of phenolic substances in basidiomycetes. Mycological Research, 101, 552-556.

Fernandes, Â., Antonio, A. L., Oliveira, M. B. P. P., Martins, A., \& Ferreira, I. C. F. R. (2012). Effect of gamma and electron beam irradiation on the physico-chemical and nutritional properties of mushrooms: A review. Food Chemistry, 135, 641-650.

Gil-Ramírez, A., Clavijo, C., Palanisamy, M., Ruiz-Rodríguez, A., Navarro-Rubio, M., Pérez, M., Marín, F. R., Reglero, G., \& Soler-Rivas, C. (2013). Study on the 3-hydroxy-3-methyl-glutaryl CoA reductase inhibitory properties of Agaricus bisporus and extraction of bioactive fractions using pressurised solvent technologies. Journal of the Science of Food and Agriculture, 93, 2789-2796.

Grotewold, E. (2006). The science of flavonoids. New York: Springer-verlag New York.

Guillamón, E., García-Lafuente, A., Lozano, M., D’Arrigo, M., Rostagno, M. A., Villares, A., \& Martínez, J. A. (2010). Edible mushrooms: Role in the prevention of cardiovascular diseases. Fitoterapia, 81, 715723.

Harborne, J. B. (1994). The flavonoids-Advances in research since 1986 London, U.K.: Chapman \& Hall.

Huang, X. D., Cai, J. X., Xu, L.-X., \& Zhao, I. Z. (2012). Study on antioxidant effects in vitro and in vivo of total flavonoids from Inonotus obliquus. Journal of food Science and Biotechnology, 31, 1062-1068.

Jayakumar, T., Thomas, P. A., Sheu, J. R., \& Geraldine, P. (2011). In-vitro and in-vivo antioxidant effects of the oyster mushroom Pleurotus ostreatus. Food Research International, 44, 851-861.

Jeong, S.-C., Koyyalamudi, S. R., Hughes, J. M., Khoo, C., Bailey, T., Marripudi, K., Park, J. P., Kim, J. H., \& Song, C.-H. (2013). Antioxidant and Immunomodulating Activities of Exo-and Endopolysaccharide Fractions from Submerged Mycelia Cultures of Culinary-Medicinal Mushrooms. 15, 251-266. 
Jourdan, P. S., Mclntosh, C. A., \& Mansell, R. L. (1985). Naringin Levels in Citrus Tissues : II. Quantitative Distribution of Naringin in Citrus paradisi MacFad. Plant Physiology, 77, 903-908.

Kalogeropoulos, N., Yanni, A. E., Koutrotsios, G., \& Aloupi, M. (2013). Bioactive microconstituents and antioxidant properties of wild edible mushrooms from the island of Lesvos, Greece. Food and Chemical Toxicology, 55, 378-385.

Karaman, M., Stahl, M., Vulić, J., Vesić, M., \& Čanadanović-Brunet, J. (2014). Wild-growing lignicolous mushroom species as sources of novel agents with antioxidative and antibacterial potentials. International Journal of Food Sciences and Nutrition, 65, 311-319.

Kumari, B., Upadhyay, R. C., \& Atri, N. S. (2013). Evaluation of Nutraceutical Components and Antioxidant Potential of North Indian Wild Culinary-Medicinal Termitophilous Mushrooms. 15, 191-197.

Leal, A. R., Barros, L., Barreira, J. C. M., Sousa, M. J., Martins, A., Santos-Buelga, C., \& Ferreira, I. C. F. R. (2013). Portuguese wild mushrooms at the "pharma-nutrition" interface: Nutritional characterization and antioxidant properties. Food Research International, 50, 1-9.

Liu, J., Jia, L., Kan, J., \& Jin, C.-h. (2013). In vitro and in vivo antioxidant activity of ethanolic extract of white button mushroom (Agaricus bisporus). Food and Chemical Toxicology, 51, 310-316.

Markham, K. R. (1988). Distribution of flavonoids in the lower plants and its evolutionary significance. In J. B. Harborne (Ed.), The flavonoids. Advances in research since 1980. (pp. 427-468). London: Chapman and Hall.

Mattila, P., Könkö, K., Eurola, M., Pihlava, J.-M., Astola, J., Vahteristo, L., Hietaniemi, V., Kumpulainen, J., Valtonen, M., \& Piironen, V. (2001). Contents of Vitamins, Mineral Elements, and Some Phenolic Compounds in Cultivated Mushrooms. Journal of Agricultural and Food Chemistry, 49, 2343-2348.

Orhan, D. D., Özçelik, B., Özgen, S., \& Ergun, F. (2010). Antibacterial, antifungal, and antiviral activities of some flavonoids. Microbiological Research, 165, 496-504.

Ortuño, A., Reynaldo, I., Fuster, M. D., Botía, J., Puig, D. G., Sabater, F., Lidón, A. G., Porras, I., \& Del Río, J. (1997). Citrus cultivars with high flavonoid contents in the fruits. Scientia Horticulturae, 68, 231236. 
Özyürek, M., Bener, M., Güçlü, K., \& Apak, R. (2014). Antioxidant/antiradical properties of microwaveassisted extracts of three wild edible mushrooms. Food Chemistry, 157, 323-331.

Palacios, I., Lozano, M., Moro, C., D’Arrigo, M., Rostagno, M. A., Martínez, J. A., García-Lafuente, A., Guillamón, E., \& Villares, A. (2011). Antioxidant properties of phenolic compounds occurring in edible mushrooms. Food Chemistry, 128, 674-678.

Park, Y. K., Koo, M. H., Ikegaki, M., \& Contado, J. I. (1997). Comparison of the flavonoid aglycone contents of Apis mellifera propolis from various regions of Brazil. Arquivos de biologia e tecnologia, 40, 97-106.

Pękal, A., \& Pyrzynska, K. (2014). Evaluation of Aluminium Complexation Reaction for Flavonoid Content Assay. Food Analytical Methods, 7, 1776-1782.

Puttaraju, N. G., Venkateshaiah, S. U., Dharmesh, S. M., Urs, S. M. N., \& Somasundaram, R. (2006). Antioxidant Activity of Indigenous Edible Mushrooms. Journal of Agricultural and Food Chemistry, $54,9764-9772$.

Ramírez-Anguiano, A. C., Santoyo, S., Reglero, G., \& Soler-Rivas, C. (2007). Radical scavenging activities, endogenous oxidative enzymes and total phenols in edible mushrooms commonly consumed in Europe. Journal of the Science of Food and Agriculture, 87, 2272-2278.

Rausher, M. D. (2006). The evolution of flavonoids and their genes. In E. Goteworld (Ed.), The science of flavonoids (pp. 71-95). New York: Springer.

Robards, K., \& Antolovich, M. (1997). Analytical Chemistry of Fruit BioflavonoidsA Review. Analyst, 122, $11 \mathrm{R}-34 \mathrm{R}$

Ruiz-Rodríguez, A., Polonia, I., Soler-Rivas, C., \& Wichers, H. J. (2011). Ligninolytic enzymes activities of Oyster mushrooms cultivated on OMW (olive mill waste) supplemented media, spawn and substrates. International Biodeterioration \& Biodegradation, 65, 285-293.

Ruiz-Rodriguez, A., Soler-Rivas, C., Polonia, I., \& Wichers, H. J. (2010). Effect of olive mill waste (OMW) supplementation to Oyster mushrooms substrates on the cultivation parameters and fruiting bodies quality. International Biodeterioration \& Biodegradation, 64, 638-645. 
Sapozhnikova, Y., Byrdwell, W. C., Lobato, A., \& Romig, B. (2014). Effects of UV-B Radiation Levels on Concentrations of Phytosterols, Ergothioneine, and Polyphenolic Compounds in Mushroom Powders Used As Dietary Supplements. Journal of Agricultural and Food Chemistry, 62, 3034-3042.

Sharma, S. K., \& Gautam, N. (2015). Chemical, Bioactive, and Antioxidant Potential of Twenty Wild Culinary Mushroom Species. BioMed Research International, 2015, 12.

Soler-Rivas, C., Jolivet, S., Arpin, N., Olivier, J. M., \& Wichers, H. J. (1999). Biochemical and physiological aspects of brown blotch disease of Agaricus bisporus. FEMS Microbiology Reviews, 23, 591-614.

Tevfik, O., Cihan, D., Oznur, A., \& Ibrahim, T. (2011). Screening of Antioxidant, Antimicrobial Activities and Chemical Contents of Edible Mushrooms Wildly Grown in the Black Sea Region of Turkey. Combinatorial Chemistry \& High Throughput Screening, 14, 72-84.

Velísek, J., \& Cejpek, K. (2011). Pigments of higher fungi: A review. Czech Journal of Food Sciences, 29, 87102.

Winkel, B. S. J. (2006). The biosynthesis of flavonoids. In E. Grotewold (Ed.), The science of flavonoids (pp. 274). New York: Springer-verlag New York.

Yongcai, Q., Xin, Z., \& Yaung-lee, L. (2013). Antioxidant and anticancer effects of edible and medicinal mushrooms. Journal of the Korean Society of Food Science and Nutrition, 42, 655-662.

Zhang, N., Chen, H., Zhang, Y., Xing, L., Li, S., Wang, X., \& Sun, Z. (2015). Chemical composition and antioxidant properties of five edible Hymenomycetes mushrooms. International Journal of Food Science \& Technology, 50, 465-471.

Zhishen, J., Mengcheng, T., \& Jianming, W. (1999). The determination of flavonoid contents in mulberry and their scavenging effects on superoxide radicals. Food Chemistry, 64, 555-559. 


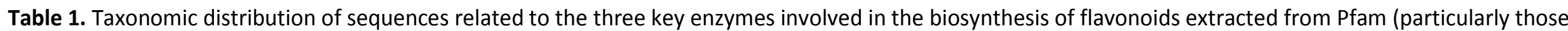
present in the fungal kingdom).

\begin{tabular}{|c|c|c|c|c|c|c|c|c|c|c|}
\hline Enzyme & Function & PFamily & Kingdom * & Phyllum & Class & Order & Family & Genus & Specie & Seq. \\
\hline \multirow{16}{*}{ PAL } & \multirow{16}{*}{$\begin{array}{l}\text { Transform } \\
\text { L-phenylalanine } \\
\text { to ammonia and } \\
\text { trans-cinnamic } \\
\text { acid (first } \\
\text { phenolic } \\
\text { compound in the } \\
\text { phenyl propanoid } \\
\text { pathway) }\end{array}$} & \multirow{16}{*}{$\begin{array}{c}\text { Lyase } \\
\text { aromatic } \\
\text { (PF 00221) }\end{array}$} & No Kingdom & NS & NS & NS & NS & NS & 20 & 37 \\
\hline & & & Viridiplantae & NS & NS & NS & NS & NS & 312 & 1007 \\
\hline & & & Metazoa & NS & NS & NS & NS & NS & 91 & 142 \\
\hline & & & \multirow{12}{*}{ Fungi } & \multirow{9}{*}{ Basidiomycota } & \multirow{4}{*}{ Agaricomycetes } & \multirow{4}{*}{ Agaricales } & Agaricaceae & Agaricus & bisporus & 1 \\
\hline & & & & & & & Tricholomataceae & Tricholoma & matsutake & 3 \\
\hline & & & & & & & Amanitaceae & Amanita & muscaria & 1 \\
\hline & & & & & & & Pleurotaceae & Pleurotus & eryngii & 1 \\
\hline & & & & & Ustilaginomycetes & Ustilaginales & Ustilaginaceae & Pseudozyma & brasiliensis & 1 \\
\hline & & & & & \multirow{4}{*}{ No class } & \multirow{4}{*}{ Sporidiobolales } & \multirow{4}{*}{ No Family } & Rhodosporidium & toruloides & 1 \\
\hline & & & & & & & & \multirow{2}{*}{ Rhodotorula } & mucilaginosa & 1 \\
\hline & & & & & & & & & glutinis & 3 \\
\hline & & & & & & & & Sporidiobolus & salmonicolor & 3 \\
\hline & & & & \multirow{3}{*}{ Ascomycota } & Eurotiomycetes & Eurotiales & Aspergillaceae & Penicillum & roqueforti & 1 \\
\hline & & & & & Sordariomycetes & Hypocreales & Nectriaceae & Fusarium & graminearum & 1 \\
\hline & & & & & Lecanoromycetes & Lecanorales & Parmeliaceae & Letharia & vulpina & 1 \\
\hline & & & Uncategorized & NS & NS & NS & NS & NS & 28 & 102 \\
\hline \multirow[b]{2}{*}{$\mathrm{CHS}$} & \multirow[b]{2}{*}{\begin{tabular}{|c|} 
Catalyzes the \\
conversion of \\
4-coumaroyl-CoA \\
and malonyl-CoA \\
to naringenin \\
chalcone (first \\
flavonoid)
\end{tabular}} & \multirow[b]{2}{*}{$\begin{array}{l}\text { Chalcone } \\
\text { and } \\
\text { stilbene } \\
\text { synthases, } \\
\text { C-terminal } \\
\text { domain } \\
\text { (PF02797) }\end{array}$} & Viridiplantae & NS & NS & NS & NS & NS & 751 & 2687 \\
\hline & & & Uncategorized & NS & NS & NS & NS & NS & 61 & 199 \\
\hline \multirow{3}{*}{$\mathrm{CHI}$} & \multirow{3}{*}{$\begin{array}{l}\text { Catalyzes the che } \\
\text { mical reaction: a } \\
\text { chalcone <-> a } \\
\text { flavanone }\end{array}$} & \multirow{3}{*}{$\begin{array}{l}\text { Chalcone } \\
\text { (PF02431) }\end{array}$} & Viridiplantae & NS & NS & NS & NS & NS & 146 & 398 \\
\hline & & & Uncategorized & NS & NS & NS & NS & NS & 15 & 55 \\
\hline & & & No Kingdom & NS & NS & NS & NS & NS & 2 & 2 \\
\hline
\end{tabular}

*Only inside Eukariota domain. PAL, phenylalanine ammonia-lyase; CHS, chalcone synthase; CHI, chalcone isomerase. NS, non-specified data. 
Table 2. Results of the alignments of the Chalcone synthase (CHS) sequence from Vitis vinifera with other

organisms using Blastp. Data included are those showing higher percentage of homology.

\begin{tabular}{|c|c|c|c|c|c|}
\hline Organism & Term searched & Genus & Specie & Homology with & $\begin{array}{c}\% \text { alignment } \\
\text { (query } \\
\text { cover) }\end{array}$ \\
\hline Plant & Vitis vinifera & Vitis & vinifera & Chalcone synthase & 100 \\
\hline Plant & $\begin{array}{l}\text { Arabidopsis } \\
\text { thaliana }\end{array}$ & Arabidopsis & thaliana & Chalcone synthase & 97 \\
\hline \multirow{3}{*}{ Plant } & \multirow{3}{*}{ Mulberry } & Morus & alba var. multicaulis & Chalcone synthase & 98 \\
\hline & & Morus & notabilis & Chalcone synthase & 98 \\
\hline & & Morus & $a l b a$ & Chalcone synthase & 65 \\
\hline Plant & Strawberry & Fragaria & ananassa & Chalcone synthase & 98 \\
\hline \multirow{3}{*}{ Plant } & \multirow{3}{*}{ Solanum } & Solanum & lycopersicum & Chalcone synthase $1 \& 2$ & 98 \\
\hline & & Solanum & tuberosum & Chalcone synthase & 98 \\
\hline & & Solanum & pinnatisectum & Chalcone synthase & 98 \\
\hline \multirow{4}{*}{ Plant } & \multirow{4}{*}{ Citrus } & Citrus & reticulata & Chalcone synthase & 98 \\
\hline & & Citrus & ichangensis & Chalcone synthase & 98 \\
\hline & & Citrus & maxima & Chalcone synthase & 98 \\
\hline & & Citrus & clementina & $\begin{array}{c}\text { Hypothetical protein CICLE } \\
\text { v } 10015535 \mathrm{mg} \\
\end{array}$ & 98 \\
\hline Plant & $\begin{array}{l}\text { Arabidopsis } \\
\text { thaliana }\end{array}$ & Arabidopsis & thaliana & Chalcone synthase & 97 \\
\hline Animal & Human & Homo & sapiens & $\begin{array}{c}\text { No significant similarity } \\
\text { found }\end{array}$ & 0 \\
\hline Animal & Mouse & Mus & musculus & $\begin{array}{c}\text { No significant similarity } \\
\text { found }\end{array}$ & 0 \\
\hline Animal & $\begin{array}{c}\text { Caenorhabditis } \\
\text { elegans }\end{array}$ & Caenorhabditis & elegans & $\begin{array}{c}\text { No significant similarity } \\
\text { found }\end{array}$ & 0 \\
\hline Fungi & $\begin{array}{c}\text { Saccharomyces } \\
\text { cerevisiae }\end{array}$ & Saccharomyces & cerevisiae & $\begin{array}{c}\text { No significant similarity } \\
\text { found }\end{array}$ & 0 \\
\hline \multirow{4}{*}{ Fungi } & \multirow{4}{*}{ Agaricus } & Agaricus & $\begin{array}{c}\text { bisporus var. burnettii } \\
\text { JB137-S8 }\end{array}$ & $\begin{array}{l}\text { Hypothetical protein } \\
\text { AGABI2DRAFT } 11251\end{array}$ & 7 \\
\hline & & Agaricus & $\begin{array}{c}\text { bisporus var. bisporus } \\
\text { H97 }\end{array}$ & $\begin{array}{c}\text { Hypothetical protein } \\
\text { AGABI2DRAFT } 193398\end{array}$ & 7 \\
\hline & & Agaricus & $\begin{array}{c}\text { bisporus var. burnettii } \\
\text { JB137-S8 }\end{array}$ & $\begin{array}{l}\text { Hypothetical protein } \\
\text { AGABI2DRAFT } 74201\end{array}$ & 3 \\
\hline & & Agaricus & $\begin{array}{c}\text { bisporus var. bisporus } \\
\text { H97 }\end{array}$ & $\begin{array}{l}\text { Hypothetical protein } \\
\text { AGABI2DRAFT } 207020\end{array}$ & 3 \\
\hline Fungi & $\begin{array}{l}\text { Pleurotus } \\
\text { ostreatus }\end{array}$ & Pleurotus & ostreatus PC15 & $\begin{array}{l}\text { Hypothetical protein } \\
\text { PLEOSDRAFT } 1059391\end{array}$ & 17 \\
\hline Fungi & Pleurotus eryngii* & Pleurotus & eryngii var. tuoliensis & $\begin{array}{l}\text { Homeodomain } 1 \text { mating } \\
\text { type protein (genome not } \\
\text { completely sequenced) }\end{array}$ & 3 \\
\hline Fungi & Lentinula edodes* & Lentinula & edodes & $\begin{array}{l}\text { No significant similarity } \\
\text { found }\end{array}$ & 0 \\
\hline Fungi & $\begin{array}{l}\text { Ganoderma } \\
\text { lucidum* }\end{array}$ & Ganoderma & lucidum & $\begin{array}{c}\text { No significant similarity } \\
\text { found }\end{array}$ & 0 \\
\hline Fungi & $\begin{array}{l}\text { Lactarius } \\
\text { deliciosus* }\end{array}$ & Lactarius & deliciosus & $\begin{array}{c}\text { No significant similarity } \\
\text { found }\end{array}$ & 0 \\
\hline \multirow[t]{2}{*}{ Others } & \multirow[t]{2}{*}{ Microbes } & Pseudomonas & pseudoalcaligenes & $\begin{array}{l}\text { Hypothetical protein } \\
\text { N619_00405 }\end{array}$ & 55 \\
\hline & & Gordonia & rhizosphera & Stilbene synthase & 34 \\
\hline
\end{tabular}

*Genomes from mushrooms not completely sequenced (in 2015). 


\section{Figure captions}

Figure 1. Number of scientific works published up to October 2015 determining flavonoids in mushrooms (according to Web of Science). References were shorted by the impact factor of the journal where they were published the year that they were published (except for 2015).

Figure 2. Total phenols and the colorimetric results obtained after using the method to determine 'total flavonoids' in several mushrooms species (at $510 \mathrm{~nm}$ ).

Figure 3. VIS spectra of quercetin, L-DOPA and ergosterol standard compounds when they were treated with $\mathrm{Al}\left(\mathrm{Cl}_{3}\right)_{3}$ and $\mathrm{NaNO}_{2}$ solutions as indicated in the test used to measure 'total flavonoids' in mushrooms.

Figure 4. HPLC chromatogram at $340 \mathrm{~nm}$ of a) onion waste b) substrate supplemented with onion waste after cultivation of $P$. ostreatus and c) $P$. ostreatus fruiting bodies grown on substrate supplemented with onion waste $\left(\mathrm{Rt}=8.76 \mathrm{~min}\right.$. quercetin 3,7 - or $3,4^{\prime}$-diglucoside; $\mathrm{Rt}=10.02 \mathrm{~min}$. quercetin $3,7-$ or $3,4^{\prime}$ diglucoside; Rt= $10.81 \mathrm{~min}$. isorhamnetin 3-diglucoside (or 3-sophoroside); Rt=16.02 min. quercetin 3glucoside and $\mathrm{Rt}=17.39 \mathrm{~min}$. isorhamnetin 3-glucoside).

Figure 5. Mycelial growth of $P$. ostreatus grown on MEA media supplemented with different concentrations of a) luteolin dissolved in ethanol and b) caffeic acid. 
Table 1. Taxonomic distribution of sequences related to the three key enzymes involved in the biosynthesis of flavonoids extracted from Pfam (particularly those present in the fungal kingdom).

\begin{tabular}{|c|c|c|c|c|c|c|c|c|c|c|}
\hline Enzyme & Function & PFamily & Kingdom * & Phyllum & Class & Order & Family & Genus & Specie & Seq. \\
\hline \multirow{16}{*}{ PAL } & \multirow{16}{*}{$\begin{array}{c}\text { Transform } \\
\text { L-phenylalanine } \\
\text { to ammonia and } \\
\text { trans-cinnamic } \\
\text { acid (first } \\
\text { phenolic } \\
\text { compound in } \\
\text { the phenyl } \\
\text { propanoid } \\
\text { pathwoy) }\end{array}$} & \multirow{16}{*}{$\begin{array}{c}\text { Lyase } \\
\text { aromatic } \\
\text { (PF } \\
00221)\end{array}$} & No Kingdom & NS & NS & NS & NS & NS & 20 & 37 \\
\hline & & & \begin{tabular}{|l|} 
Viridiplantae \\
\end{tabular} & NS & NS & NS & NS & NS & 312 & 1007 \\
\hline & & & Metazoa & NS & NS & NS & NS & NS & 91 & 142 \\
\hline & & & \multirow{12}{*}{ Fungi } & \multirow{9}{*}{ Basidiomycota } & \multirow{4}{*}{ Agaricomycetes } & \multirow{4}{*}{ Agaricales } & Agaricaceae & Agaricus & bisporus & 1 \\
\hline & & & & & & & Tricholomataceae & Trichaioma & motsutake & 3 \\
\hline & & & & & & & Amanitaceac & Amanito & muscaria & 1 \\
\hline & & & & & & & Pleurotacese & Pleurotus & eryngiï & 1 \\
\hline & & & & & Ustilaginomycetes & Ustilaginales & Ustilaginaceae & Pseudozymo & brasiliensis & 1 \\
\hline & & & & & \multirow{4}{*}{ No class } & \multirow{4}{*}{ Sporidiobolales } & \multirow{4}{*}{ No Family } & Rhodosporidium & toruloides & 1 \\
\hline & & & & & & & & \multirow{2}{*}{ Rhodotoruio } & muciloginoso & 1 \\
\hline & & & & & & & & & glutinis & 3 \\
\hline & & & & & & & & Sponidiobolus & solmonicolor & 3 \\
\hline & & & & \multirow{3}{*}{ Ascomycota } & Eurotiomycetes & Eurotiales & Aspergillacese & Penicillum & roqueforti & 1 \\
\hline & & & & & Sordariomycetes & Hypocreales & Nectriaceae & Fusarium & graminearum & 1 \\
\hline & & & & & Lecanoromycetes & Lecanorales & Parmeliaceae & Letharia & vulpino & 1 \\
\hline & & & Uncategorised & NS & NS & NS & NS & NS & 28 & 102 \\
\hline \multirow[b]{2}{*}{ CHS } & \multirow[b]{2}{*}{$\begin{array}{l}\text { Catalyzes the } \\
\text { conversion of } \\
\text { 4-coumaroyl- } \\
\text { CoA and } \\
\text { malonyl-CoA to } \\
\text { naringenin } \\
\text { chalcone (first } \\
\text { flavonoid) }\end{array}$} & \multirow[b]{2}{*}{$\begin{array}{c}\text { Chalcone } \\
\text { and } \\
\text { stilbene } \\
\text { synthases } \\
\text { C- } \\
\text { terminal } \\
\text { domain } \\
\text { (PF02797) }\end{array}$} & \begin{tabular}{|l|} 
Viridiplantae \\
\end{tabular} & NS & NS & NS & NS & NS & 751 & 2687 \\
\hline & & & Uncategorised & NS & NS & NS & NS & NS & 61 & 199 \\
\hline \multirow{3}{*}{$\mathrm{CHI}$} & \multirow{3}{*}{$\begin{array}{c}\text { Catalyzes the ch } \\
\text { emical reactionc } \\
\text { a chalcone <-> a } \\
\text { flavanone }\end{array}$} & \multirow{3}{*}{$\begin{array}{l}\text { Chaicone } \\
\text { (PF02431) }\end{array}$} & Viridiplantae & NS & NS & NS & NS & NS & 146 & 398 \\
\hline & & & \begin{tabular}{|l|} 
Uncategorized \\
\end{tabular} & NS & NS & NS & NS & NS & 15 & 55 \\
\hline & & & No Kingdom & NS & NS & NS & NS & NS & 2 & 2 \\
\hline
\end{tabular}

\footnotetext{
*Only inside Eukariota domain. PAL, phenylalanine ammonia-lyase; CHS, chalcone synthase; CHI, chalcone isomerase. NS, non-specified data.
} 
Table 2

Click here to download high resolution image

Table 2. Results of the alignments of the Chalconesynthase (CHS) sequence from vitis viniffera with other organisms using Blastp. Data included are those showing higher percentage of homology.

\begin{tabular}{|c|c|c|c|c|c|}
\hline Organisen & Termsearched & Genus & Specie & Homology with & $\begin{array}{l}\text { Salignment } \\
\text { (query cover) }\end{array}$ \\
\hline Plant & Vifisvinilera & vias & vinifers & Chalcone synthase & 100 \\
\hline Plant & $\begin{array}{l}\text { Arabidopatiz } \\
\text { thariang }\end{array}$ & Arabidopeis & thaliane & Chalcone synthase & 97 \\
\hline \multirow{3}{*}{ Plant } & \multirow{3}{*}{ Muberry } & Morut & aba var. muiticaulis & Chalcone synthase & 96 \\
\hline & & Morun & notabilin & Chalcene synthase & 58 \\
\hline & & Mtorvs & aiba & Chalcone synthase & 65 \\
\hline Plant & Strawberny & Fragaria & ananossa & Chalcone synthase & 98 \\
\hline \multirow{3}{*}{ Plant } & \multirow{3}{*}{ Solanum } & Solanum & broopersicam & $\begin{array}{c}\text { Chalcone synthase } \\
1 \mathrm{a2}\end{array}$ & 98 \\
\hline & & Solanum & tuberosum & Chalcone synthase & 98 \\
\hline & & Solanum & pinnotisectumn & Chaicone synthase & 96 \\
\hline \multirow{4}{*}{ Plant } & \multirow{4}{*}{ Citrus } & Citrun & reticusata & Chalcone synthase & 96 \\
\hline & & Corve & ichangenais & Chalcone symthase & 68 \\
\hline & & Cibrut & moxims & Chalcone synthase & Go \\
\hline & & Citrus & clementina & $\begin{array}{l}\text { Hysothetical protein } \\
\text { CKCLE v } 10015535 \mathrm{my}\end{array}$ & 96 \\
\hline Pant & $\begin{array}{l}\text { Arabidoptiz } \\
\text { theliand }\end{array}$ & Arabidopsia & thaliana & Chaicone synthase & 97 \\
\hline Anina: & Human & Home & sapiens & $\begin{array}{c}\text { Wio significant smilarty } \\
\text { found }\end{array}$ & 0 \\
\hline Aninal & Mouse & Mus & musculus & $\begin{array}{c}\text { Nive significant simiarity } \\
\text { found }\end{array}$ & 0 \\
\hline Animat & $\begin{array}{c}\text { Cesenorhabdits } \\
\text { elegans }\end{array}$ & Cannorhabotis & nlogans & $\begin{array}{c}\text { Ho significant simlarty } \\
\text { found }\end{array}$ & 0 \\
\hline Fung & $\begin{array}{l}\text { Seccharompress } \\
\text { cerevisiat }\end{array}$ & Saccharamyces & conrequiatial & $\begin{array}{c}\text { No significant simsiarty } \\
\text { found }\end{array}$ & 0 \\
\hline \multirow{4}{*}{ Fungi } & \multirow{4}{*}{ Agaricus } & Aparicus & $\begin{array}{c}\text { biaporuavar, bumethi } \\
\text { JB137.58 }\end{array}$ & $\begin{array}{l}\text { Hybothetical proten } \\
\text { AGABOOAAFT } 11251\end{array}$ & 7 \\
\hline & & Agaricus & $\begin{array}{c}\text { bisporvovar bisponss } \\
\text { H97 }\end{array}$ & $\begin{array}{c}\text { Hybothetical procein } \\
\text { AGABQDRATT } \\
193398 \\
\end{array}$ & 7 \\
\hline & & Agaricus & $\begin{array}{c}\text { bisponusfar bumetil } \\
\text { JBis-Se }\end{array}$ & $\begin{array}{l}\text { Wypothetical proten } \\
\text { AGABQDRAFT } 74201\end{array}$ & 3 \\
\hline & & Aparicus & $\begin{array}{c}\text { bisporusvar bisposs } \\
\qquad 197\end{array}$ & $\begin{array}{c}\text { Mypothefical protein } \\
\text { AGAACDRAFT } \\
207020\end{array}$ & 3 \\
\hline Fungi & Pleurctus ostreatut & Pleurectus & ostreatus PC15 & $\begin{array}{c}\text { Hypothetical prosen } \\
\text { PLEOSDRAFT } \\
1059391\end{array}$ & 17 \\
\hline Fungi & Pleurotus engngi" & Pleurotus & eryngiv var fuoliensis & $\begin{array}{l}\text { Homeodomain } 1 \\
\text { matho type proten } \\
\text { (genome not } \\
\text { completely sequenced) }\end{array}$ & 3 \\
\hline Fungi & Lentinuls edodes' & Lentinula & ododes & $\begin{array}{c}\text { No significant similarty } \\
\text { found }\end{array}$ & 0 \\
\hline Fungi & $\begin{array}{l}\text { Ganodermat } \\
\text { fueidum" }\end{array}$ & Ganoderma & tucidum & $\begin{array}{c}\text { Ho significant simianty } \\
\text { fousd }\end{array}$ & 0 \\
\hline Fungi & $\begin{array}{l}\text { Lactarius: } \\
\text { deticiosur }\end{array}$ & Lactorivis & delieiesos & $\begin{array}{c}\text { No significant simiarty } \\
\text { feuod }\end{array}$ & 0 \\
\hline \multirow[t]{2}{*}{ Others } & \multirow[t]{2}{*}{ Microtes } & Psevdomonas & psecudosicarigenes & $\begin{array}{l}\text { Hypothetical preten } \\
\text { N619_00405: }\end{array}$ & 58 \\
\hline & & Gordontia & thizosphers & Sticene synthase & 34 \\
\hline
\end{tabular}

*Genomes from mushrooms not completely sequenced (in 2015). 
(please, use the colour figure only for online version)

\section{Figure 1.}

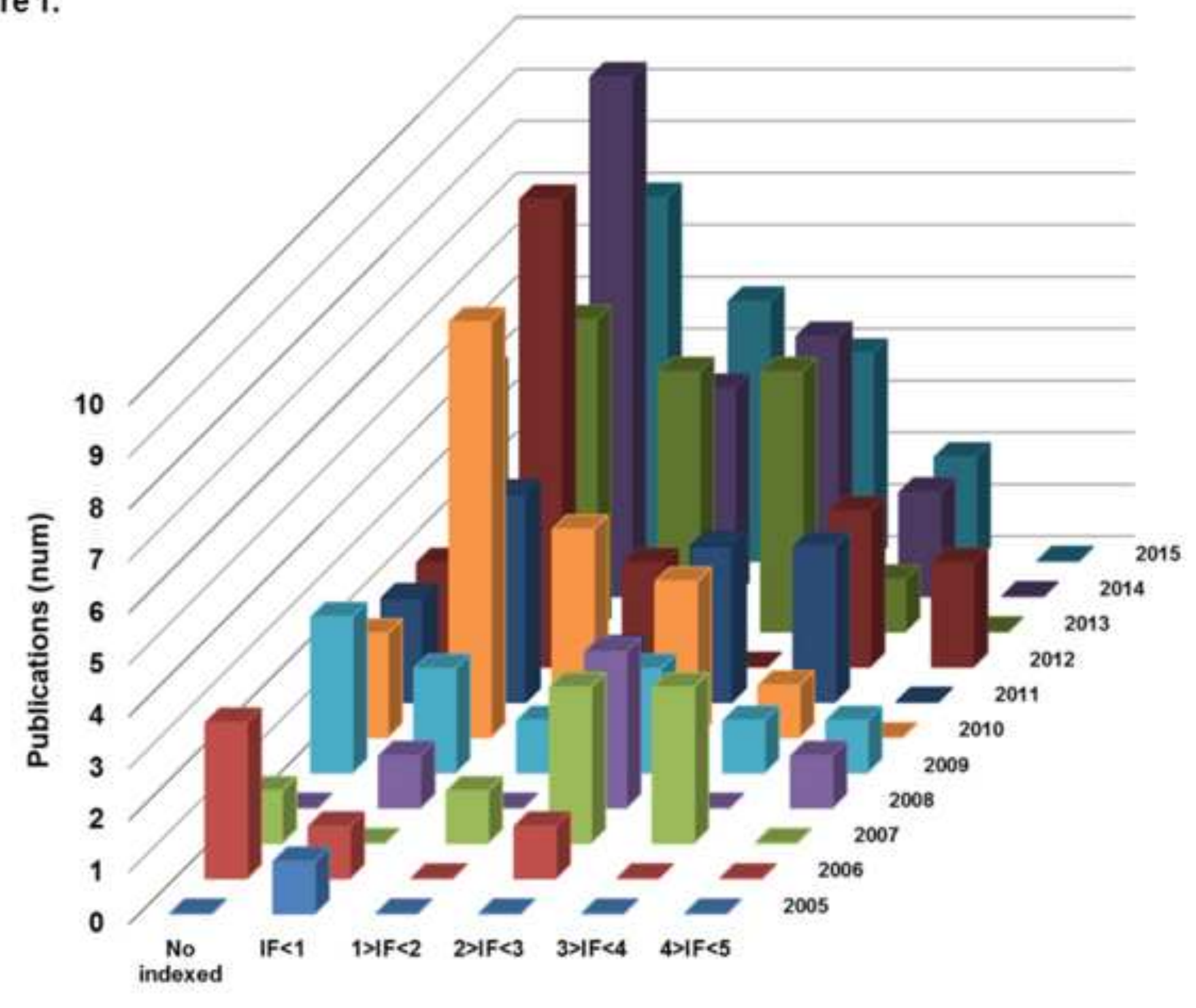


Figure 1.

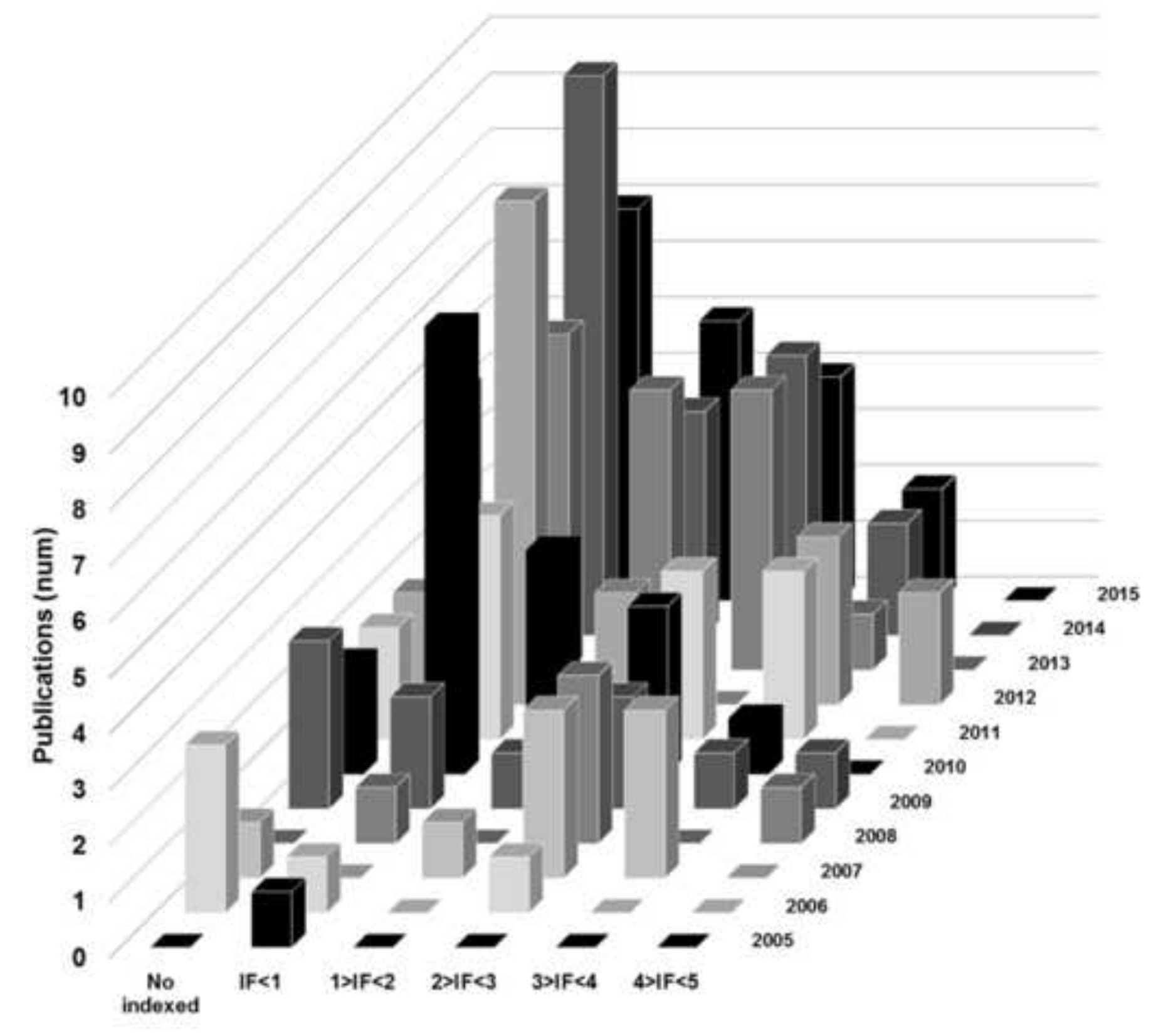


Figure 2.

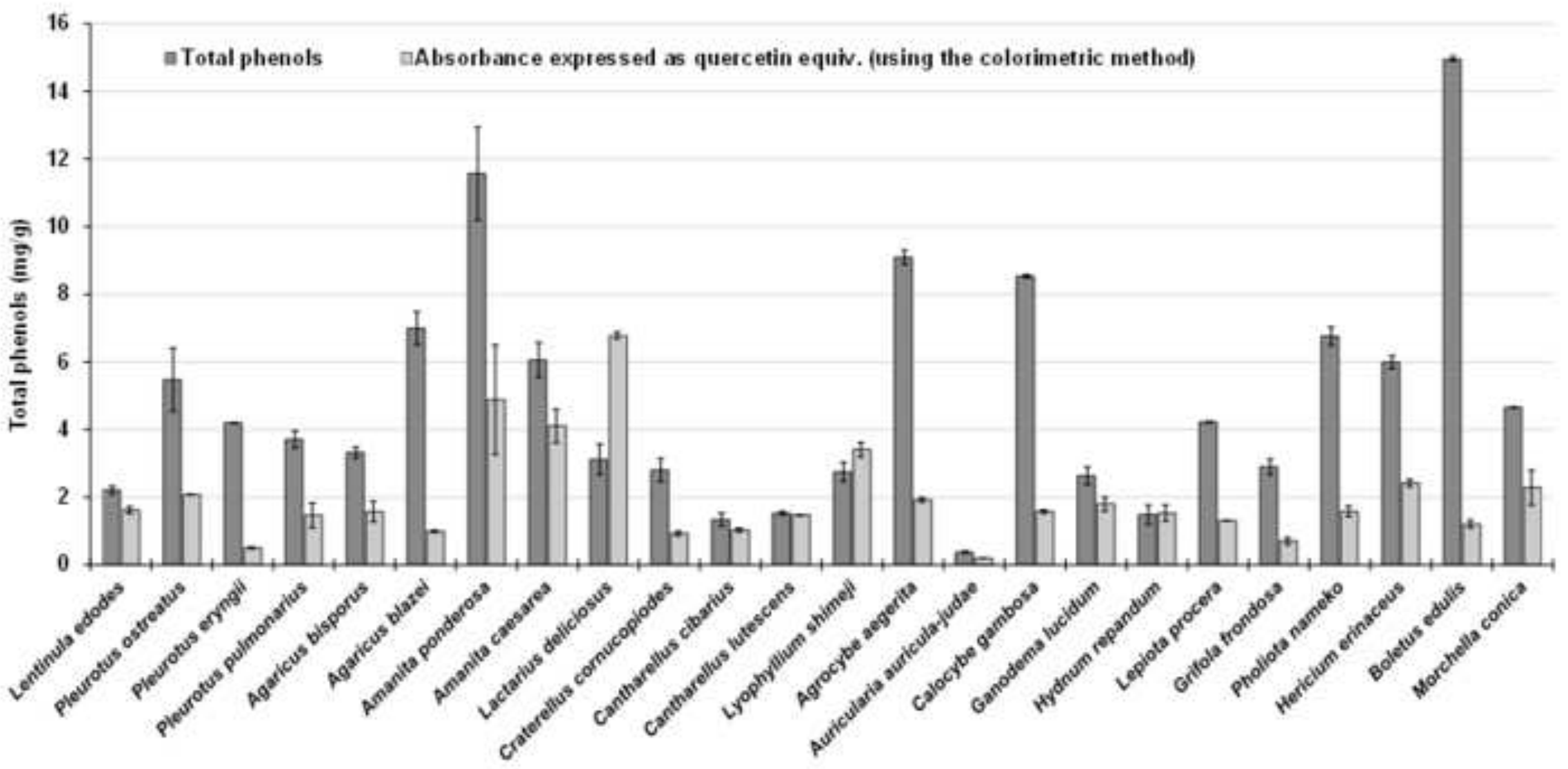




\section{Figure 3.}

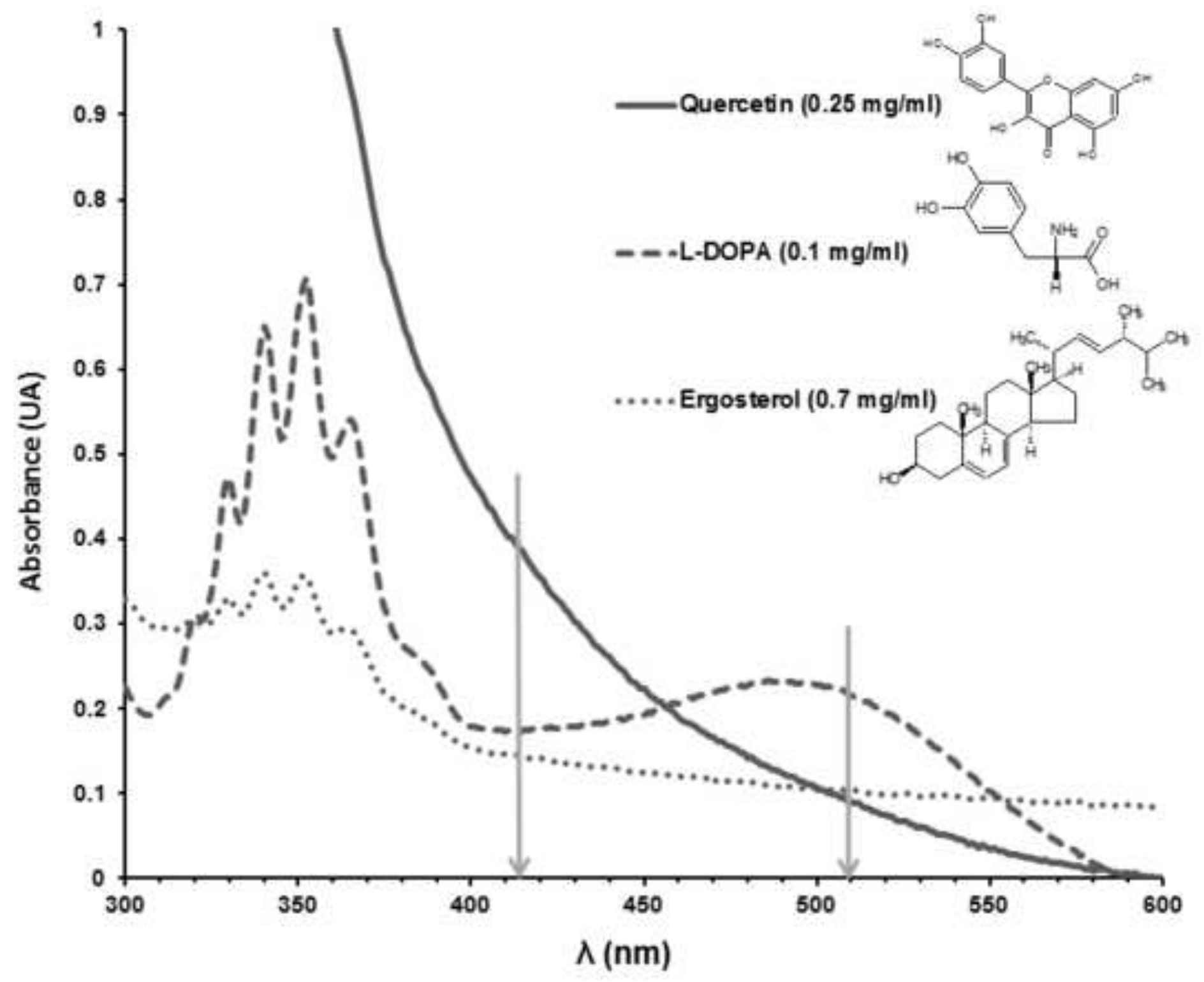


Click here to download high resolution image

\section{Figure 4.}

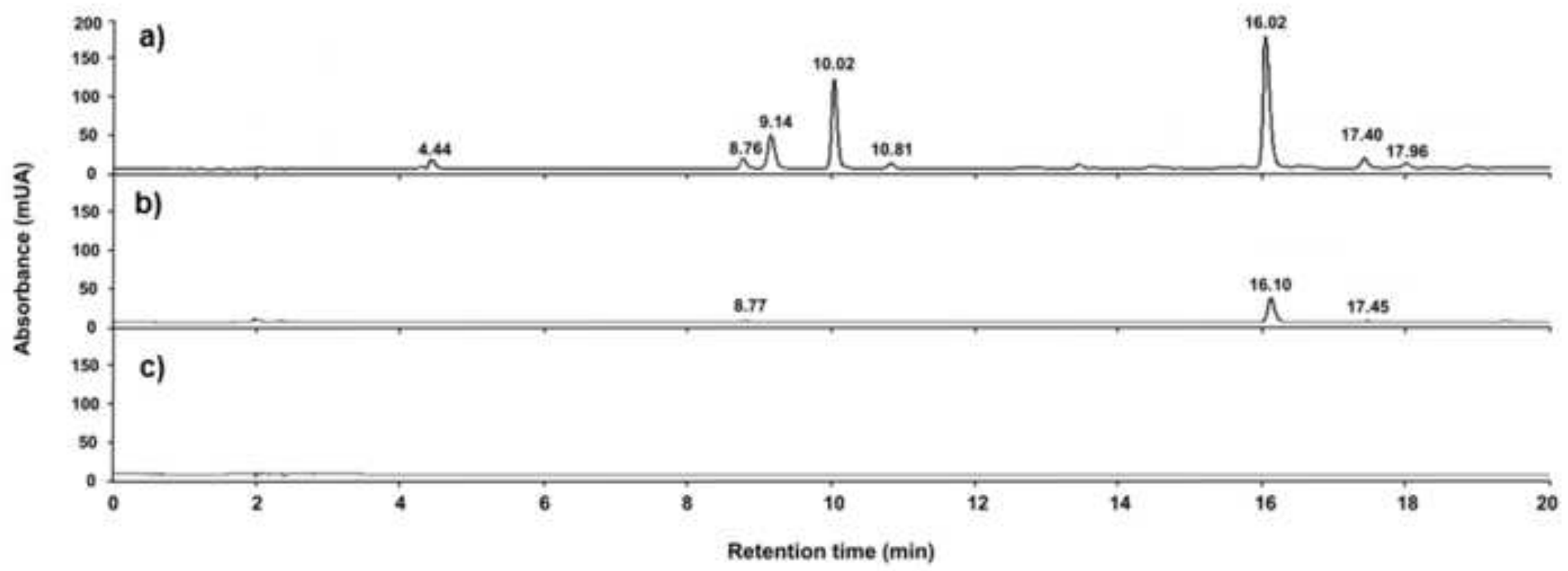




\section{Figure 5.}

a)

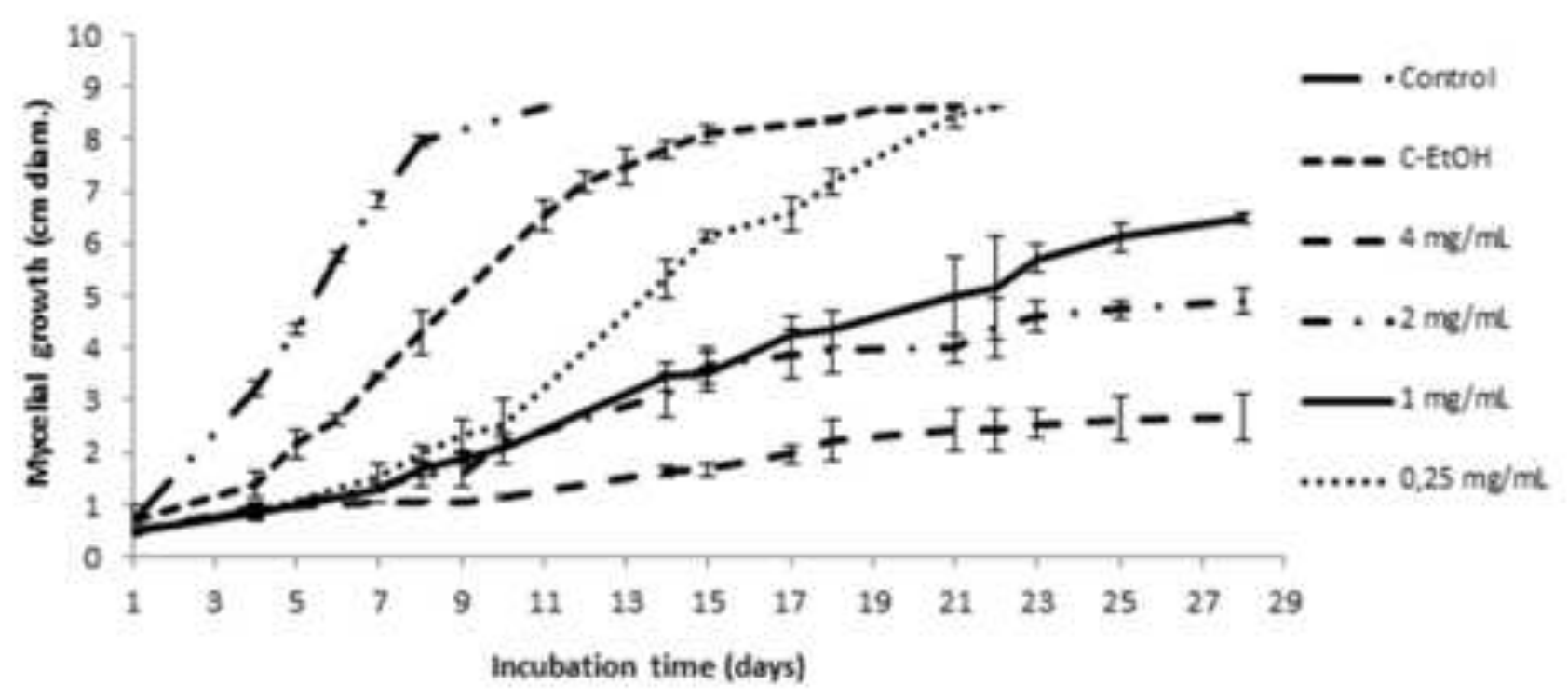

b)

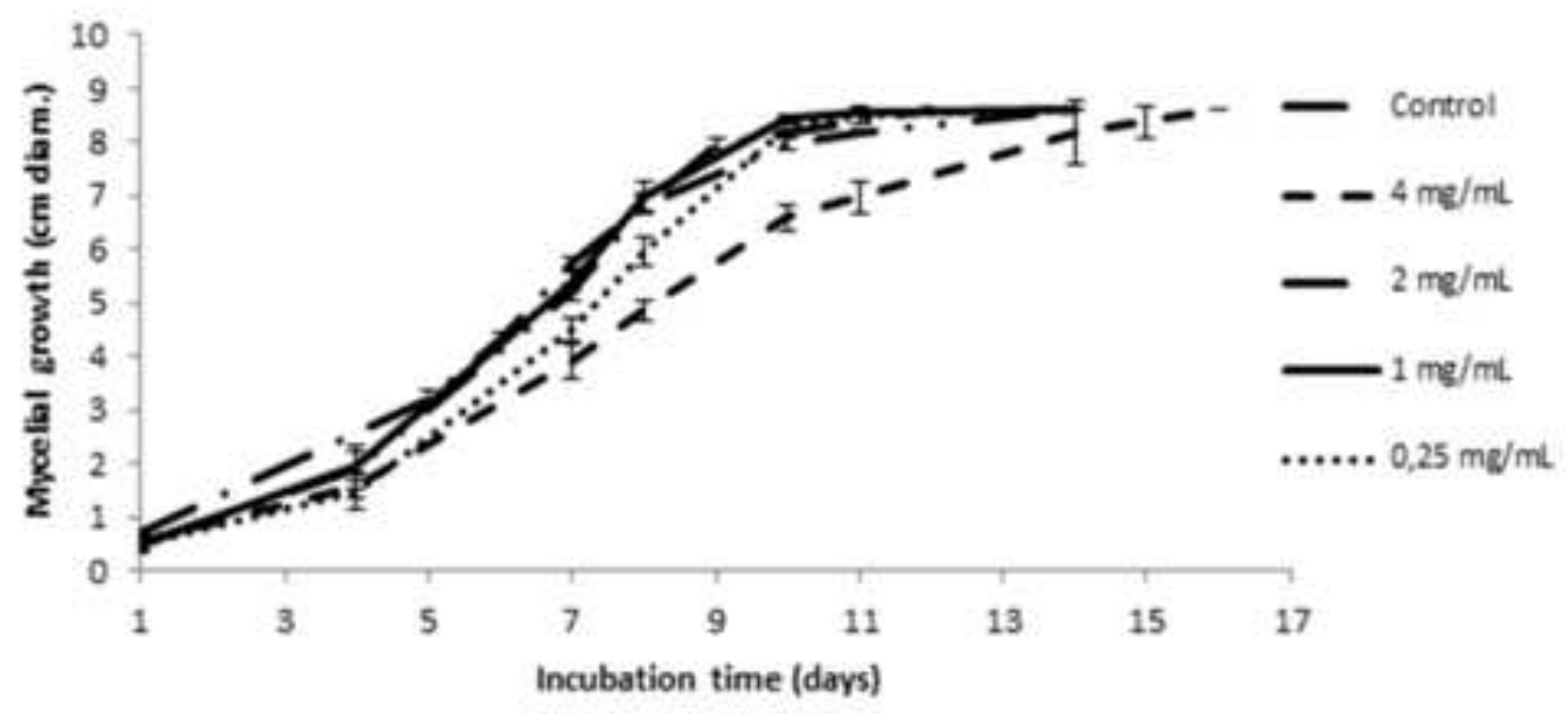




\section{Appendix-Supplementary Table 1}

\begin{tabular}{|c|c|c|c|c|c|c|c|c|c|c|c|}
\hline Number & Year & Journal & $\begin{array}{l}\text { Impact } \\
\text { factor }\end{array}$ & First author & Title & $\begin{array}{l}\text { Volumen, } \\
\text { Issue, } \\
\text { pages }\end{array}$ & $\begin{array}{l}\text { Compounds } \\
\text { found in } \\
\text { mushrooms }\end{array}$ & $\begin{array}{l}\text { Method } \\
\text { utilized to } \\
\text { measure } \\
\text { flavonoids }\end{array}$ & $\begin{array}{c}\text { Detection } \\
\text { device or } \\
\text { wavelength } \\
\text { used }\end{array}$ & $\begin{array}{l}\text { Solvents } \\
\text { used for } \\
\text { extraction }\end{array}$ & $\begin{array}{l}\text { Mushroom } \\
\text { specie } \\
\text { studied }\end{array}$ \\
\hline 1 & 2005 & $\begin{array}{l}\text { Food Science and } \\
\text { Biotechnology }\end{array}$ & 0.645 & $\begin{array}{l}\text { Choi, YM. et } \\
\text { al. }\end{array}$ & $\begin{array}{l}\text { Antioxidant activities and } \\
\text { total phenolics of ethanol } \\
\text { extracts from several edible } \\
\text { mushrooms produced in } \\
\text { Korea. }\end{array}$ & $\begin{array}{c}14,5 \\
700-703\end{array}$ & $\begin{array}{c}\text { Total } \\
\text { flavonoids }\end{array}$ & Colorimetric & NF & Ethanol & $\begin{array}{c}\text { Ganoderma } \\
\text { lucidum and } \\
\text { Pleurotus } \\
\text { eryngii }\end{array}$ \\
\hline 2 & 2006 & Food Chemistry & 2.433 & Choi, Y. et al. & $\begin{array}{c}\text { Influence of heat treatment } \\
\text { on the antioxidant activities } \\
\text { and polyphenolic compounds } \\
\text { of Shiitake (Lentinus edodes) } \\
\text { mushroom. }\end{array}$ & $\begin{array}{c}99,2 \\
381-387\end{array}$ & $\begin{array}{c}\text { Total } \\
\text { flavonoids }\end{array}$ & $\begin{array}{l}\mathrm{NaNO}_{2}+ \\
10 \% \mathrm{AlCl}_{3} \\
\quad \mathrm{H}_{2} \mathrm{O}\end{array}$ & VIS $510 \mathrm{~nm}$ & $\begin{array}{c}80 \% \\
\text { Ethanol }\end{array}$ & $\begin{array}{l}\text { Lentinus } \\
\text { edodes }\end{array}$ \\
\hline 3 & 2006 & $\begin{array}{l}\text { Journal of } \\
\text { Culinary Science } \\
\text { and Technology }\end{array}$ & NF & $\begin{array}{l}\text { Ganguli, A. } \\
\text { et al. }\end{array}$ & $\begin{array}{c}\text { Antioxidant activities and } \\
\text { total phenolics of pickles } \\
\text { produced from the edible } \\
\text { mushroom, Agaricus } \\
\text { bisporus. }\end{array}$ & $\begin{array}{c}5,2-3 \\
131-142\end{array}$ & $\begin{array}{c}\text { Total } \\
\text { flavonoids }\end{array}$ & $10 \% \mathrm{Al}\left(\mathrm{NO}_{3}\right)_{3}$ & $\begin{array}{c}\text { UV/VIS } 415 \\
n m\end{array}$ & Ethanol & $\begin{array}{l}\text { Agaricus } \\
\text { bisporus }\end{array}$ \\
\hline 4 & 2006 & $\begin{array}{c}\text { Annals of } \\
\text { Microbiology }\end{array}$ & 0.427 & $\begin{array}{l}\text { Mercan, N. et } \\
\text { al. }\end{array}$ & $\begin{array}{c}\text { Antioxidant and antimicrobial } \\
\text { properties of ethanolic extract } \\
\text { from Lepista nuda (Bull.) } \\
\text { Cooke. }\end{array}$ & $\begin{array}{c}56,4 \\
339-344\end{array}$ & $\begin{array}{c}\text { Total } \\
\text { flavonoids }\end{array}$ & $10 \% \mathrm{Al}\left(\mathrm{NO}_{3}\right)_{3}$ & $\begin{array}{c}\text { UV/VIS } 415 \\
n m\end{array}$ & Ethanol & Lepista nuda \\
\hline 5 & 2006 & $\begin{array}{l}\text { African Journal of } \\
\text { Biotechnology }\end{array}$ & NF & $\begin{array}{l}\text { Gezer, K. et } \\
\text { al. }\end{array}$ & $\begin{array}{l}\text { Free-radical scavenging } \\
\text { capacity and antimicrobial } \\
\text { activity of wild edible } \\
\text { mushroom from Turkey. }\end{array}$ & $\begin{array}{l}5,20 \\
1924- \\
1928\end{array}$ & $\begin{array}{c}\text { Total } \\
\text { flavonoids }\end{array}$ & $10 \% \mathrm{Al}\left(\mathrm{NO}_{3}\right)_{3}$ & $\begin{array}{c}\text { UV/VIS } 415 \\
n m\end{array}$ & Ethanol & $\begin{array}{l}\text { Wild edible } \\
\text { mushrooms }\end{array}$ \\
\hline 6 & 2006 & $\begin{array}{l}\text { African Journal of } \\
\text { Biotechnology }\end{array}$ & NF & $\begin{array}{l}\text { Turkoglu, A. } \\
\text { et al. }\end{array}$ & $\begin{array}{c}\text { Antioxidant and antimicrobial } \\
\text { activities of Morchella conica } \\
\text { Pers. }\end{array}$ & $\begin{array}{l}5,11 \\
1146- \\
1150\end{array}$ & $\begin{array}{c}\text { Total } \\
\text { flavonoids }\end{array}$ & $10 \% \mathrm{Al}\left(\mathrm{NO}_{3}\right)_{3}$ & $\begin{array}{c}\text { UV/VIS } 415 \\
n m\end{array}$ & Ethanol & $\begin{array}{l}\text { Morchella } \\
\text { conica }\end{array}$ \\
\hline 7 & 2007 & Food Chemistry & 3.052 & $\begin{array}{l}\text { Turkoglu, A. } \\
\text { et al. }\end{array}$ & $\begin{array}{c}\text { Antioxidant and antimicrobial } \\
\text { activities of Laetiporus } \\
\text { sulphureus (Bull.) Murrill }\end{array}$ & $\begin{array}{c}101,1 \\
267-273\end{array}$ & $\begin{array}{c}\text { Total } \\
\text { flavonoids }\end{array}$ & $10 \% \mathrm{Al}\left(\mathrm{NO}_{3}\right)_{3}$ & $\begin{array}{c}\text { UV/VIS } 415 \\
n m\end{array}$ & Ethanol & $\begin{array}{l}\text { Laetiporus } \\
\text { sulphureus }\end{array}$ \\
\hline 8 & 2007 & $\begin{array}{l}\text { Food and } \\
\text { Chemical } \\
\text { Toxicology }\end{array}$ & 2.186 & $\begin{array}{l}\text { Barros, L. et } \\
\text { al. }\end{array}$ & $\begin{array}{l}\text { Effect of Lactarius piperatus } \\
\text { fruiting body maturity stage } \\
\text { on antioxidant activity }\end{array}$ & $\begin{array}{c}45,9 \\
1731- \\
1737\end{array}$ & $\begin{array}{c}\text { Total } \\
\text { flavonoids }\end{array}$ & $\begin{array}{l}\mathrm{NaNO}_{2}+ \\
10 \% \mathrm{AlCl}_{3} \\
\mathrm{H}_{2} \mathrm{O}\end{array}$ & VIS $510 \mathrm{~nm}$ & Methanol & $\begin{array}{l}\text { Lactarius } \\
\text { piperatus }\end{array}$ \\
\hline
\end{tabular}




\section{Appendix-Supplementary Table 1}

\begin{tabular}{|c|c|c|c|c|c|c|c|c|c|c|c|}
\hline Number & Year & Journal & $\begin{array}{l}\text { Impact } \\
\text { factor }\end{array}$ & First author & Title & $\begin{array}{l}\text { Volumen, } \\
\text { Issue, } \\
\text { pages }\end{array}$ & $\begin{array}{c}\text { Compounds } \\
\text { found in } \\
\text { mushrooms }\end{array}$ & $\begin{array}{l}\text { Method } \\
\text { utilized to } \\
\text { measure } \\
\text { flavonoids }\end{array}$ & $\begin{array}{c}\text { Detection } \\
\text { device or } \\
\text { wavelength } \\
\text { used }\end{array}$ & $\begin{array}{l}\text { Solvents } \\
\text { used for } \\
\text { extraction }\end{array}$ & $\begin{array}{l}\text { Mushroom } \\
\text { specie } \\
\text { studied }\end{array}$ \\
\hline & & & & & $\begin{array}{l}\text { measured by several } \\
\text { biochemical assays. }\end{array}$ & & & & & & \\
\hline 9 & 2007 & Food Chemistry & 3.052 & $\begin{array}{l}\text { Barros, L. et } \\
\text { al. }\end{array}$ & $\begin{array}{l}\text { Bioactive properties of the } \\
\text { medicinal mushroom } \\
\text { Leucopaxillus giganteus } \\
\text { mycelium obtained in the } \\
\text { presence of different nitrogen } \\
\text { sources. }\end{array}$ & $\begin{array}{c}105,1 \\
179-186\end{array}$ & $\begin{array}{c}\text { Total } \\
\text { flavonoids }\end{array}$ & $\begin{array}{l}\mathrm{NaNO}_{2}+ \\
10 \% \mathrm{AlCl}_{3} \\
\mathrm{H}_{2} \mathrm{O}\end{array}$ & VIS $510 \mathrm{~nm}$ & Methanol & $\begin{array}{l}\text { Leucopaxillus } \\
\text { giganteus }\end{array}$ \\
\hline 10 & 2007 & Food Chemistry & 3.052 & $\begin{array}{l}\text { Lim, HW. et } \\
\text { al. }\end{array}$ & $\begin{array}{c}\text { Free radical-scavenging and } \\
\text { inhibition of nitric oxide } \\
\text { production by four grades of } \\
\text { pine mushroom (Tricholoma } \\
\text { matsutake Sing.) }\end{array}$ & $\begin{array}{l}103,4 \\
1337- \\
1342\end{array}$ & $\begin{array}{c}\text { Total } \\
\text { flavonoids }\end{array}$ & $\begin{array}{l}\mathrm{NaNO}_{2}+ \\
10 \% \mathrm{AlCl}_{3} \\
\mathrm{H}_{2} \mathrm{O}\end{array}$ & VIS $510 \mathrm{~nm}$ & $\begin{array}{l}\text { Ethyl } \\
\text { acetate or } \\
\text { butanol }\end{array}$ & $\begin{array}{l}\text { Tricholoma } \\
\text { matsutake }\end{array}$ \\
\hline 11 & 2007 & $\begin{array}{l}\text { Journal of } \\
\text { Agricultural and } \\
\text { Food Chemistry }\end{array}$ & 2.532 & $\begin{array}{l}\text { Barros, L. et } \\
\text { al. }\end{array}$ & $\begin{array}{c}\text { Effect of fruiting body } \\
\text { maturity stage, on chemical } \\
\text { composition and } \\
\text { antimicrobial activity of } \\
\text { Lactarius sp mushrooms. }\end{array}$ & $\begin{array}{l}55,21 \\
8766- \\
8771\end{array}$ & $\begin{array}{c}\text { Total } \\
\text { flavonoids }\end{array}$ & $\begin{array}{l}\mathrm{NaNO}_{2}+ \\
10 \% \mathrm{AlCl}_{3} \\
\mathrm{H}_{2} \mathrm{O}\end{array}$ & VIS $510 \mathrm{~nm}$ & Methanol & $\begin{array}{c}\text { Lactarius } \\
\text { deliciosus } \\
\text { and } \\
\text { L. piperatus }\end{array}$ \\
\hline 12 & 2007 & Plant Archives & NF & $\begin{array}{l}\text { Gowdaman, } \\
\text { V. et al. }\end{array}$ & $\begin{array}{l}\text { Antibacterial metabolites } \\
\text { from wood rot fungus } \\
\text { Phellinus hohnelli. }\end{array}$ & $\begin{array}{c}7,2,763- \\
765\end{array}$ & $\begin{array}{c}\text { Total } \\
\text { flavonoids }\end{array}$ & Colorimetric & NF & Ethanol & $\begin{array}{l}\text { Phellinus } \\
\text { hohnelli }\end{array}$ \\
\hline 13 & 2007 & $\begin{array}{l}\text { Food and } \\
\text { Chemical } \\
\text { Toxicology }\end{array}$ & 2.186 & $\begin{array}{l}\text { Barros, L. et } \\
\text { al. }\end{array}$ & $\begin{array}{l}\text { Effect of Lactarius piperatus } \\
\text { fruiting body maturity stage } \\
\text { on antioxidant activity } \\
\text { measured by several } \\
\text { biochemical assays. }\end{array}$ & $\begin{array}{l}45,9 \\
1731- \\
1737\end{array}$ & $\begin{array}{c}\text { Total } \\
\text { flavonoids }\end{array}$ & $\begin{array}{c}\mathrm{NaNO}_{2}+ \\
10 \% \mathrm{AlCl}_{3} . \\
\mathrm{H}_{2} \mathrm{O}\end{array}$ & VIS $510 \mathrm{~nm}$ & Methanol & L. piperatus \\
\hline 14 & 2007 & $\begin{array}{c}\text { European Food } \\
\text { Research and } \\
\text { Technology }\end{array}$ & 1.159 & $\begin{array}{l}\text { Barros, L. et } \\
\text { al. }\end{array}$ & $\begin{array}{l}\text { Antimicrobial activity and } \\
\text { bioactive compounds of } \\
\text { Portuguese wild edible } \\
\text { mushrooms methanolic } \\
\text { extracts }\end{array}$ & $\begin{array}{l}225,2 \\
151 \mathrm{EP} \\
156\end{array}$ & $\begin{array}{c}\text { Total } \\
\text { flavonoids }\end{array}$ & $\begin{array}{l}\mathrm{NaNO}_{2}+ \\
10 \% \mathrm{AlCl}_{3} \\
\mathrm{H}_{2} \mathrm{O}\end{array}$ & VIS $510 \mathrm{~nm}$ & Methanol & $\begin{array}{l}\text { L. deliciosus, } \\
\text { Sarcodon } \\
\text { imbricatus } \\
\text { and } \\
\text { Tricholoma } \\
\text { portentosum }\end{array}$ \\
\hline
\end{tabular}




\section{Appendix-Supplementary Table 1}

\begin{tabular}{|c|c|c|c|c|c|c|c|c|c|c|c|}
\hline Number & Year & Journal & $\begin{array}{l}\text { Impact } \\
\text { factor }\end{array}$ & First author & Title & $\begin{array}{l}\text { Volumen, } \\
\text { Issue, } \\
\text { pages }\end{array}$ & $\begin{array}{c}\text { Compounds } \\
\text { found in } \\
\text { mushrooms }\end{array}$ & $\begin{array}{l}\text { Method } \\
\text { utilized to } \\
\text { measure } \\
\text { flavonoids }\end{array}$ & $\begin{array}{c}\text { Detection } \\
\text { device or } \\
\text { wavelength } \\
\text { used }\end{array}$ & $\begin{array}{l}\text { Solvents } \\
\text { used for } \\
\text { extraction }\end{array}$ & $\begin{array}{l}\text { Mushroom } \\
\text { specie } \\
\text { studied }\end{array}$ \\
\hline 15 & 2008 & $\begin{array}{l}\text { Bioresource } \\
\text { Technology }\end{array}$ & 4.453 & $\begin{array}{l}\text { Sarikurkcu, } \\
\text { C. et al. }\end{array}$ & $\begin{array}{l}\text { Evaluation of the antioxidant } \\
\text { activity of four edible } \\
\text { mushrooms from the Central } \\
\text { Anatolia, Eskisehir - Turkey: } \\
\text { Lactarius deterrimus, Suillus } \\
\text { collitinus, Boletus edulis, } \\
\text { Xerocomus chrysenteron. }\end{array}$ & $\begin{array}{l}99,14 \\
6651- \\
6655\end{array}$ & $\begin{array}{c}\text { Total } \\
\text { flavonoids }\end{array}$ & $2 \% \mathrm{AlCl}_{3}$ & $\begin{array}{c}\text { UV/VIS } 415 \\
n m\end{array}$ & Methanol & $\begin{array}{l}\text { Lactarius } \\
\text { deterrimus, } \\
\text { Suillus } \\
\text { collitinus, } \\
\text { Boletus edulis } \\
\text { and } \\
\text { Xerocomus } \\
\text { chrysenteron }\end{array}$ \\
\hline 16 & 2008 & Food Chemistry & 2.696 & $\begin{array}{l}\text { Barros, L. et } \\
\text { al. }\end{array}$ & $\begin{array}{l}\text { Antioxidant activity of } \\
\text { Agaricus sp. mushrooms by } \\
\text { chemical, biochemical and } \\
\text { electrochemical assays. }\end{array}$ & $\begin{array}{l}111,1 \\
61-66\end{array}$ & $\begin{array}{c}\text { Total } \\
\text { flavonoids }\end{array}$ & $\begin{array}{l}\mathrm{NaNO}_{2}+ \\
10 \% \mathrm{AlCl}_{3} \\
\mathrm{H}_{2} \mathrm{O}\end{array}$ & VIS $510 \mathrm{~nm}$ & Methanol & $\begin{array}{c}\text { Agaricus } \\
\text { bisporus, } \\
\text { Agaricus } \\
\text { arvensis, } \\
\text { Agaricus } \\
\text { romagnesii, } \\
\text { Agaricus } \\
\text { sivaticus and } \\
\text { Agaricus } \\
\text { silvicola }\end{array}$ \\
\hline 17 & 2008 & $\begin{array}{l}\text { Food and } \\
\text { Chemical } \\
\text { Toxicology }\end{array}$ & 2.321 & $\begin{array}{l}\text { Barros, L. et } \\
\text { al. }\end{array}$ & $\begin{array}{l}\text { Wild and commercial } \\
\text { mushrooms as source of } \\
\text { nutrients and nutraceuticals. }\end{array}$ & $\begin{array}{l}46,8 \\
2742- \\
2747\end{array}$ & $\begin{array}{c}\text { Total } \\
\text { flavonoids }\end{array}$ & $\begin{array}{l}\mathrm{NaNO}_{2}+ \\
10 \% \mathrm{AlCl}_{3} \\
\mathrm{H}_{2} \mathrm{O}\end{array}$ & VIS $510 \mathrm{~nm}$ & Methanol & $\begin{array}{c}\text { B. edulis, } \\
\text { Calocybe } \\
\text { gambosa, } \\
\text { Cantharellus } \\
\text { cibarius, } \\
\text { Craterellus } \\
\text { cornucopioide } \\
\text { s, Marasmius } \\
\text { oreades, } A \text {. } \\
\text { bisporus, } A \text {. } \\
\text { sylvaticus } \\
\text { and } A . \\
\text { silvicola }\end{array}$ \\
\hline 18 & 2008 & $\begin{array}{l}\text { Journal of } \\
\text { Agricultural and } \\
\text { Food Chemistry }\end{array}$ & 2.562 & $\begin{array}{l}\text { Kim, MY. et } \\
\text { al. }\end{array}$ & $\begin{array}{l}\text { Phenolic compound } \\
\text { concentration and antioxidant } \\
\text { activities of edible and }\end{array}$ & $\begin{array}{l}56,16 \\
7265- \\
7270\end{array}$ & $\begin{array}{c}\text { Total } \\
\text { flavonoids }\end{array}$ & HPLC-DAD & UV 280 nm & $\begin{array}{c}80 \% \\
\text { Methanol }\end{array}$ & $\begin{array}{l}\text { P. eryngii, } G \text {. } \\
\text { lucidum and } \\
\text { A. bisporus }\end{array}$ \\
\hline
\end{tabular}




\section{Appendix-Supplementary Table 1}

\begin{tabular}{|c|c|c|c|c|c|c|c|c|c|c|c|}
\hline Number & Year & Journal & $\begin{array}{l}\text { Impact } \\
\text { factor }\end{array}$ & First author & Title & $\begin{array}{l}\text { Volumen, } \\
\text { Issue, } \\
\text { pages }\end{array}$ & $\begin{array}{l}\text { Compounds } \\
\text { found in } \\
\text { mushrooms }\end{array}$ & $\begin{array}{l}\text { Method } \\
\text { utilized to } \\
\text { measure } \\
\text { flavonoids }\end{array}$ & $\begin{array}{l}\text { Detection } \\
\text { device or } \\
\text { wavelength } \\
\text { used }\end{array}$ & $\begin{array}{l}\text { Solvents } \\
\text { used for } \\
\text { extraction }\end{array}$ & $\begin{array}{l}\text { Mushroom } \\
\text { specie } \\
\text { studied }\end{array}$ \\
\hline & & & & & $\begin{array}{c}\text { medicinal mushrooms from } \\
\text { Korea. }\end{array}$ & & & & & & \\
\hline 19 & 2008 & $\begin{array}{l}\text { Food Science and } \\
\text { Techonology } \\
\text { International }\end{array}$ & 0.702 & $\begin{array}{l}\text { Barros, L. et } \\
\text { al. }\end{array}$ & $\begin{array}{c}\text { Phenolics and antioxidant } \\
\text { activity of mushroom } \\
\text { Leucopaxillus giganteus } \\
\text { mycelium at different carbon } \\
\text { sources. }\end{array}$ & $\begin{array}{r}14,1 \\
47-55\end{array}$ & $\begin{array}{c}\text { Total } \\
\text { flavonoids }\end{array}$ & $\begin{array}{l}\mathrm{NaNO}_{2}+ \\
10 \% \mathrm{AlCl}_{3} \\
\mathrm{H}_{2} \mathrm{O}\end{array}$ & VIS $510 \mathrm{~nm}$ & Water & L. giganteus \\
\hline 20 & 2009 & $\begin{array}{l}\text { Innovative Food } \\
\text { Science and } \\
\text { Emerging } \\
\text { Technologies }\end{array}$ & 2.174 & $\begin{array}{l}\text { Jayakumar, } \\
\text { T. et al. }\end{array}$ & $\begin{array}{c}\text { In-vitro antioxidant activities } \\
\text { of an Ethanolic extract of the } \\
\text { oyster mushroom Pleurotus } \\
\text { ostreatus. }\end{array}$ & $\begin{array}{c}10,2 \\
228-234\end{array}$ & $\begin{array}{l}\text { Rutin and } \\
\text { chrysin }\end{array}$ & HPLC & UV 300 nm & $\begin{array}{l}95 \% \\
\text { Ethanol }\end{array}$ & $\begin{array}{l}\text { Pleurotus } \\
\text { ostreatus }\end{array}$ \\
\hline 21 & 2009 & $\begin{array}{l}\text { Food and } \\
\text { Chemical } \\
\text { Toxicology }\end{array}$ & 2.114 & $\begin{array}{l}\text { Gursoy, N. } \\
\text { et al. }\end{array}$ & $\begin{array}{l}\text { Antioxidant activities, metal } \\
\text { contents, total phenolics and } \\
\text { flavonoids of seven } \\
\text { Morchella species. }\end{array}$ & $\begin{array}{l}47,9 \\
2381- \\
2388\end{array}$ & $\begin{array}{c}\text { Total } \\
\text { flavonoids }\end{array}$ & $\mathrm{AlCl}_{3}$ & $\begin{array}{c}\text { UV/VIS } 415 \\
n m\end{array}$ & Methanol & $\begin{array}{c}\text { Morchella } \\
\text { rotunda, } \\
\text { Morchella } \\
\text { crassipes, } \\
\text { Morchella } \\
\text { esculenta var. } \\
\text { umbrina, } \\
\text { Morchella } \\
\text { deliciosa, } \\
\text { Morchella } \\
\text { elata, } \\
\text { M.conica and } \\
\text { Morchella } \\
\text { angusticeps. }\end{array}$ \\
\hline 22 & 2009 & $\begin{array}{l}\text { Micologia } \\
\text { Aplicada } \\
\text { International }\end{array}$ & NF & $\begin{array}{l}\text { Bruijn, J. et } \\
\quad \text { al. }\end{array}$ & $\begin{array}{l}\text { Antioxidant properties of } \\
\text { extracts obtained from Grifola } \\
\text { gargal mushrooms. }\end{array}$ & $\begin{array}{c}21,1,11- \\
18\end{array}$ & $\begin{array}{c}\text { Total } \\
\text { flavonoids }\end{array}$ & $\begin{array}{l}\mathrm{NaNO}_{2}+ \\
10 \% \mathrm{AlCl}_{3} \\
\mathrm{H}_{2} \mathrm{O}\end{array}$ & VIS 510 nm & $\begin{array}{c}\text { Acetone, } \\
\text { water, } \\
\text { ethanol, } \\
\text { ethyl } \\
\text { acetate, n- } \\
\text { hexane or } \\
\text { ethanol:wat } \\
\text { er mixtures }\end{array}$ & Grifola gargal \\
\hline
\end{tabular}




\section{Appendix-Supplementary Table 1}

\begin{tabular}{|c|c|c|c|c|c|c|c|c|c|c|c|}
\hline Number & Year & Journal & $\begin{array}{l}\text { Impact } \\
\text { factor }\end{array}$ & First author & Title & $\begin{array}{l}\text { Volumen, } \\
\text { Issue, } \\
\text { pages }\end{array}$ & $\begin{array}{c}\text { Compounds } \\
\text { found in } \\
\text { mushrooms }\end{array}$ & $\begin{array}{l}\text { Method } \\
\text { utilized to } \\
\text { measure } \\
\text { flavonoids }\end{array}$ & $\begin{array}{l}\text { Detection } \\
\text { device or } \\
\text { wavelength } \\
\text { used }\end{array}$ & $\begin{array}{l}\text { Solvents } \\
\text { used for } \\
\text { extraction }\end{array}$ & $\begin{array}{l}\text { Mushroom } \\
\text { specie } \\
\text { studied }\end{array}$ \\
\hline 23 & 2009 & $\begin{array}{l}\text { Asian Journal of } \\
\text { Food and } \\
\text { Agrolndustry }\end{array}$ & NF & Hip, SY. et al. & $\begin{array}{l}\text { Phenolic profiles of selected } \\
\text { edible wild mushrooms as } \\
\text { affected by extraction } \\
\text { solvent, time and } \\
\text { temperature. }\end{array}$ & $\begin{array}{c}2,3,392- \\
401\end{array}$ & $\begin{array}{c}\text { Total } \\
\text { flavonoids }\end{array}$ & $\begin{array}{l}\mathrm{NaNO}_{2}+ \\
10 \% \mathrm{AlCl}_{3} \\
\mathrm{H}_{2} \mathrm{O}\end{array}$ & $510 \mathrm{~nm}$ & $\begin{array}{l}\text { Mixtures of } \\
\text { methanol, } \\
\text { ethanol, } \\
\text { acetone, } \\
\text { water or } \\
\text { absolute } \\
\text { hexane }\end{array}$ & $\begin{array}{l}\text { Pleurotus sp., } \\
\text { Hygrocybe } \\
\text { conica, } \\
\text { Schizophyllu } \\
\text { m commune } \\
\text { and Lentinus } \\
\text { ciliatus }\end{array}$ \\
\hline 24 & 2009 & $\begin{array}{l}\text { African Journal of } \\
\text { Biotechnology }\end{array}$ & 0.565 & $\begin{array}{l}\text { Jagadish, } \\
\text { L.K., et al. }\end{array}$ & $\begin{array}{l}\text { Comparitive study on the } \\
\text { antioxidant, anticancer and } \\
\text { antimicrobial property of } \\
\text { Agaricus bisporus (J. E. } \\
\text { Lange) Imbach before and } \\
\text { after boiling. }\end{array}$ & $\begin{array}{c}8,4,654- \\
661\end{array}$ & $\begin{array}{c}\text { Total } \\
\text { flavonoids }\end{array}$ & $\mathrm{AlCl}_{3}$ & UV 367 nm & Ethanol & A. bisporus \\
\hline 25 & 2009 & $\begin{array}{l}\text { Bioresource } \\
\text { Technology }\end{array}$ & 4.253 & $\begin{array}{l}\text { Zheng, W. et } \\
\text { al. }\end{array}$ & $\begin{array}{l}\text { Accumulation of antioxidant } \\
\text { phenolic constituents in } \\
\text { submerged cultures of } \\
\text { Inonotus obliquus. }\end{array}$ & $\begin{array}{l}100,3 \\
1327- \\
1335\end{array}$ & $\begin{array}{c}\text { Total } \\
\text { flavonoids }\end{array}$ & HPLC-DAD & $\begin{array}{c}\text { UV 280-310 } \\
n m\end{array}$ & $\begin{array}{l}70 \% \\
\text { Aqueous } \\
\text { acetone }\end{array}$ & $\begin{array}{l}\text { Inonotus } \\
\text { obliquus }\end{array}$ \\
\hline 26 & 2009 & $\begin{array}{l}\text { International } \\
\text { Journal of Food } \\
\text { Sciences and } \\
\text { Nutrition }\end{array}$ & 1.313 & $\begin{array}{l}\text { Liang, L. et } \\
\text { al. }\end{array}$ & $\begin{array}{l}\text { Antioxidant activities of } \\
\text { extracts and subfractions } \\
\text { from Inonotus obliquus. }\end{array}$ & $\begin{array}{c}60,2 \\
175-184\end{array}$ & $\begin{array}{c}\text { Total } \\
\text { flavonoids }\end{array}$ & Colorimetric & NF & $\begin{array}{l}\text { Ethyl } \\
\text { acetate, } \mathrm{n}- \\
\text { butanol or } \\
\text { water }\end{array}$ & I. obliquus \\
\hline 27 & 2009 & $\begin{array}{l}\text { International } \\
\text { Journal of } \\
\text { Medicinal } \\
\text { Mushrooms }\end{array}$ & 0.661 & $\begin{array}{l}\text { Percario, S. } \\
\text { et al. }\end{array}$ & $\begin{array}{l}\text { Antioxidant activity of edible } \\
\text { blushing wood mushroom, } \\
\text { Agaricus sylvaticus Schaeff. } \\
\text { (Agaricomycetideae) in vitro. }\end{array}$ & $\begin{array}{c}11,2,133- \\
139\end{array}$ & $\begin{array}{c}\text { Total } \\
\text { flavonoids }\end{array}$ & $\mathrm{AlCl}_{3}$ & $\begin{array}{c}\text { UV/VIS } 415 \\
n m\end{array}$ & Water & A. sylvaticus \\
\hline 28 & 2009 & $\begin{array}{l}\text { Nutrition and } \\
\text { Food Science }\end{array}$ & NF & $\begin{array}{l}\text { Singla, R. et } \\
\text { al. }\end{array}$ & $\begin{array}{c}\text { Phenolics and antioxidant } \\
\text { activity of a ready-to-eat } \\
\text { snack food prepared from the } \\
\text { edible mushroom ( Agaricus } \\
\text { bisporous). }\end{array}$ & $\begin{array}{c}39,3 \\
227-234\end{array}$ & $\begin{array}{c}\text { Total } \\
\text { flavonoids }\end{array}$ & $\begin{array}{l}\mathrm{NaNO}_{2}+ \\
10 \% \mathrm{AlCl}_{3} \\
\mathrm{H}_{2} \mathrm{O}\end{array}$ & VIS $510 \mathrm{~nm}$ & NF & A. bisporus \\
\hline
\end{tabular}




\section{Appendix-Supplementary Table 1}

\begin{tabular}{|c|c|c|c|c|c|c|c|c|c|c|c|}
\hline Number & Year & Journal & $\begin{array}{l}\text { Impact } \\
\text { factor }\end{array}$ & First author & Title & $\begin{array}{l}\text { Volumen, } \\
\text { Issue, } \\
\text { pages }\end{array}$ & $\begin{array}{c}\text { Compounds } \\
\text { found in } \\
\text { mushrooms }\end{array}$ & $\begin{array}{l}\text { Method } \\
\text { utilized to } \\
\text { measure } \\
\text { flavonoids }\end{array}$ & $\begin{array}{l}\text { Detection } \\
\text { device or } \\
\text { wavelength } \\
\text { used }\end{array}$ & $\begin{array}{l}\text { Solvents } \\
\text { used for } \\
\text { extraction }\end{array}$ & $\begin{array}{l}\text { Mushroom } \\
\text { specie } \\
\text { studied }\end{array}$ \\
\hline 29 & 2009 & $\begin{array}{l}\text { Environmental } \\
\text { Research }\end{array}$ & 3.237 & $\begin{array}{l}\text { Froufe, } \\
\text { H.J.C. et al. }\end{array}$ & $\begin{array}{c}\text { A QCAR model for predicting } \\
\text { antioxidant activity of wild } \\
\text { mushrooms. }\end{array}$ & $\begin{array}{c}20,5-6 \\
579-590\end{array}$ & $\begin{array}{c}\text { Total } \\
\text { flavonoids }\end{array}$ & Colorimetric & NF & NF & $\begin{array}{l}\text { Wild } \\
\text { mushrooms }\end{array}$ \\
\hline 30 & 2010 & Food Chemistry & 3.458 & $\begin{array}{l}\text { Jiang, T. et } \\
\text { al. }\end{array}$ & $\begin{array}{c}\text { Effect of integrated } \\
\text { application of gamma } \\
\text { irradiation and modified } \\
\text { atmosphere packaging on } \\
\text { physicochemical and } \\
\text { microbiological properties of } \\
\text { shiitake mushroom (Lentinus } \\
\text { edodes). }\end{array}$ & $\begin{array}{c}122,3 \\
761-767\end{array}$ & $\begin{array}{c}\text { Total } \\
\text { flavonoids }\end{array}$ & $\begin{array}{l}\mathrm{NaNO}_{2}+ \\
10 \% \mathrm{AlCl}_{3} \\
\mathrm{H}_{2} \mathrm{O}\end{array}$ & VIS $510 \mathrm{~nm}$ & $\begin{array}{l}\text { Ethanol or } \\
\text { water }\end{array}$ & L. edodes \\
\hline 31 & 2010 & $\begin{array}{l}\text { Postharvest } \\
\text { Biology and } \\
\text { Technology }\end{array}$ & 2.256 & $\begin{array}{l}\text { Jiang, T. et } \\
\text { al. }\end{array}$ & $\begin{array}{l}\text { Influence of UV-C treatment } \\
\text { on antioxidant capacity, } \\
\text { antioxidant enzyme activity } \\
\text { and texture of postharvest } \\
\text { shiitake (Lentinus edodes) } \\
\text { mushrooms during storage. }\end{array}$ & $\begin{array}{c}56,3 \\
209-215\end{array}$ & $\begin{array}{c}\text { Total } \\
\text { flavonoids }\end{array}$ & $\begin{array}{l}\mathrm{NaNO}_{2}+ \\
10 \% \mathrm{AlCl}_{3} \\
\mathrm{H}_{2} \mathrm{O}\end{array}$ & VIS $510 \mathrm{~nm}$ & Ethanol & L.edodes \\
\hline 32 & 2010 & $\begin{array}{l}\text { Journal of } \\
\text { Agricultural and } \\
\text { Food Chemistry }\end{array}$ & 2.816 & $\begin{array}{l}\text { Chen, XH. et } \\
\text { al. }\end{array}$ & $\begin{array}{c}\text { Chemical composition and } \\
\text { antioxidant activities of } \\
\text { Russula griseocarnosa sp. } \\
\text { nov. }\end{array}$ & $\begin{array}{l}58,11 \\
6966- \\
6971\end{array}$ & Quercetine & HPLC-DAD & UV 273 nm & $\begin{array}{l}\text { Acetonitrile } \\
\text { and } \\
\text { hydrocloric } \\
\text { acid }\end{array}$ & $\begin{array}{c}\text { Russula } \\
\text { griseocarnos } \\
\text { a }\end{array}$ \\
\hline 33 & 2010 & $\begin{array}{l}\text { Journal of Central } \\
\text { European } \\
\text { Agriculture }\end{array}$ & NF & Mujić, I. et al. & $\begin{array}{l}\text { Antioxidant properties of } \\
\text { selected edible mushroom } \\
\text { species. }\end{array}$ & $\begin{array}{c}11,4, \\
387-392\end{array}$ & $\begin{array}{c}\text { Total } \\
\text { flavonoids }\end{array}$ & $\mathrm{AlCl}_{3}$ & NF & $\begin{array}{c}50 \% \\
\text { Ethanol }\end{array}$ & $\begin{array}{c}\text { L. edodes, } \\
\text { Hericium } \\
\text { erinaceus } \\
\text { and Agrocybe } \\
\text { aegerita }\end{array}$ \\
\hline
\end{tabular}




\section{Appendix-Supplementary Table 1}

\begin{tabular}{|c|c|c|c|c|c|c|c|c|c|c|c|}
\hline Number & Year & Journal & $\begin{array}{l}\text { Impact } \\
\text { factor }\end{array}$ & First author & Title & $\begin{array}{l}\text { Volumen, } \\
\text { Issue, } \\
\text { pages }\end{array}$ & $\begin{array}{c}\text { Compounds } \\
\text { found in } \\
\text { mushrooms }\end{array}$ & $\begin{array}{l}\text { Method } \\
\text { utilized to } \\
\text { measure } \\
\text { flavonoids }\end{array}$ & $\begin{array}{l}\text { Detection } \\
\text { device or } \\
\text { wavelength } \\
\text { used }\end{array}$ & $\begin{array}{l}\text { Solvents } \\
\text { used for } \\
\text { extraction }\end{array}$ & $\begin{array}{l}\text { Mushroom } \\
\text { specie } \\
\text { studied }\end{array}$ \\
\hline 34 & 2010 & $\begin{array}{l}\text { Food Science and } \\
\text { Biotechnology }\end{array}$ & 0.505 & $\begin{array}{l}\text { Gursoy, N. } \\
\text { et al. }\end{array}$ & $\begin{array}{c}\text { Evaluation of antioxidant } \\
\text { activities of } 3 \text { edible } \\
\text { mushrooms: Ramaria flava } \\
\text { (Schaef.: Fr.) Quél., } \\
\text { Rhizopogon roseolus (Corda) } \\
\text { T.M. Fries., and Russula } \\
\text { delica Fr. }\end{array}$ & $\begin{array}{c}19,3 \\
691-696\end{array}$ & $\begin{array}{c}\text { Total } \\
\text { flavonoids }\end{array}$ & $\mathrm{AlCl}_{3}$ & $\begin{array}{c}\text { UV/VIS } 415 \\
n m\end{array}$ & Methanol & $\begin{array}{l}\text { Ramaria } \\
\text { flava, } \\
\text { Rhizopogon } \\
\text { roseolus and } \\
\text { Russula } \\
\text { delica }\end{array}$ \\
\hline 35 & 2010 & $\begin{array}{l}\text { Pharmacognosy } \\
\text { Research }\end{array}$ & NF & $\begin{array}{l}\text { Ramesh, } \mathrm{CH} \text {. } \\
\text { et al. }\end{array}$ & $\begin{array}{c}\text { Antimicrobial properties, } \\
\text { antioxidant activity and } \\
\text { bioactive compounds from } \\
\text { six wild edible mushrooms of } \\
\text { western ghats of Karnataka, } \\
\text { India. }\end{array}$ & $\begin{array}{c}2,2,107- \\
112\end{array}$ & $\begin{array}{c}\text { Total } \\
\text { flavonoids }\end{array}$ & $10 \% \mathrm{Al}\left(\mathrm{NO}_{3}\right)_{3}$ & $\begin{array}{c}\text { UV/VIS } 415 \\
n m\end{array}$ & Methanol & $\begin{array}{c}\text { Lycoperdon } \\
\text { perlatum, Ca } \\
\text { ntharellus } \\
\text { cibarius, Clav } \\
\text { aria } \\
\text { vermiculris, } R \\
\text { amaria } \\
\text { Formosa, Mar } \\
\text { asmius } \\
\text { oreades } \\
\text { and Pleurotus } \\
\text { pulmonarius }\end{array}$ \\
\hline 36 & 2010 & $\begin{array}{l}\text { Indian Journal of } \\
\text { Experimental } \\
\text { Biology }\end{array}$ & 0.702 & Pal, J. et al. & $\begin{array}{c}\text { In vitro free radical } \\
\text { scavenging activity of wild } \\
\text { edible mushroom, Pleurotus } \\
\text { squarrosulus (Mont.) Singer }\end{array}$ & $\begin{array}{l}48,12 \\
1210- \\
1218\end{array}$ & $\begin{array}{c}\text { Total } \\
\text { flavonoids }\end{array}$ & $10 \% \mathrm{Al}\left(\mathrm{NO}_{3}\right)_{3}$ & $\begin{array}{c}\text { UV/VIS } 415 \\
n m\end{array}$ & $\begin{array}{l}\text { Cold } / \text { hot } \\
\text { water and } \\
\text { methanol }\end{array}$ & $\begin{array}{c}\text { Pleurotus } \\
\text { squarrosulus }\end{array}$ \\
\hline 37 & 2010 & $\begin{array}{l}\text { Asian Journal of } \\
\text { Chemistry }\end{array}$ & 0.247 & $\begin{array}{l}\text { Chen, } \mathrm{XH} \text {. et } \\
\text { al. }\end{array}$ & $\begin{array}{l}\text { Chemical composition and } \\
\text { antioxidant activity of two } \\
\text { edible mycorrhizal fungi from } \\
\text { South China. }\end{array}$ & $\begin{array}{l}22,9 \\
6867- \\
6878\end{array}$ & $\begin{array}{c}\text { Total } \\
\text { flavonoids }\end{array}$ & Colorimetric & NF & NF & $\begin{array}{c}\text { Russula } \\
\text { virescens and } \\
\text { Cantharellus } \\
\text { cibarius }\end{array}$ \\
\hline 38 & 2010 & $\begin{array}{l}\text { Pharmacognosy } \\
\text { Magazine }\end{array}$ & 0.432 & $\begin{array}{l}\text { Ozen, T. et } \\
\text { al. }\end{array}$ & $\begin{array}{c}\text { Antioxidant activities of } \\
\text { Sarcodon imbricatum wildly } \\
\text { grown in the black sea region } \\
\text { of Turkey. }\end{array}$ & $\begin{array}{c}6,22,89- \\
97\end{array}$ & $\begin{array}{c}\text { Total } \\
\text { flavonoids }\end{array}$ & $10 \% \mathrm{Al}\left(\mathrm{NO}_{3}\right)_{3}$ & $\begin{array}{c}\text { UV/VIS } 415 \\
n m\end{array}$ & Methanol & S. imbricatus \\
\hline
\end{tabular}




\section{Appendix-Supplementary Table 1}

\begin{tabular}{|c|c|c|c|c|c|c|c|c|c|c|c|}
\hline Number & Year & Journal & $\begin{array}{l}\text { Impact } \\
\text { factor }\end{array}$ & First author & Title & $\begin{array}{l}\text { Volumen, } \\
\text { Issue, } \\
\text { pages }\end{array}$ & $\begin{array}{l}\text { Compounds } \\
\text { found in } \\
\text { mushrooms }\end{array}$ & $\begin{array}{l}\text { Method } \\
\text { utilized to } \\
\text { measure } \\
\text { flavonoids }\end{array}$ & $\begin{array}{c}\text { Detection } \\
\text { device or } \\
\text { wavelength } \\
\text { used }\end{array}$ & $\begin{array}{l}\text { Solvents } \\
\text { used for } \\
\text { extraction }\end{array}$ & $\begin{array}{l}\text { Mushroom } \\
\text { specie } \\
\text { studied }\end{array}$ \\
\hline 39 & 2010 & Molecules & 1.988 & $\mathrm{Li}$, B. et al. & $\begin{array}{c}\text { Antioxidant properties of cap } \\
\text { and stipe from Coprinus } \\
\text { comatus. }\end{array}$ & $\begin{array}{l}15,3 \\
1473- \\
1486\end{array}$ & $\begin{array}{c}\text { Total } \\
\text { flavonoids }\end{array}$ & 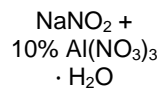 & VIS $510 \mathrm{~nm}$ & $\begin{array}{l}\text { Ethanol or } \\
\text { hot water }\end{array}$ & $\begin{array}{l}\text { Coprinus } \\
\text { comatus }\end{array}$ \\
\hline 40 & 2010 & $\begin{array}{l}\text { Journal of Food } \\
\text { Composition and } \\
\text { Analysis }\end{array}$ & 1.948 & $\begin{array}{l}\text { Al-Laith, } \\
\text { AAA. }\end{array}$ & $\begin{array}{l}\text { Antioxidant components and } \\
\text { antioxidant/antiradical } \\
\text { activities of desert truffle } \\
\text { (Tirmania nivea) from various } \\
\text { Middle Eastern origins. }\end{array}$ & $\begin{array}{c}23,1,15- \\
22\end{array}$ & $\begin{array}{c}\text { Total } \\
\text { flavonoids }\end{array}$ & $\begin{array}{l}\text { Comparison } \\
\text { of fee } \\
\text { phenolic } \\
\text { content after } \\
\text { formaldehyde } \\
\text { precipation. }\end{array}$ & $\begin{array}{c}\text { Folin- } \\
\text { Ciocalteu } \\
\text { method (765 } \\
\text { mn) }\end{array}$ & $\begin{array}{c}80 \% \\
\text { Ethanol }\end{array}$ & $\begin{array}{l}\text { Tirmania } \\
\text { nivea }\end{array}$ \\
\hline 41 & 2010 & $\begin{array}{l}\text { International } \\
\text { Journal of Food } \\
\text { Properties }\end{array}$ & 0.947 & $\begin{array}{l}\text { Singla, R. et } \\
\text { al. }\end{array}$ & $\begin{array}{l}\text { Antioxidant activities and } \\
\text { polyphenolic properties of } \\
\text { raw and osmotically } \\
\text { dehydrated dried mushroom ( } \\
\text { Agaricus bisporous) snack } \\
\text { food. }\end{array}$ & $\begin{array}{l}3,6 \\
1290- \\
1299\end{array}$ & $\begin{array}{c}\text { Total } \\
\text { flavonoids }\end{array}$ & $\begin{array}{l}\mathrm{NaNO}_{2}+ \\
10 \% \mathrm{AlCl}_{3} \\
\mathrm{H}_{2} \mathrm{O}\end{array}$ & VIS $510 \mathrm{~nm}$ & $\begin{array}{c}99 \% \\
\text { Ethanol }\end{array}$ & A. bisporus \\
\hline 42 & 2010 & $\begin{array}{l}\text { International } \\
\text { Journal of } \\
\text { Medicinal } \\
\text { Mushrooms }\end{array}$ & 0.639 & $\begin{array}{l}\text { Ebrahimzade } \\
\text { h, MA. et al. }\end{array}$ & $\begin{array}{l}\text { Antioxidant and free radical } \\
\text { scavenging activities of } \\
\text { culinary-medicinal } \\
\text { mushrooms, Golden } \\
\text { Chanterelle Cantharellus } \\
\text { cibarius and Angel's Wings } \\
\text { Pleurotus porrigens. }\end{array}$ & $\begin{array}{c}12,3,265 \\
-272\end{array}$ & $\begin{array}{c}\text { Total } \\
\text { flavonoids }\end{array}$ & Colorimetric & NF & $\begin{array}{l}\text { Ethyl } \\
\text { acetate or } \\
\text { methanol }\end{array}$ & $\begin{array}{l}\text { C. cibarius } \\
\text { and Pleurotus } \\
\text { porrigens }\end{array}$ \\
\hline 43 & 2010 & $\begin{array}{l}\text { International } \\
\text { Journal of } \\
\text { Medicinal } \\
\text { Mushrooms }\end{array}$ & 0.639 & Lai, LK. et al. & $\begin{array}{c}\text { Anti-Human Papillomavirus } \\
\text { (HPV) } 16 \text { E6 activity of Ling } \\
\text { Zhi or Reishi medicinal } \\
\text { mushroom, Ganoderma } \\
\text { lucidum (W. Curt.: Fr.) P. } \\
\text { Karst. } \\
\text { (Aphyllophoromycetideae) } \\
\text { extracts. }\end{array}$ & $\begin{array}{c}12,3 \\
279-286\end{array}$ & $\begin{array}{c}\text { Total } \\
\text { flavonoids }\end{array}$ & Colorimetric & NF & $\begin{array}{l}\text { Dichlorome } \\
\text { thane }\end{array}$ & G. Iucidum \\
\hline
\end{tabular}




\section{Appendix-Supplementary Table 1}

\begin{tabular}{|c|c|c|c|c|c|c|c|c|c|c|c|}
\hline Number & Year & Journal & $\begin{array}{l}\text { Impact } \\
\text { factor }\end{array}$ & First author & Title & $\begin{array}{l}\text { Volumen, } \\
\text { Issue, } \\
\text { pages }\end{array}$ & $\begin{array}{c}\text { Compounds } \\
\text { found in } \\
\text { mushrooms }\end{array}$ & $\begin{array}{l}\text { Method } \\
\text { utilized to } \\
\text { measure } \\
\text { flavonoids }\end{array}$ & $\begin{array}{l}\text { Detection } \\
\text { device or } \\
\text { wavelength } \\
\text { used }\end{array}$ & $\begin{array}{l}\text { Solvents } \\
\text { used for } \\
\text { extraction }\end{array}$ & $\begin{array}{l}\text { Mushroom } \\
\text { specie } \\
\text { studied }\end{array}$ \\
\hline 44 & 2010 & $\begin{array}{l}\text { Journal of Food } \\
\text { Science }\end{array}$ & 1.733 & $\begin{array}{l}\text { Lung, MY. et } \\
\text { al. }\end{array}$ & $\begin{array}{l}\text { Antioxidant properties of } \\
\text { edible Basidiomycete } \\
\text { Phellinus igniarius in } \\
\text { submerged cultures. }\end{array}$ & $\begin{array}{c}75,1,18- \\
24\end{array}$ & $\begin{array}{c}\text { Total } \\
\text { flavonoids }\end{array}$ & $\begin{array}{c}\mathrm{NaNO}_{2}+ \\
10 \% \mathrm{AlCl}_{3} . \\
\mathrm{H}_{2} \mathrm{O}\end{array}$ & $\begin{array}{c}\text { UV/VIS } 415 \\
n m\end{array}$ & $\begin{array}{l}\text { Hot water } \\
\text { and } \\
\text { methanol }\end{array}$ & $\begin{array}{l}\text { Phellinus } \\
\text { igniarius } \\
\text { (mycellium) }\end{array}$ \\
\hline 45 & 2010 & $\begin{array}{l}\text { Journal of } \\
\text { Nutrition and } \\
\text { Metabolism }\end{array}$ & NF & $\begin{array}{c}\text { Robaszkiewic } \\
\text { z, A. et al. }\end{array}$ & $\begin{array}{c}\text { The role of polyphenols, } \\
\text { beta-carotene, and lycopene } \\
\text { in the antioxidative action of } \\
\text { the extracts of dried, edible } \\
\text { mushrooms. }\end{array}$ & $\begin{array}{c}2010,-, 9 \\
\text { (ID } \\
173274)\end{array}$ & $\begin{array}{c}\text { Total } \\
\text { flavonoids }\end{array}$ & $\begin{array}{l}\mathrm{NaNO}_{2}+ \\
10 \% \mathrm{AlCl}_{3} \\
\quad \mathrm{H}_{2} \mathrm{O}\end{array}$ & VIS $515 \mathrm{~nm}$ & $\begin{array}{l}\text { Hot water } \\
\text { and } \\
\text { methanol }\end{array}$ & $\begin{array}{l}\text { Polish } \\
\text { mushrooms }\end{array}$ \\
\hline 46 & 2011 & Food Chemistry & 3.655 & Guo, T. et al. & $\begin{array}{l}\text { Antioxidant activities of } \\
\text { extract and fractions from } \\
\text { Tuber indicum Cooke \& } \\
\text { Massee. }\end{array}$ & $\begin{array}{c}127,4 \\
1634- \\
1640\end{array}$ & $\begin{array}{c}\text { Total } \\
\text { flavonoids }\end{array}$ & $\begin{array}{c}\mathrm{NaNO}_{2}+ \\
10 \% \mathrm{Al}\left(\mathrm{NO}_{3}\right)_{3} \\
\cdot \mathrm{H}_{2} \mathrm{O}\end{array}$ & VIS 510nm & Ethanol & $\begin{array}{l}\text { Tuber } \\
\text { indicum }\end{array}$ \\
\hline 47 & 2011 & Food Chemistry & 3.655 & Oke, F. et al. & $\begin{array}{l}\text { Protective effect of two edible } \\
\text { mushrooms against oxidative } \\
\text { cell damage and their } \\
\text { phenolic composition. }\end{array}$ & $\begin{array}{c}128,3 \\
613-619\end{array}$ & Luteolin & HPLC-DAD & UV 278 nm & $\begin{array}{l}\text { Methanol or } \\
\text { water }\end{array}$ & $\begin{array}{l}\text { P. eryngii and } \\
\text { Auricularia } \\
\text { auricula- } \\
\text { judae }\end{array}$ \\
\hline 48 & 2011 & $\begin{array}{l}\text { Food and } \\
\text { Chemical } \\
\text { Toxicology }\end{array}$ & 2.999 & $\begin{array}{c}\text { Öztürk, M. et } \\
\text { al. }\end{array}$ & $\begin{array}{c}\text { In vitro antioxidant, } \\
\text { anticholinesterase and } \\
\text { antimicrobial activity studies } \\
\text { on three Agaricus species } \\
\text { with fatty acid compositions } \\
\text { and iron contents: A } \\
\text { comparative study on the } \\
\text { three most edible } \\
\text { mushrooms. }\end{array}$ & $\begin{array}{c}49,6 \\
1353- \\
1360\end{array}$ & $\begin{array}{c}\text { Total } \\
\text { flavonoids }\end{array}$ & $10 \% \mathrm{Al}\left(\mathrm{NO}_{3}\right)_{3}$ & $\begin{array}{c}\text { UV/VIS } 415 \\
n m\end{array}$ & $\begin{array}{l}\text { Hexane, } \\
\text { ethyl } \\
\text { acetate or } \\
\text { aqueous } \\
\text { methanol }\end{array}$ & $\begin{array}{l}\text { Agaricus } \\
\text { essettei, } \\
\text { Agaricus } \\
\text { bitorquis and } \\
\text { A. bisporus. }\end{array}$ \\
\hline
\end{tabular}




\section{Appendix-Supplementary Table 1}

\begin{tabular}{|c|c|c|c|c|c|c|c|c|c|c|c|}
\hline Number & Year & Journal & $\begin{array}{l}\text { Impact } \\
\text { factor }\end{array}$ & First author & Title & $\begin{array}{l}\text { Volumen, } \\
\text { Issue, } \\
\text { pages }\end{array}$ & $\begin{array}{c}\text { Compounds } \\
\text { found in } \\
\text { mushrooms }\end{array}$ & $\begin{array}{l}\text { Method } \\
\text { utilized to } \\
\text { measure } \\
\text { flavonoids }\end{array}$ & $\begin{array}{l}\text { Detection } \\
\text { device or } \\
\text { wavelength } \\
\text { used }\end{array}$ & $\begin{array}{l}\text { Solvents } \\
\text { used for } \\
\text { extraction }\end{array}$ & $\begin{array}{l}\text { Mushroom } \\
\text { specie } \\
\text { studied }\end{array}$ \\
\hline \multirow{2}{*}{49} & \multirow{2}{*}{2011} & \multirow{2}{*}{ Food Chemistry } & \multirow{2}{*}{3.655} & \multirow{2}{*}{$\begin{array}{c}\text { Palacios, I. et } \\
\text { al. }\end{array}$} & \multirow{2}{*}{$\begin{array}{l}\text { Antioxidant properties of } \\
\text { phenolic compounds } \\
\text { occurring in edible } \\
\text { mushrooms. }\end{array}$} & \multirow{2}{*}{$\begin{array}{c}128,3 \\
674-678\end{array}$} & $\begin{array}{c}\text { Total } \\
\text { flavonoids }\end{array}$ & $\mathrm{AlCl}_{3}$ & NF & \multirow{2}{*}{ Methanol } & \multirow{2}{*}{$\begin{array}{l}\text { A. bisporus, } \\
\text { B. edulis, C. } \\
\text { gambosa, } C \text {. } \\
\text { cibarius, C. } \\
\text { cornucopioid, } \\
\text { Hygrophorus } \\
\text { marzuolus, } L \text {. } \\
\text { deliciosus } \\
\text { and } P \text {. } \\
\text { ostreatus. }\end{array}$} \\
\hline & & & & & & & $\begin{array}{l}\text { Catechin } \\
\text { and } \\
\text { myricetin }\end{array}$ & HPLC-DAD & $\begin{array}{c}280 \mathrm{y} \\
320 \mathrm{~nm}\end{array}$ & & \\
\hline 50 & 2011 & $\begin{array}{l}\text { International } \\
\text { Food Research } \\
\text { Journal }\end{array}$ & 0.282 & $\begin{array}{l}\text { Imran, MM. } \\
\text { et al. }\end{array}$ & $\begin{array}{l}\text { Determination of total phenol, } \\
\text { flavonoid and antioxidant } \\
\text { activity of edible mushrooms } \\
\text { Pleurotus florida and } \\
\text { Pleurotus eous. }\end{array}$ & $\begin{array}{c}18,2 \\
579-582\end{array}$ & $\begin{array}{c}\text { Total } \\
\text { flavonoids }\end{array}$ & $\mathrm{AlCl}_{3}$ & $\begin{array}{c}\text { UV/VIS } 415 \\
n m\end{array}$ & Methanol & $\begin{array}{l}\text { Pleurotus } \\
\text { florida and } \\
\text { Pleurotus } \\
\text { eous }\end{array}$ \\
\hline \multirow{2}{*}{51} & \multirow{2}{*}{2011} & \multirow{2}{*}{$\begin{array}{l}\text { Journal of } \\
\text { Chemical and } \\
\text { Pharmaceutical } \\
\text { Research }\end{array}$} & \multirow{2}{*}{ NF } & \multirow{2}{*}{$\begin{array}{c}\text { Sathyaprabh } \\
\text { a, G. et al. }\end{array}$} & \multirow{2}{*}{$\begin{array}{l}\text { Analysis of antioxidant } \\
\text { activity, total phenol, total } \\
\text { flavonoid and screening of } \\
\text { phytocomponents in } \\
\text { Pleurotus platypus and } \\
\text { Pleurotus eous. }\end{array}$} & \multirow{2}{*}{$3,6,1-6$} & \multirow{2}{*}{$\begin{array}{c}\text { Total } \\
\text { flavonoids }\end{array}$} & $\begin{array}{c}\text { Detection: } \\
\text { amonia } \\
\text { solution }+ \\
\text { sulphuric acid }\end{array}$ & $\begin{array}{l}\text { Presence of } \\
\text { yellow color }\end{array}$ & \multirow{2}{*}{ Water } & \multirow{2}{*}{$\begin{array}{l}\text { P. eous and } \\
\text { Pleurotus } \\
\text { platypus }\end{array}$} \\
\hline & & & & & & & & $\begin{array}{c}\text { Cuantification } \\
: \mathrm{NaNO}_{2}+ \\
10 \% \mathrm{AlCl}_{3} \cdot \\
\mathrm{H} 2 \mathrm{O} \\
\end{array}$ & VIS $510 \mathrm{~nm}$ & & \\
\hline 52 & 2011 & $\begin{array}{l}\text { International } \\
\text { Journal of } \\
\text { Molecular } \\
\text { Sciences }\end{array}$ & 2.6 & $\begin{array}{l}\text { Lung, MY. et } \\
\text { al. }\end{array}$ & $\begin{array}{l}\text { Antioxidant properties of the } \\
\text { edible Basidiomycete } \\
\text { Armillaria mellea in } \\
\text { submerged cultures. }\end{array}$ & $\begin{array}{l}12,10 \\
6367- \\
6384\end{array}$ & $\begin{array}{c}\text { Total } \\
\text { flavonoids }\end{array}$ & $\begin{array}{l}\mathrm{NaNO}_{2}+ \\
10 \% \mathrm{AlCl}_{3} \\
\underset{\mathrm{H}}{2} \mathrm{O}\end{array}$ & $\begin{array}{c}\text { UV/VIS } 415 \\
n m\end{array}$ & $\begin{array}{c}\text { Hot water } \\
\text { or methanol }\end{array}$ & $\begin{array}{c}\text { Armillaria } \\
\text { mellea } \\
\text { (micellium) }\end{array}$ \\
\hline 53 & 2011 & Molecules & 2.386 & $\begin{array}{l}\text { Yeh, JY. et } \\
\text { al. }\end{array}$ & $\begin{array}{l}\text { Antioxidant properties and } \\
\text { antioxidant compounds of } \\
\text { various extracts from the } \\
\text { edible Basidiomycete Grifola } \\
\text { Frondosa (Maitake). }\end{array}$ & $\begin{array}{c}16 \\
4,3197- \\
3211\end{array}$ & $\begin{array}{c}\text { Total } \\
\text { flavonoids }\end{array}$ & $\begin{array}{l}\mathrm{NaNO}_{2}+ \\
10 \% \mathrm{AlCl}_{3} \\
\mathrm{H}_{2} \mathrm{O}\end{array}$ & $\begin{array}{c}\text { UV/VIS } 415 \\
n m\end{array}$ & $\begin{array}{l}\text { Cold/hot } \\
\text { water or } \\
\text { methanol }\end{array}$ & $\begin{array}{c}\text { Grifola } \\
\text { frondosa }\end{array}$ \\
\hline
\end{tabular}




\section{Appendix-Supplementary Table 1}

\begin{tabular}{|c|c|c|c|c|c|c|c|c|c|c|c|}
\hline Number & Year & Journal & $\begin{array}{l}\text { Impact } \\
\text { factor }\end{array}$ & First author & Title & $\begin{array}{l}\text { Volumen, } \\
\text { Issue, } \\
\text { pages }\end{array}$ & $\begin{array}{l}\text { Compounds } \\
\text { found in } \\
\text { mushrooms }\end{array}$ & $\begin{array}{l}\text { Method } \\
\text { utilized to } \\
\text { measure } \\
\text { flavonoids }\end{array}$ & $\begin{array}{l}\text { Detection } \\
\text { device or } \\
\text { wavelength } \\
\text { used }\end{array}$ & $\begin{array}{l}\text { Solvents } \\
\text { used for } \\
\text { extraction }\end{array}$ & $\begin{array}{l}\text { Mushroom } \\
\text { specie } \\
\text { studied }\end{array}$ \\
\hline 54 & 2011 & $\begin{array}{l}\text { African Journal of } \\
\text { Biotechnology }\end{array}$ & $\mathrm{NI}$ & $\begin{array}{l}\text { Alam, N. et } \\
\text { al. }\end{array}$ & $\begin{array}{l}\text { Evaluation of the antioxidant } \\
\text { and antityrosinase activities } \\
\text { of three extracts from } \\
\text { Pleurotus nebrodensis } \\
\text { fruiting bodies. }\end{array}$ & $\begin{array}{c}10 \\
11,2978- \\
2986\end{array}$ & $\begin{array}{l}\text { naringenin, } \\
\text { hesperetin }\end{array}$ & HPLC-DAD & UV 280 nm & \begin{tabular}{c|}
$60 \%$ \\
acetone \\
$80 \%$ \\
methanol or \\
hot water
\end{tabular} & $\begin{array}{c}\text { Pleurotus } \\
\text { nebrodensis }\end{array}$ \\
\hline 55 & 2011 & $\begin{array}{l}\text { Combinatorial } \\
\text { Chemistry \& High } \\
\text { Throughput } \\
\text { Screening }\end{array}$ & 1.785 & $\begin{array}{l}\text { Ozen, T. et } \\
\text { al. }\end{array}$ & $\begin{array}{l}\text { Screening of antioxidant, } \\
\text { antimicrobial activities and } \\
\text { chemical contents of edible } \\
\text { mushrooms wildly grown in } \\
\text { the Black Sea region of } \\
\text { Turkey. }\end{array}$ & $\begin{array}{c}14,2,72- \\
84\end{array}$ & $\begin{array}{c}\text { Total } \\
\text { flavonoids } \\
\text { and } \\
\text { anthocyanin } \\
\text { s }\end{array}$ & Colorimetric & NF & NF & $\begin{array}{l}\text { Twelve } \\
\text { commonly } \\
\text { consumed } \\
\text { wild edible } \\
\text { mushrooms }\end{array}$ \\
\hline 56 & 2011 & $\begin{array}{l}\text { International } \\
\text { Journal of } \\
\text { Agriculture and } \\
\text { Biology }\end{array}$ & 0.94 & $\begin{array}{l}\text { Jahangir, } \\
\text { MM. et al. }\end{array}$ & $\begin{array}{c}\text { Effect of spermine on } \\
\text { bioactive components and } \\
\text { antioxidant properties of } \\
\text { sliced } \\
\text { buttonmushroom (Agaricus } \\
\text { bisporus) during storage. }\end{array}$ & $\begin{array}{c}13,5 \\
771-775\end{array}$ & $\begin{array}{c}\text { Total } \\
\text { flavonoids }\end{array}$ & $\begin{array}{c}\mathrm{NaNO}_{2}+ \\
10 \% \mathrm{AlCl}_{3} \\
\mathrm{H}_{2} \mathrm{O}\end{array}$ & VIS $510 \mathrm{~nm}$ & Methanol & A. bisporus \\
\hline 57 & 2011 & $\begin{array}{l}\text { Journal of Food } \\
\text { Nutrition and } \\
\text { Research }\end{array}$ & 0.679 & $\begin{array}{l}\text { Lagnika, C. } \\
\text { et al. }\end{array}$ & $\begin{array}{l}\text { Effect of high argon pressure } \\
\text { and modified atmosphere } \\
\text { packaging on the } \\
\text { white mushroom(Agaricus } \\
\text { bisporus) physico-chemical } \\
\text { and microbiological } \\
\text { properties. }\end{array}$ & $\begin{array}{c}50,3 \\
167-176\end{array}$ & $\begin{array}{c}\text { Total } \\
\text { flavonoids }\end{array}$ & $\begin{array}{l}\mathrm{NaNO}_{2}+ \\
10 \% \mathrm{AlCl}_{3} \\
\mathrm{H}_{2} \mathrm{O}\end{array}$ & VIS $510 \mathrm{~nm}$ & Water & A. bisporus \\
\hline 58 & 2011 & $\begin{array}{l}\text { Journal of Food } \\
\text { Quality }\end{array}$ & 0.54 & $\begin{array}{l}\text { Da Silva, AC. } \\
\text { et al. }\end{array}$ & $\begin{array}{l}\text { Antioxidant properties } \\
\text { of Lentinus } \\
\text { edodes and Agaricus } \\
\text { blazei extracts. }\end{array}$ & $\begin{array}{c}34,6 \\
386-394\end{array}$ & $\begin{array}{c}\text { Total } \\
\text { flavonoids }\end{array}$ & Colorimetric & NF & NF & $\begin{array}{c}\text { L. edodes } \\
\text { and Agaricus } \\
\text { blazei }\end{array}$ \\
\hline
\end{tabular}




\section{Appendix-Supplementary Table 1}

\begin{tabular}{|c|c|c|c|c|c|c|c|c|c|c|c|}
\hline Number & Year & Journal & $\begin{array}{l}\text { Impact } \\
\text { factor }\end{array}$ & First author & Title & $\begin{array}{l}\text { Volumen, } \\
\text { Issue, } \\
\text { pages }\end{array}$ & $\begin{array}{l}\text { Compounds } \\
\text { found in } \\
\text { mushrooms }\end{array}$ & $\begin{array}{l}\text { Method } \\
\text { utilized to } \\
\text { measure } \\
\text { flavonoids }\end{array}$ & $\begin{array}{c}\text { Detection } \\
\text { device or } \\
\text { wavelength } \\
\text { used }\end{array}$ & $\begin{array}{l}\text { Solvents } \\
\text { used for } \\
\text { extraction }\end{array}$ & $\begin{array}{l}\text { Mushroom } \\
\text { specie } \\
\text { studied }\end{array}$ \\
\hline 59 & 2012 & Food Chemistry & 3.334 & $\begin{array}{l}\text { Dong, J. et } \\
\text { al. }\end{array}$ & $\begin{array}{c}\text { Nitric oxide fumigation } \\
\text { stimulates flavonoid and } \\
\text { phenolic accumulation and } \\
\text { enhances antioxidant activity } \\
\text { of mushroom. }\end{array}$ & $\begin{array}{l}135,3 \\
1220- \\
1225\end{array}$ & $\begin{array}{c}\text { Total } \\
\text { flavonoids }\end{array}$ & $\begin{array}{c}\mathrm{NaNO}_{2}+ \\
10 \% \mathrm{Al}\left(\mathrm{NO}_{3}\right)_{3} \\
\cdot \mathrm{H}_{2} \mathrm{O}\end{array}$ & VIS 510nm & Methanol & $\begin{array}{c}R . \\
\text { griseocarnos } \\
a\end{array}$ \\
\hline 60 & 2012 & Food Chemistry & 3.334 & $\begin{array}{c}\text { Pereira, E. et } \\
\text { al. }\end{array}$ & $\begin{array}{l}\text { Towards chemical and } \\
\text { nutritional inventory of } \\
\text { Portuguese wild edible } \\
\text { mushrooms in different } \\
\text { habitats. }\end{array}$ & $\begin{array}{c}130,2 \\
394-403\end{array}$ & $\begin{array}{c}\text { Total } \\
\text { flavonoids }\end{array}$ & $\begin{array}{l}\mathrm{NaNO}_{2}+ \\
10 \% \mathrm{AlCl}_{3} \\
\mathrm{H}_{2} \mathrm{O}\end{array}$ & VIS $510 \mathrm{~nm}$ & Methanol & $\begin{array}{l}\text { Twelve } \\
\text { Portuguese } \\
\text { wild edible } \\
\text { mushrooms }\end{array}$ \\
\hline 61 & 2012 & $\begin{array}{l}\text { Asian Pacific } \\
\text { Journal of } \\
\text { Tropical } \\
\text { Biomedicine }\end{array}$ & 0.502 & $\begin{array}{c}\text { Shirmila, JG. } \\
\text { et al. }\end{array}$ & $\begin{array}{c}\text { Identification and } \\
\text { determination of antioxidant } \\
\text { constituents of } \\
\text { bioluminescent mushroom. }\end{array}$ & $\begin{array}{c}2,1 \\
\text { suppleme } \\
\text { nt, } 386- \\
391\end{array}$ & $\begin{array}{c}\text { Total } \\
\text { flavonoids }\end{array}$ & $\mathrm{AlCl}_{3}$ & $\begin{array}{c}\text { UV/VIS } 420 \\
n m\end{array}$ & Methanol & $\begin{array}{l}\text { Omphalotus } \\
\text { nidiformis }\end{array}$ \\
\hline 62 & 2012 & $\begin{array}{l}\text { Food and } \\
\text { Chemical } \\
\text { Toxicology }\end{array}$ & 3.01 & Liu, YT. et al. & $\begin{array}{l}\text { Chemical composition of five } \\
\text { wild edible mushrooms } \\
\text { collected from Southwest } \\
\text { China and their } \\
\text { antihyperglycemic and } \\
\text { antioxidant activity. }\end{array}$ & $\begin{array}{c}50,5 \\
1238- \\
1244\end{array}$ & $\begin{array}{l}\text { Total } \\
\text { flavonoids, } \\
\text { quercetin } \\
\text { and catechin }\end{array}$ & HPLC-DAD & UV 273 nm & Ethanol & $\begin{array}{c}\text { Clitocybe } \\
\text { maxima, } \\
\text { Catathelasma } \\
\text { ventricosum, } \\
\text { Stropharia } \\
\text { rugoso- } \\
\text { annulata, C. } \\
\text { cornucopioide } \\
\text { s and } \\
\text { Laccaria } \\
\text { amethystea }\end{array}$ \\
\hline 63 & 2012 & $\begin{array}{l}\text { Iranian Journal of } \\
\text { Pharmaceutical } \\
\text { Research }\end{array}$ & 0.54 & $\begin{array}{l}\text { Kosanić, M. } \\
\text { et al. }\end{array}$ & $\begin{array}{c}\text { Mushrooms as possible } \\
\text { antioxidant and antimicrobial } \\
\text { agents. }\end{array}$ & $\begin{array}{l}11,4 \\
1095- \\
1102\end{array}$ & $\begin{array}{c}\text { Total } \\
\text { flavonoids }\end{array}$ & $\mathrm{AlCl}_{3}$ & $\begin{array}{c}\text { UV/VIS } 415 \\
\mathrm{~nm}\end{array}$ & $\begin{array}{l}\text { Acetone } \\
\text { and } \\
\text { methanol }\end{array}$ & $\begin{array}{l}\text { Boletus } \\
\text { aestivalis, } B . \\
\text { edulis and } \\
\text { Leccinum } \\
\text { carpini }\end{array}$ \\
\hline
\end{tabular}




\section{Appendix-Supplementary Table 1}

\begin{tabular}{|c|c|c|c|c|c|c|c|c|c|c|c|}
\hline Number & Year & Journal & $\begin{array}{l}\text { Impact } \\
\text { factor }\end{array}$ & First author & Title & $\begin{array}{l}\text { Volumen, } \\
\text { Issue, } \\
\text { pages }\end{array}$ & $\begin{array}{c}\text { Compounds } \\
\text { found in } \\
\text { mushrooms }\end{array}$ & $\begin{array}{l}\text { Method } \\
\text { utilized to } \\
\text { measure } \\
\text { flavonoids }\end{array}$ & $\begin{array}{l}\text { Detection } \\
\text { device or } \\
\text { wavelength } \\
\text { used }\end{array}$ & $\begin{array}{l}\text { Solvents } \\
\text { used for } \\
\text { extraction }\end{array}$ & $\begin{array}{l}\text { Mushroom } \\
\text { specie } \\
\text { studied }\end{array}$ \\
\hline 64 & 2012 & $\begin{array}{l}\text { Food Science and } \\
\text { Biotechnology }\end{array}$ & 0.695 & $\mathrm{Li}, \mathrm{H}$ et al. & $\begin{array}{l}\text { Targeted phenolic analysis in } \\
\text { Hericium erinaceum and its } \\
\text { antioxidant activities. }\end{array}$ & $\begin{array}{c}21,3 \\
881-888\end{array}$ & $\begin{array}{c}\text { Total } \\
\text { flavonoids }\end{array}$ & $10 \% \mathrm{Al}\left(\mathrm{NO}_{3}\right)_{3}$ & $\begin{array}{c}\text { UV/VIS } 415 \\
n m\end{array}$ & Methanol & H. erinaceum \\
\hline 65 & 2012 & $\begin{array}{l}\text { Food Analytical } \\
\text { Methods }\end{array}$ & 1.969 & Tel, G.et al. & $\begin{array}{c}\text { Antioxidant and } \\
\text { cholinesterase inhibition } \\
\text { activities of three Tricholoma } \\
\text { species with total phenolic } \\
\text { and flavonoid contents: The } \\
\text { edible mushrooms from } \\
\text { Anatolia. }\end{array}$ & $\begin{array}{l}5,3,495- \\
504\end{array}$ & $\begin{array}{c}\text { Total } \\
\text { flavonoids }\end{array}$ & $10 \% \mathrm{Al}\left(\mathrm{NO}_{3}\right)_{3}$ & $\begin{array}{c}\text { UV/VIS } 415 \\
n m\end{array}$ & Methanol & $\begin{array}{l}\text { Tricholoma } \\
\text { fracticum, } \\
\text { Tricholoma } \\
\text { imbricatum } \\
\text { and } \\
\text { Tricholoma } \\
\text { terreum }\end{array}$ \\
\hline 66 & 2012 & $\begin{array}{l}\text { Revista } \\
\text { Iberoamericana } \\
\text { de Micología }\end{array}$ & 1.312 & $\begin{array}{l}\text { Ayala- } \\
\text { Zavala, FJ. et } \\
\text { al. }\end{array}$ & $\begin{array}{l}\text { Antioxidant and antifungal } \\
\text { potential of methanol extracts } \\
\text { of Phellinus spp. from } \\
\text { Sonora, Mexico. }\end{array}$ & $\begin{array}{c}29,3 \\
132-138\end{array}$ & $\begin{array}{c}\text { Total } \\
\text { flavonoids }\end{array}$ & $\begin{array}{l}\mathrm{NaNO}_{2}+ \\
10 \% \mathrm{AlCl}_{3} \\
\quad \mathrm{H}_{2} \mathrm{O}\end{array}$ & $\begin{array}{c}\text { UV/VIS } 415 \\
n m\end{array}$ & Methanol & $\begin{array}{l}\text { Phellinus } \\
\text { gilvus, } \\
\text { Phellinus } \\
\text { rimosus and } \\
\text { Phellinus } \\
\text { badius }\end{array}$ \\
\hline 67 & 2012 & $\begin{array}{l}\text { Food Science and } \\
\text { Biotechnology }\end{array}$ & 0.695 & $\begin{array}{c}\text { Sudha, G. et } \\
\text { al. }\end{array}$ & $\begin{array}{c}\text { Antioxidant activity of various } \\
\text { extracts from an } \\
\text { edible mushroom Pleurotus } \\
\text { eous. }\end{array}$ & $\begin{array}{l}21 \\
3,661- \\
668\end{array}$ & $\begin{array}{c}\text { Total } \\
\text { flavonoids }\end{array}$ & $\begin{array}{l}\mathrm{NaNO}_{2}+ \\
10 \% \mathrm{AlCl}_{3} \\
\mathrm{H}_{2} \mathrm{O}\end{array}$ & VIS $510 \mathrm{~nm}$ & $\begin{array}{c}\text { Ethyl } \\
\text { acetate, } \\
\text { methanol or } \\
\text { hot water }\end{array}$ & $P$. eous \\
\hline 68 & 2012 & $\begin{array}{l}\text { Current topics in } \\
\text { Nutraceutical } \\
\text { Research }\end{array}$ & 0.262 & $\begin{array}{l}\text { Akyuz, M. et } \\
\text { al. }\end{array}$ & $\begin{array}{l}\text { Flavonoids contents and 2,2- } \\
\text { diphenyl-1-picrylhydrazyl } \\
\text { radical scavenging activity of } \\
\text { some edible mushrooms } \\
\text { from Turkey: } A \text {. bisporus and } \\
\text { Pleurotus spp. }\end{array}$ & $\begin{array}{c}10,2 \\
133-136\end{array}$ & $\begin{array}{c}\text { Rutin, } \\
\text { myricetin, } \\
\text { morin, } \\
\text { quercetin, } \\
\text { kaempferol, } \\
\text { catechin, } \\
\text { naringenin } \\
\text { and naringin }\end{array}$ & HPLC-DAD & $\begin{array}{c}\text { UV 254-280 } \\
n m\end{array}$ & $\begin{array}{c}80 \% \\
\text { Methanol }\end{array}$ & $\begin{array}{l}\text { A. bisporus, } \\
\text { P. eryngii var. } \\
\text { eryngii, } P . \\
\text { eryngii var. } \\
\text { ferulae, } \\
\text { Pleurotus } \\
\text { sajor-caju, } P \text {. } \\
\text { ostreatus and } \\
\text { Pleurotus } \\
\text { florida }\end{array}$ \\
\hline
\end{tabular}




\section{Appendix-Supplementary Table 1}

\begin{tabular}{|c|c|c|c|c|c|c|c|c|c|c|c|}
\hline Number & Year & Journal & $\begin{array}{l}\text { Impact } \\
\text { factor }\end{array}$ & First author & Title & $\begin{array}{l}\text { Volumen, } \\
\text { Issue, } \\
\text { pages }\end{array}$ & $\begin{array}{l}\text { Compounds } \\
\text { found in } \\
\text { mushrooms }\end{array}$ & $\begin{array}{l}\text { Method } \\
\text { utilized to } \\
\text { measure } \\
\text { flavonoids }\end{array}$ & $\begin{array}{l}\text { Detection } \\
\text { device or } \\
\text { wavelength } \\
\text { used }\end{array}$ & $\begin{array}{l}\text { Solvents } \\
\text { used for } \\
\text { extraction }\end{array}$ & $\begin{array}{l}\text { Mushroom } \\
\text { specie } \\
\text { studied }\end{array}$ \\
\hline 69 & 2012 & $\begin{array}{l}\text { Food and } \\
\text { Bioprocess } \\
\text { Technology }\end{array}$ & 4.115 & $\begin{array}{l}\text { Singla, R. et } \\
\text { al. }\end{array}$ & $\begin{array}{l}\text { Physicochemical and } \\
\text { nutritional characteristics of } \\
\text { organic acid-treated button } \\
\text { mushrooms (Agaricus } \\
\text { bisporous). }\end{array}$ & $\begin{array}{c}5,2,808- \\
815\end{array}$ & $\begin{array}{c}\text { Total } \\
\text { flavonoids }\end{array}$ & $\begin{array}{c}\mathrm{NaNO}_{2}+ \\
10 \% \mathrm{AlCl}_{3} \\
\mathrm{H}_{2} \mathrm{O}\end{array}$ & VIS $510 \mathrm{~nm}$ & NF & A. bisporus \\
\hline 70 & 2012 & $\begin{array}{l}\text { Journal of Food } \\
\text { Science and } \\
\text { Biotechnology }\end{array}$ & 0.695 & $\begin{array}{l}\text { Huang, XD. } \\
\text { et al. }\end{array}$ & $\begin{array}{c}\text { Study on antioxidation } \\
\text { effect in vitro and in vivo of } \\
\text { total flavonoids from Inonotus } \\
\text { obliquus. }\end{array}$ & $\begin{array}{l}31,10 \\
1062- \\
1068\end{array}$ & $\begin{array}{c}\text { Total } \\
\text { flavonoids }\end{array}$ & NF & NF & NF & I. obliquus \\
\hline 71 & 2012 & $\begin{array}{l}\text { International } \\
\text { Journal of } \\
\text { Medicinal } \\
\text { Mushrooms }\end{array}$ & 0.838 & Yin, X. et al. & $\begin{array}{l}\text { Immunomodulatory activities } \\
\text { of different solvent extracts } \\
\text { from Tricholoma matsutake } \\
\text { (S. Ito et S. Imai) Singer } \\
\text { (higher Basidiomycetes) on } \\
\text { normal mice. }\end{array}$ & $\begin{array}{c}14,6 \\
549-556\end{array}$ & $\begin{array}{c}\text { Total } \\
\text { flavonoids }\end{array}$ & Colorimetric & NF & $\begin{array}{c}\text { Water or } \mathrm{n}- \\
\text { butyl } \\
\text { alcohol. }\end{array}$ & T. matsutake \\
\hline 72 & 2012 & $\begin{array}{l}\text { International } \\
\text { Journal of } \\
\text { Medicinal } \\
\text { Mushrooms }\end{array}$ & 0.838 & $\begin{array}{c}\text { Ayala-Zavala, } \\
\text { FJ. et al. }\end{array}$ & $\begin{array}{l}\text { Polar fractionation affects the } \\
\text { antioxidant properties of } \\
\text { methanolic extracts from } \\
\text { species of genus Phellinus } \\
\text { Quel. (higher } \\
\text { Basidiomycetes). }\end{array}$ & $\begin{array}{c}14,6 \\
563-573\end{array}$ & $\begin{array}{c}\text { Total } \\
\text { flavonoids }\end{array}$ & Colorimetric & NF & $\begin{array}{l}\text { Water or } \\
\text { ethyl } \\
\text { acetate }\end{array}$ & $\begin{array}{c}\text { Phellinus } \\
\text { fastuosus, } \\
\text { Phellinus } \\
\text { grenadensis, } \\
\text { Phellinus } \\
\text { merrillii, and } \\
\text { Phellinus } \\
\text { badius }\end{array}$ \\
\hline 73 & 2012 & $\begin{array}{l}\text { Journal of the } \\
\text { Korean Society of } \\
\text { Food Science and } \\
\text { Nutrition }\end{array}$ & NF & $\begin{array}{l}\text { Baek, GH. et } \\
\text { al. }\end{array}$ & $\begin{array}{l}\text { Pharmacological activity of } \\
\text { chaga mushroom on } \\
\text { extraction conditions and } \\
\text { immunostimulating } \\
\text { polysaccharide. }\end{array}$ & $\begin{array}{l}41,10 \\
1378- \\
1387\end{array}$ & $\begin{array}{c}\text { Total } \\
\text { flavonoids }\end{array}$ & Colorimetric & NF & $\begin{array}{l}\text { Hot water } \\
\text { or hot } \\
\text { ethanol }\end{array}$ & I. obliquus \\
\hline 74 & 2012 & $\begin{array}{l}\text { Journal of the } \\
\text { Korean Society of } \\
\text { Food Science and } \\
\text { Nutrition }\end{array}$ & NF & $\begin{array}{l}\text { Hong, MH. et } \\
\text { al. }\end{array}$ & $\begin{array}{l}\text { Antioxidant properties and } \\
\text { ubiquinone contents in } \\
\text { different parts of several } \\
\text { commerical mushrooms. }\end{array}$ & $\begin{array}{l}41,9 \\
1235- \\
1241\end{array}$ & $\begin{array}{c}\text { Total } \\
\text { flavonoids }\end{array}$ & Colorimetric & NF & Methanol & $\begin{array}{c}14 \\
\text { commercial } \\
\text { mushrooms }\end{array}$ \\
\hline
\end{tabular}




\section{Appendix-Supplementary Table 1}

\begin{tabular}{|c|c|c|c|c|c|c|c|c|c|c|c|}
\hline Number & Year & Journal & $\begin{array}{l}\text { Impact } \\
\text { factor }\end{array}$ & First author & Title & $\begin{array}{l}\text { Volumen, } \\
\text { Issue, } \\
\text { pages }\end{array}$ & $\begin{array}{c}\text { Compounds } \\
\text { found in } \\
\text { mushrooms }\end{array}$ & $\begin{array}{l}\text { Method } \\
\text { utilized to } \\
\text { measure } \\
\text { flavonoids }\end{array}$ & $\begin{array}{c}\text { Detection } \\
\text { device or } \\
\text { wavelength } \\
\text { used }\end{array}$ & $\begin{array}{l}\text { Solvents } \\
\text { used for } \\
\text { extraction }\end{array}$ & $\begin{array}{l}\text { Mushroom } \\
\text { specie } \\
\text { studied }\end{array}$ \\
\hline 75 & 2012 & $\begin{array}{l}\text { International } \\
\text { Journal of } \\
\text { Medicinal } \\
\text { Mushrooms }\end{array}$ & 0.838 & $\begin{array}{l}\text { Wang, Y. et } \\
\text { al. }\end{array}$ & $\begin{array}{c}\text { Contents of some } \\
\text { metabolites in the peel and } \\
\text { flesh of the } \\
\text { medicinal mushroom Wolfipo } \\
\text { ria cocos (F.A. Wolf) } \\
\text { Ryvarden et Gilb. (Higher } \\
\text { Basidiomycetes). }\end{array}$ & $\begin{array}{c}14,1,79- \\
83\end{array}$ & $\begin{array}{c}\text { Total } \\
\text { flavonoids }\end{array}$ & Colorimetric & NF & NF & $\begin{array}{l}\text { Wolfiporia } \\
\text { cocos }\end{array}$ \\
\hline 76 & 2013 & $\begin{array}{l}\text { Food Research } \\
\text { International }\end{array}$ & 3.05 & $\begin{array}{l}\text { Leal, AR. et } \\
\text { al. }\end{array}$ & $\begin{array}{l}\text { Portuguese wild mushrooms } \\
\text { at the "pharma-nutrition" } \\
\text { interface: nutritional } \\
\text { characterization and } \\
\text { antioxidant properties. }\end{array}$ & $50,1,1-9$ & $\begin{array}{l}\text { Chrysin } \\
\text { derivatives }\end{array}$ & $\begin{array}{l}\text { HPLC- } \\
\text { DAD/MS }\end{array}$ & $\begin{array}{l}\text { UV } 280-370 ; \\
\text { comparison } \\
\text { of mass } \\
\text { spectras } \\
\text { and } \\
\text { retention } \\
\text { times }\end{array}$ & $\begin{array}{c}80 \% \\
\text { Methanol }\end{array}$ & $\begin{array}{c}\text { Amanita } \\
\text { crocea, } \\
\text { Amanita } \\
\text { mairei, } \\
\text { Boletus } \\
\text { porosporus, } \\
\text { Boletus } \\
\text { regius, } \\
\text { Gyromitra } \\
\text { esculenta, } \\
\text { Helvella } \\
\text { lacunosa, } \\
\text { Russula } \\
\text { aurea and } R \text {. } \\
\text { virescens }\end{array}$ \\
\hline 77 & 2013 & $\begin{array}{l}\text { Food and } \\
\text { Chemical } \\
\text { Toxicology }\end{array}$ & 2.61 & Liu, J. et al. & $\begin{array}{c}\text { In vitro and in vivo } \\
\text { antioxidant activity of } \\
\text { ethanolic extract of white } \\
\text { button mushroom (Agaricus } \\
\text { bisporus). }\end{array}$ & $\begin{array}{c}51,-, 310- \\
316\end{array}$ & $\begin{array}{c}\text { Myricetin } \\
\text { and catechin }\end{array}$ & $\begin{array}{l}\text { HPLC-ESI- } \\
\text { MS/MS }\end{array}$ & $\begin{array}{l}\text { Comparison } \\
\text { of mass } \\
\text { spectras } \\
\text { and } \\
\text { retention } \\
\text { times }\end{array}$ & $\begin{array}{c}80 \% \\
\text { Ethanol }\end{array}$ & A. bisporus \\
\hline 78 & 2013 & $\begin{array}{l}\text { Journal of Natural } \\
\text { Products and } \\
\text { Plant Resources }\end{array}$ & NF & $\begin{array}{l}\text { Abugria, DA. } \\
\text { et al. }\end{array}$ & $\begin{array}{l}\text { Extraction of total phenolic } \\
\text { and flavonoids from edible } \\
\text { wild and cultivated medicinal } \\
\text { mushrooms as affected by } \\
\text { different solvents. }\end{array}$ & $\begin{array}{c}3,3,37- \\
42\end{array}$ & $\begin{array}{c}\text { Total } \\
\text { flavonoids }\end{array}$ & $\begin{array}{c}\mathrm{NaNO}_{2}+ \\
10 \% \mathrm{AlCl}_{3} \\
\mathrm{H}_{2} \mathrm{O}\end{array}$ & VIS $510 \mathrm{~nm}$ & $\begin{array}{c}\text { Mehtnaol or } \\
\text { water }\end{array}$ & $\begin{array}{l}\text { A. bisporus, } \\
\text { Trametes } \\
\text { versicolor, } \\
\text { Ganoderma } \\
\text { applanatum } \\
\text { and Fomes } \\
\text { fomentarius. }\end{array}$ \\
\hline
\end{tabular}




\section{Appendix-Supplementary Table 1}

\begin{tabular}{|c|c|c|c|c|c|c|c|c|c|c|c|}
\hline Number & Year & Journal & $\begin{array}{l}\text { Impact } \\
\text { factor }\end{array}$ & First author & Title & $\begin{array}{l}\text { Volumen, } \\
\text { Issue, } \\
\text { pages }\end{array}$ & $\begin{array}{l}\text { Compounds } \\
\text { found in } \\
\text { mushrooms }\end{array}$ & $\begin{array}{l}\text { Method } \\
\text { utilized to } \\
\text { measure } \\
\text { flavonoids }\end{array}$ & $\begin{array}{l}\text { Detection } \\
\text { device or } \\
\text { wavelength } \\
\text { used }\end{array}$ & $\begin{array}{l}\text { Solvents } \\
\text { used for } \\
\text { extraction }\end{array}$ & $\begin{array}{l}\text { Mushroom } \\
\text { specie } \\
\text { studied }\end{array}$ \\
\hline 79 & 2013 & $\begin{array}{l}\text { International Food } \\
\text { Research Journal }\end{array}$ & NF & Gan, C. et al. & $\begin{array}{c}\text { Antioxidant analysis of } \\
\text { different types of edible } \\
\text { mushrooms (Agaricus } \\
\text { bisporous and Agaricus } \\
\text { brasiliensis). }\end{array}$ & $\begin{array}{l}20,3 \\
1095- \\
1102\end{array}$ & $\begin{array}{c}\text { Total } \\
\text { flavonoids }\end{array}$ & $\begin{array}{l}\mathrm{NaNO}_{2}+ \\
10 \% \mathrm{AlCl}_{3} \\
\quad \mathrm{H}_{2} \mathrm{O}\end{array}$ & VIS $510 \mathrm{~nm}$ & $\begin{array}{l}60 \% \\
\text { Ethanol or } \\
\text { water }\end{array}$ & $\begin{array}{l}\text { A. bisporus } \\
\text { and Agaricus } \\
\text { brasiliensis }\end{array}$ \\
\hline 80 & 2013 & $\begin{array}{l}\text { Tropical Journal } \\
\text { of Pharmaceutical } \\
\text { Research }\end{array}$ & 0.495 & $\begin{array}{l}\text { Wong, FC. } \\
\text { et al. }\end{array}$ & $\begin{array}{l}\text { Evaluation of bioactivities } \\
\text { and phenolic content of } \\
\text { selected edible mushrooms } \\
\text { in Malaysia. }\end{array}$ & $\begin{array}{l}12,6 \\
1011- \\
1016\end{array}$ & $\begin{array}{c}\text { Total } \\
\text { flavonoids }\end{array}$ & $\begin{array}{l}\mathrm{NaNO}_{2}+ \\
10 \% \mathrm{AlCl}_{3} \\
\mathrm{H}_{2} \mathrm{O}\end{array}$ & VIS $510 \mathrm{~nm}$ & $\begin{array}{c}90 \% \\
\text { Ethanol }\end{array}$ & $\begin{array}{l}\text { Hypsizygus te } \\
\text { ssulatus, } P \text {. } \\
\text { eryngii, } P \text {. } \\
\text { florida, } \\
\text { Auricularia } \\
\text { polytricha and } \\
\text { Flammulina } \\
\text { velutipes }\end{array}$ \\
\hline 81 & 2013 & $\begin{array}{l}\text { International } \\
\text { Journal of } \\
\text { Pharmacy and } \\
\text { Pharmaceutical } \\
\text { Sciences }\end{array}$ & NF & $\begin{array}{l}\text { Shirmila, J, et } \\
\text { al. }\end{array}$ & $\begin{array}{l}\text { In vitro antioxidant activities, } \\
\text { total phenolics and flavonoid } \\
\text { of wild edible mushroom } \\
\text { Macrolepiota Mastoidea (Fr.) } \\
\text { Singer. }\end{array}$ & $\begin{array}{c}5,2,161- \\
166\end{array}$ & $\begin{array}{c}\text { Total } \\
\text { flavonoids }\end{array}$ & $\mathrm{AlCl}_{3}$ & $\begin{array}{c}\text { UV/VIS } 415 \\
n m\end{array}$ & Methanol & $\begin{array}{c}\text { Macrolepiota } \\
\text { mastoidea }\end{array}$ \\
\hline 82 & 2013 & $\begin{array}{l}\text { Journal of Soil } \\
\text { Science and Plant } \\
\text { Nutrition }\end{array}$ & 0.582 & Akyüz, M. & $\begin{array}{l}\text { Nutritive value, flavonoid } \\
\text { content and radical } \\
\text { scavenging activity of the } \\
\text { truffle (Terfezia boudieri } \\
\text { Chatin). }\end{array}$ & $\begin{array}{c}13,1 \\
143-151\end{array}$ & $\begin{array}{l}\text { Myricetin, } \\
\text { kaempferol, } \\
\text { naringin and } \\
\text { naringenin }\end{array}$ & HPLC-DAD & $\begin{array}{c}\text { UV 254-280 } \\
n m\end{array}$ & $\begin{array}{c}80 \% \\
\text { Methanol }\end{array}$ & $\begin{array}{l}\text { Terfezia } \\
\text { boudieri }\end{array}$ \\
\hline 83 & 2013 & Mycosphere & NF & $\begin{array}{l}\text { Arbaayah, } \\
\text { HH. et al. }\end{array}$ & $\begin{array}{l}\text { Antioxidant properties in the } \\
\text { oyster mushrooms (Pleurotus } \\
\text { spp.) and split gill mushroom } \\
\text { (Schizophyllum commune) } \\
\text { ethanolic extracts. }\end{array}$ & $\begin{array}{c}4,4,661- \\
673\end{array}$ & $\begin{array}{c}\text { Total } \\
\text { flavonoids }\end{array}$ & $\begin{array}{l}\mathrm{NaNO}_{2}+ \\
10 \% \mathrm{AlCl}_{3} \\
\mathrm{H}_{2} \mathrm{O}\end{array}$ & VIS $510 \mathrm{~nm}$ & Ethanol & $\begin{array}{l}\text { Pleurotus } \\
\text { djamor var. } \\
\text { djamor and } \\
\text { Schizophyllu } \\
\text { m commne }\end{array}$ \\
\hline 84 & 2013 & $\begin{array}{l}\text { Journal of Food } \\
\text { Research }\end{array}$ & 1.791 & $\begin{array}{l}\text { Wandati, TW. } \\
\text { et al. }\end{array}$ & $\begin{array}{l}\text { Phytochemicals in edible wild } \\
\text { mushrooms from selected } \\
\text { areas in Kenya. }\end{array}$ & $\begin{array}{c}2,3,137- \\
144\end{array}$ & $\begin{array}{c}\text { Total } \\
\text { flavonoids }\end{array}$ & $\begin{array}{l}\mathrm{NaNO}_{2}+ \\
10 \% \mathrm{AlCl}_{3} \\
\mathrm{H}_{2} \mathrm{O}\end{array}$ & $\begin{array}{c}\text { UV/VIS } 415 \\
n m\end{array}$ & Ethanol & $\begin{array}{l}\text { P. florida and } \\
\text { A. biporus }\end{array}$ \\
\hline
\end{tabular}




\section{Appendix-Supplementary Table 1}

\begin{tabular}{|c|c|c|c|c|c|c|c|c|c|c|c|}
\hline Number & Year & Journal & $\begin{array}{l}\text { Impact } \\
\text { factor }\end{array}$ & First author & Title & $\begin{array}{l}\text { Volumen, } \\
\text { Issue, } \\
\text { pages }\end{array}$ & $\begin{array}{c}\text { Compounds } \\
\text { found in } \\
\text { mushrooms }\end{array}$ & $\begin{array}{l}\text { Method } \\
\text { utilized to } \\
\text { measure } \\
\text { flavonoids }\end{array}$ & $\begin{array}{l}\text { Detection } \\
\text { device or } \\
\text { wavelength } \\
\text { used }\end{array}$ & $\begin{array}{l}\text { Solvents } \\
\text { used for } \\
\text { extraction }\end{array}$ & $\begin{array}{l}\text { Mushroom } \\
\text { specie } \\
\text { studied }\end{array}$ \\
\hline 85 & 2013 & $\begin{array}{l}\text { Food and } \\
\text { Agricultural } \\
\text { Immunology }\end{array}$ & 0.984 & $\begin{array}{l}\text { Llaurado, G. } \\
\text { et al. }\end{array}$ & $\begin{array}{l}\text { Phytochemical screening and } \\
\text { effects on cell-mediated } \\
\text { immune response of } \\
\text { Pleurotus fruiting bodies } \\
\text { powder. }\end{array}$ & $\begin{array}{r}24,3 \\
295-304\end{array}$ & $\begin{array}{c}\text { Total } \\
\text { flavonoids }\end{array}$ & Colorimetric & NF & NF & Pleurotus \\
\hline \multirow[b]{2}{*}{86} & \multirow[b]{2}{*}{2013} & \multirow[b]{2}{*}{ Molecules } & \multirow[b]{2}{*}{2.095} & \multirow[b]{2}{*}{$\begin{array}{l}\text { Hasnat, A. et } \\
\text { al. }\end{array}$} & \multirow[b]{2}{*}{$\begin{array}{l}\text { Acetylcholinesterase } \\
\text { inhibition and in vitro and in } \\
\text { vivo antioxidant activities of } \\
\text { Ganoderma lucidum grown } \\
\text { on germinated brown rice. }\end{array}$} & \multirow[b]{2}{*}{$\begin{array}{c}18 \\
6,6663- \\
6678\end{array}$} & $\begin{array}{c}\text { Total } \\
\text { flavonoids }\end{array}$ & $\begin{array}{c}\mathrm{NaNO}_{2}+ \\
10 \% \mathrm{AlCl}_{3} \\
\mathrm{H}_{2} \mathrm{O}\end{array}$ & VIS $517 \mathrm{~nm}$ & \multirow[b]{2}{*}{ Water } & \multirow[b]{2}{*}{ G. lucidum } \\
\hline & & & & & & & $\begin{array}{l}\text { Quercetin, } \\
\text { kaempferol, } \\
\text { cateuin, } \\
\text { myricetin, } \\
\text { rutin, } \\
\text { epicatechin }\end{array}$ & $\begin{array}{l}\text { HPLC- } \\
\text { DAD/MS }\end{array}$ & $\begin{array}{l}\text { UV } 280 \mathrm{~nm} \text {; } \\
\text { comparison } \\
\text { of mass } \\
\text { spectras } \\
\text { and } \\
\text { retention } \\
\text { times }\end{array}$ & & \\
\hline 87 & 2013 & $\begin{array}{l}\text { Food and } \\
\text { Chemical } \\
\text { toxicology }\end{array}$ & 2.61 & $\begin{array}{l}\text { Kalogeropoul } \\
\text { os, N. et al. }\end{array}$ & $\begin{array}{l}\text { Bioactive microconstituents } \\
\text { and antioxidant properties of } \\
\text { wild edible mushrooms from } \\
\text { the island of Lesvos, Greece. }\end{array}$ & $\begin{array}{c}55,-, 378- \\
385\end{array}$ & $\begin{array}{l}\text { Chrysin, } \\
\text { genistein, } \\
\text { kaempferol } \\
\text { and } \\
\text { quercetin }\end{array}$ & GC-MS & $\begin{array}{l}\text { Comparison } \\
\text { of mass } \\
\text { spectras } \\
\text { and } \\
\text { retention } \\
\text { times }\end{array}$ & Methanol & $\begin{array}{l}\text { L. deliciosus, } \\
\text { Lactarius } \\
\text { sanguifluus, } \\
\text { Lactarius } \\
\text { semisanguiflu } \\
\text { us, } R \text {. delica } \\
\text { and Suillus } \\
\text { bellinii }\end{array}$ \\
\hline 88 & 2013 & $\begin{array}{l}\text { Journal of Food } \\
\text { Science and } \\
\text { Technology }\end{array}$ & 2.024 & $\begin{array}{c}\text { Babu, DR. et } \\
\text { al. }\end{array}$ & $\begin{array}{l}\text { Antioxidant properties and } \\
\text { electrochemical behavior of } \\
\text { cultivated commercial Indian } \\
\text { edible mushrooms. }\end{array}$ & $\begin{array}{c}50 \\
2,301- \\
308\end{array}$ & $\begin{array}{c}\text { Total } \\
\text { flavonoids }\end{array}$ & $\mathrm{AlCl}_{3}$ & $\begin{array}{c}\text { UV/VIS } 415 \\
n m\end{array}$ & $\begin{array}{c}95 \% \\
\text { Etahnol }\end{array}$ & $\begin{array}{l}\text { A. bisporus, } \\
\text { Hypsizygus } \\
\text { ulmarius and } \\
\text { Calocybe } \\
\text { indica }\end{array}$ \\
\hline 89 & 2013 & $\begin{array}{l}\text { Food Science and } \\
\text { Biotechnology }\end{array}$ & 0.656 & $\begin{array}{l}\text { Singdevsach } \\
\text { an, SK. et al. }\end{array}$ & $\begin{array}{l}\text { Nutritional and bioactive } \\
\text { potential of two wild edible } \\
\text { mushrooms (Lentinus sajor- } \\
\text { caju and Lentinus torulosus) } \\
\text { from Similipal Biosphere } \\
\text { Reserve, India. }\end{array}$ & $\begin{array}{c}22,1 \\
137-145\end{array}$ & $\begin{array}{c}\text { Total } \\
\text { flavonoids }\end{array}$ & $\begin{array}{l}\mathrm{NaNO}_{2}+ \\
10 \% \mathrm{AlCl}_{3} \\
\mathrm{H}_{2} \mathrm{O}\end{array}$ & VIS $510 \mathrm{~nm}$ & $\begin{array}{c}\text { Ethanol, } \\
\text { methanol or } \\
\text { water }\end{array}$ & $\begin{array}{l}\text { Lentinus } \\
\text { sajor-caju } \\
\text { and Lentinus } \\
\text { torulosus }\end{array}$ \\
\hline
\end{tabular}




\section{Appendix-Supplementary Table 1}

\begin{tabular}{|c|c|c|c|c|c|c|c|c|c|c|c|}
\hline Number & Year & Journal & $\begin{array}{l}\text { Impact } \\
\text { factor }\end{array}$ & First author & Title & $\begin{array}{l}\text { Volumen, } \\
\text { Issue, } \\
\text { pages }\end{array}$ & $\begin{array}{c}\text { Compounds } \\
\text { found in } \\
\text { mushrooms }\end{array}$ & $\begin{array}{l}\text { Method } \\
\text { utilized to } \\
\text { measure } \\
\text { flavonoids }\end{array}$ & $\begin{array}{c}\text { Detection } \\
\text { device or } \\
\text { wavelength } \\
\text { used }\end{array}$ & $\begin{array}{l}\text { Solvents } \\
\text { used for } \\
\text { extraction }\end{array}$ & $\begin{array}{l}\text { Mushroom } \\
\text { specie } \\
\text { studied }\end{array}$ \\
\hline 90 & 2013 & $\begin{array}{l}\text { International } \\
\text { Journal of } \\
\text { Medicinal } \\
\text { Mushrooms }\end{array}$ & 1.123 & $\begin{array}{l}\text { Durgo, K. et } \\
\text { al. }\end{array}$ & $\begin{array}{l}\text { Cytotoxicity of blended } \\
\text { versus single } \\
\text { medicinal mushroom extracts } \\
\text { on human cancer cell lines: } \\
\text { contribution of polyphenol } \\
\text { and polysaccharide content. }\end{array}$ & $\begin{array}{c}15,5 \\
435-448\end{array}$ & $\begin{array}{c}\text { Total } \\
\text { flavonoids }\end{array}$ & Colorimetric & NF & NF & $\begin{array}{l}\text { L. edodes, } G \text {. } \\
\text { lucidum, } A \text {. } \\
\text { bisporus, } G \text {. } \\
\text { frondosa, } T \text {. } \\
\text { massutake } \\
\text { and } P \text {. } \\
\text { ostreatus }\end{array}$ \\
\hline 91 & 2013 & $\begin{array}{l}\text { BioMed Research } \\
\text { International }\end{array}$ & 2.706 & $\begin{array}{l}\text { Vamanu, E. } \\
\text { et al. }\end{array}$ & $\begin{array}{l}\text { Antioxidant capacity and the } \\
\text { correlation with major } \\
\text { phenolic compounds, } \\
\text { anthocyanin, and tocopherol } \\
\text { content in various extracts } \\
\text { from the wild edible Boletus } \\
\text { edulis mushroom. }\end{array}$ & $\begin{array}{c}2013,-, \\
11 \text { (ID } \\
313905)\end{array}$ & $\begin{array}{c}\text { Total } \\
\text { flavonoids }\end{array}$ & $\begin{array}{c}\mathrm{NaNO}_{2}+ \\
10 \% \mathrm{AlCl}_{3} . \\
\mathrm{H}_{2} \mathrm{O}\end{array}$ & $\begin{array}{c}\text { UV/VIS } 410 \\
n m\end{array}$ & $\begin{array}{l}\text { Ethanol, } \\
\text { methanol or } \\
\text { cold/hot } \\
\text { water }\end{array}$ & B. edulis \\
\hline 92 & 2013 & $\begin{array}{l}\text { International } \\
\text { Journal of } \\
\text { Medicinal } \\
\text { Mushrooms }\end{array}$ & 1.123 & $\begin{array}{l}\text { Lai, MN. et } \\
\text { al. }\end{array}$ & $\begin{array}{l}\text { Antioxidant and antiedema } \\
\text { properties of solid-state } \\
\text { cultured honey mushroom, } \\
\text { Armillaria mellea (Higher } \\
\text { Basidiomycetes), extracts } \\
\text { and their polysaccharide and } \\
\text { polyphenol contents. }\end{array}$ & $\begin{array}{c}15,1,1- \\
8\end{array}$ & $\begin{array}{c}\text { Total } \\
\text { flavonoids }\end{array}$ & Colorimetric & NF & $\begin{array}{l}\text { Ethanol or } \\
\text { water }\end{array}$ & A. mellea \\
\hline 93 & 2013 & $\begin{array}{l}\text { International } \\
\text { Journal of } \\
\text { Medicinal } \\
\text { Mushrooms }\end{array}$ & 1.123 & $\begin{array}{l}\text { Kumari, B. et } \\
\text { al. }\end{array}$ & $\begin{array}{l}\text { Evaluation of nutraceutical } \\
\text { components and antioxidant } \\
\text { potential of North Indian wild } \\
\text { culinary-medicinal } \\
\text { termitophilous mushrooms. }\end{array}$ & $\begin{array}{c}15,2,191- \\
197\end{array}$ & $\begin{array}{c}\text { Total } \\
\text { flavonoids }\end{array}$ & Colorimetric & NF & NF & $\begin{array}{c}\text { Termitomyce } \\
\text { s } \\
\text { microcarpus, } \\
\text { Termitomyce } \\
\text { s radicatus, } \\
\text { Termitomyce } \\
\text { s badius, } \\
\text { Termitomyce } \\
\text { s medius, } \\
\text { Termitomyce } \\
\text { s heimii } \\
\text { and Termitom } \\
\text { yces striatus }\end{array}$ \\
\hline
\end{tabular}




\section{Appendix-Supplementary Table 1}

\begin{tabular}{|c|c|c|c|c|c|c|c|c|c|c|c|}
\hline Number & Year & Journal & $\begin{array}{l}\text { Impact } \\
\text { factor }\end{array}$ & First author & Title & $\begin{array}{l}\text { Volumen, } \\
\text { Issue, } \\
\text { pages }\end{array}$ & $\begin{array}{l}\text { Compounds } \\
\text { found in } \\
\text { mushrooms }\end{array}$ & $\begin{array}{l}\text { Method } \\
\text { utilized to } \\
\text { measure } \\
\text { flavonoids }\end{array}$ & $\begin{array}{l}\text { Detection } \\
\text { device or } \\
\text { wavelength } \\
\text { used }\end{array}$ & $\begin{array}{l}\text { Solvents } \\
\text { used for } \\
\text { extraction }\end{array}$ & $\begin{array}{l}\text { Mushroom } \\
\text { specie } \\
\text { studied }\end{array}$ \\
\hline 94 & 2013 & $\begin{array}{l}\text { International } \\
\text { Journal of } \\
\text { Medicinal } \\
\text { Mushrooms }\end{array}$ & 1.123 & $\begin{array}{l}\text { Jeong, SC. et } \\
\text { al. }\end{array}$ & $\begin{array}{c}\text { Antioxidant and } \\
\text { immunomodulating activities } \\
\text { of exo- and } \\
\text { endopolysaccharide fractions } \\
\text { from submerged mycelia } \\
\text { cultures of culinary-medicinal } \\
\text { mushrooms. }\end{array}$ & $\begin{array}{c}15,3 \\
251-266\end{array}$ & $\begin{array}{c}\text { Total } \\
\text { flavonoids }\end{array}$ & Colorimetric & NF & NF & $\begin{array}{l}\text { Cryptosporus } \\
\text { volvatus and } \\
\text { Cordyceps } \\
\text { militaris }\end{array}$ \\
\hline 95 & 2013 & $\begin{array}{l}\text { Journal of the } \\
\text { Korean Society of } \\
\text { Food Science and } \\
\text { Nutrition }\end{array}$ & $\mathrm{NI}$ & Qi, Y. et al. & $\begin{array}{l}\text { Antioxidant and anticancer } \\
\text { effects of edible and } \\
\text { medicinal mushrooms. }\end{array}$ & $\begin{array}{c}42,5 \\
655-662\end{array}$ & $\begin{array}{c}\text { Total } \\
\text { flavonoids }\end{array}$ & Colorimetric & NF & Methanol & $\begin{array}{l}\text { L. edodes, } A \text {. } \\
\text { blazei, } C \text {. } \\
\text { militaris, } G \text {. } \\
\text { lucidum, I. } \\
\text { obliquus and } \\
\text { Phellinus } \\
\text { linteus }\end{array}$ \\
\hline 96 & 2013 & $\begin{array}{l}\text { Journal of Food } \\
\text { Biochemistry }\end{array}$ & 0.853 & $\begin{array}{l}\text { Debnath, T. } \\
\text { et al. }\end{array}$ & $\begin{array}{c}\text { Antioxidant activity } \\
\text { of Inonotus obliquus grown } \\
\text { on germinated brown rice } \\
\text { extracts. }\end{array}$ & $\begin{array}{c}37,4 \\
456-464\end{array}$ & $\begin{array}{c}\text { Total } \\
\text { flavonoids }\end{array}$ & $\begin{array}{l}\mathrm{NaNO}_{2}+ \\
10 \% \mathrm{AlCl}_{3} \\
\mathrm{H}_{2} \mathrm{O}\end{array}$ & VIS $517 \mathrm{~nm}$ & $\begin{array}{c}\text { Ethanol, } \\
\text { methanol or } \\
\text { water }\end{array}$ & I. obliquus \\
\hline 97 & 2014 & Food Chemistry & 3.391 & $\begin{array}{l}\text { Woldegiorgis, } \\
\text { AZ. et al. }\end{array}$ & $\begin{array}{l}\text { Antioxidant property of edible } \\
\text { mushrooms collected from } \\
\text { Ethiopia. }\end{array}$ & $\begin{array}{c}157,15 \\
30-36\end{array}$ & $\begin{array}{c}\text { Total } \\
\text { flavonoids }\end{array}$ & $\begin{array}{l}\mathrm{NaNO}_{2}+ \\
10 \% \mathrm{AlCl}_{3} \\
\quad \mathrm{H}_{2} \mathrm{O}\end{array}$ & VIS 510 nm & Methanol & $\begin{array}{c}\text { P. ostreatus, } \\
\text { L. edodes, } L . \\
\text { sulphureus, } \\
\text { Agaricus } \\
\text { campestris, } \\
\text { Termocyes } \\
\text { clypeatus, } T \text {. } \\
\text { microcarpus } \\
\text { and } \\
\text { Termocytes } \\
\text { letestui }\end{array}$ \\
\hline 98 & 2014 & Food Chemistry & 3.391 & $\begin{array}{l}\text { Özyürek, M. } \\
\text { et al. }\end{array}$ & $\begin{array}{l}\text { Antioxidant/antiradical } \\
\text { properties of microwave- } \\
\text { assisted extracts of three wild } \\
\text { edible mushrooms. }\end{array}$ & $\begin{array}{l}157,15 \\
323-331\end{array}$ & $\begin{array}{c}\text { Rutin, } \\
\text { quercetin, } \\
\text { hesperidin, } \\
\text { naringenin, } \\
\text { kaempferol } \\
\text { and apigenin }\end{array}$ & $\begin{array}{l}\text { UPLC-ESI- } \\
\text { MS/M }\end{array}$ & $\begin{array}{l}\text { Comparison } \\
\text { of mass } \\
\text { spectras } \\
\text { and } \\
\text { retention } \\
\text { times }\end{array}$ & $\begin{array}{c}80 \% \\
\text { Methanol }\end{array}$ & $\begin{array}{l}\text { T. boudieri } \\
\text { Chatin, } B \text {. } \\
\text { edulis and } \\
\text { Lactarius } \\
\text { volemus }\end{array}$ \\
\hline
\end{tabular}




\section{Appendix-Supplementary Table 1}

\begin{tabular}{|c|c|c|c|c|c|c|c|c|c|c|c|}
\hline Number & Year & Journal & $\begin{array}{l}\text { Impact } \\
\text { factor }\end{array}$ & First author & Title & $\begin{array}{l}\text { Volumen, } \\
\text { Issue, } \\
\text { pages }\end{array}$ & $\begin{array}{l}\text { Compounds } \\
\text { found in } \\
\text { mushrooms }\end{array}$ & $\begin{array}{l}\text { Method } \\
\text { utilized to } \\
\text { measure } \\
\text { flavonoids }\end{array}$ & $\begin{array}{c}\text { Detection } \\
\text { device or } \\
\text { wavelength } \\
\text { used }\end{array}$ & $\begin{array}{l}\text { Solvents } \\
\text { used for } \\
\text { extraction }\end{array}$ & $\begin{array}{l}\text { Mushroom } \\
\text { specie } \\
\text { studied }\end{array}$ \\
\hline 99 & 2014 & $\begin{array}{l}\text { Journal of Food } \\
\text { Science and } \\
\text { Technology }\end{array}$ & 2.203 & $\begin{array}{c}\text { Babu, DR. et } \\
\text { al. }\end{array}$ & $\begin{array}{c}\text { Antioxidant and } \\
\text { electrochemical properties of } \\
\text { cultivated Pleurotus spp. and } \\
\text { their sporeless/low sporing } \\
\text { mutants. }\end{array}$ & $\begin{array}{l}51,11 \\
3317- \\
3324\end{array}$ & $\begin{array}{c}\text { Total } \\
\text { flavonoids }\end{array}$ & $\mathrm{AlCl}_{3}$ & $\begin{array}{c}\text { UV/VIS } 415 \\
n m\end{array}$ & $\begin{array}{c}95 \% \\
\text { Ethanol }\end{array}$ & $\begin{array}{l}\text { P. florida, } P \text {. } \\
\text { sajor-caju, } \\
\text { Pleurotus } \\
\text { cystidiosus } \\
\text { and } P \text {. djamor }\end{array}$ \\
\hline 100 & 2014 & $\begin{array}{l}\text { International } \\
\text { Journal of } \\
\text { Medicinal } \\
\text { Mushrooms }\end{array}$ & 0.927 & $\begin{array}{c}\text { Rathor, R. et } \\
\text { al. }\end{array}$ & $\begin{array}{l}\text { Scientific validation of the } \\
\text { Chinese caterpillar } \\
\text { medicinal mushroom, } \\
\text { Ophiocordyceps sinensis } \\
\text { (Ascomycetes) from India: } \\
\text { immunomodulatory and } \\
\text { antioxidant activity. }\end{array}$ & $\begin{array}{c}16,6 \\
541-553\end{array}$ & $\begin{array}{c}\text { Total } \\
\text { flavonoids }\end{array}$ & Colorimetric & NF & Water & $\begin{array}{c}\text { Ophiocordyce } \\
\text { ps sinensis }\end{array}$ \\
\hline 101 & 2014 & $\begin{array}{l}\text { International } \\
\text { Journal of } \\
\text { Medicinal } \\
\text { Mushrooms }\end{array}$ & 0.927 & $\begin{array}{l}\text { Dong, } \mathrm{CH} \text {. et } \\
\text { al. }\end{array}$ & $\begin{array}{l}\text { A comparative study of the } \\
\text { antimicrobial, antioxidant, } \\
\text { and cytotoxic activities of } \\
\text { methanol extracts from fruit } \\
\text { bodies and fermented } \\
\text { mycelia of caterpillar } \\
\text { medicinal mushroom Cordyc } \\
\text { eps militaris (Ascomycetes). }\end{array}$ & $\begin{array}{c}16,5 \\
485-495 .\end{array}$ & $\begin{array}{c}\text { Total } \\
\text { flavonoids }\end{array}$ & Colorimetric & NF & Methanol & C. militaris \\
\hline 102 & 2014 & $\begin{array}{l}\text { International } \\
\text { Journal of } \\
\text { Medicinal } \\
\text { Mushrooms }\end{array}$ & 0.927 & $\begin{array}{l}\text { Gupta, A. et } \\
\text { al. }\end{array}$ & $\begin{array}{l}\text { Wound healing activity of an } \\
\text { aqueous extract of the } \\
\text { Lingzhi or Reishi } \\
\text { medicinal mushroom Ganode } \\
\text { rma lucidum (higher } \\
\text { Basidiomycetes). }\end{array}$ & $\begin{array}{c}6,4,345- \\
354 .\end{array}$ & $\begin{array}{c}\text { Total } \\
\text { flavonoids }\end{array}$ & Colorimetric & NF & Water & G. lucidum \\
\hline 103 & 2014 & $\begin{array}{l}\text { LWT-Food } \\
\text { Sciences and } \\
\text { Technology }\end{array}$ & 2.416 & $\begin{array}{c}\text { Jaworska, G. } \\
\text { et al. }\end{array}$ & $\begin{array}{c}\text { Vitamins, phenolics and } \\
\text { antioxidant activity of culinary } \\
\text { prepared Suillus luteus (L.) } \\
\text { Roussel mushroom. }\end{array}$ & $\begin{array}{l}59,2(1), \\
701-706\end{array}$ & $\begin{array}{c}\text { Total } \\
\text { flavonoids }\end{array}$ & $\begin{array}{c}\mathrm{NaNO}_{2}+ \\
10 \% \mathrm{AlCl}_{3} \\
\mathrm{H}_{2} \mathrm{O}\end{array}$ & VIS $510 \mathrm{~nm}$ & Methanol & Suillus luteus \\
\hline
\end{tabular}




\section{Appendix-Supplementary Table 1}

\begin{tabular}{|c|c|c|c|c|c|c|c|c|c|c|c|}
\hline Number & Year & Journal & $\begin{array}{l}\text { Impact } \\
\text { factor }\end{array}$ & First author & Title & $\begin{array}{l}\text { Volumen, } \\
\text { Issue, } \\
\text { pages }\end{array}$ & $\begin{array}{c}\text { Compounds } \\
\text { found in } \\
\text { mushrooms }\end{array}$ & $\begin{array}{l}\text { Method } \\
\text { utilized to } \\
\text { measure } \\
\text { flavonoids }\end{array}$ & $\begin{array}{l}\text { Detection } \\
\text { device or } \\
\text { wavelength } \\
\text { used }\end{array}$ & $\begin{array}{l}\text { Solvents } \\
\text { used for } \\
\text { extraction }\end{array}$ & $\begin{array}{l}\text { Mushroom } \\
\text { specie } \\
\text { studied }\end{array}$ \\
\hline 104 & 2014 & $\begin{array}{l}\text { Journal of Food } \\
\text { Science and } \\
\text { Technology }\end{array}$ & 2.203 & $\begin{array}{l}\text { Gogavekar, } \\
\text { SS. et al }\end{array}$ & $\begin{array}{c}\text { Important nutritional } \\
\text { constituents, flavour } \\
\text { components, antioxidant and } \\
\text { antibacterial properties of } \\
\text { Pleurotus sajor-caju. }\end{array}$ & $\begin{array}{l}51,8 \\
1483- \\
1491\end{array}$ & $\begin{array}{c}\text { Total } \\
\text { flavonoids }\end{array}$ & $\mathrm{AlCl}_{3}$ & $\begin{array}{c}\text { UV/VIS } 415 \\
n m\end{array}$ & Methanol & P. sajor-caju \\
\hline 105 & 2014 & $\begin{array}{l}\text { Journal of } \\
\text { Consumer } \\
\text { Protection and } \\
\text { Food Safety }\end{array}$ & 0.719 & $\begin{array}{l}\text { Singdevsach } \\
\text { an, SK. et al. }\end{array}$ & $\begin{array}{l}\text { Evaluation of nutritional and } \\
\text { nutraceutical potentials of } \\
\text { three wild edible mushrooms } \\
\text { from Similipal Biosphere } \\
\text { Reserve, Odisha, India. }\end{array}$ & $\begin{array}{c}9,2,111- \\
120\end{array}$ & $\begin{array}{c}\text { Total } \\
\text { flavonoids }\end{array}$ & $\begin{array}{l}\mathrm{NaNO}_{2}+ \\
10 \% \mathrm{AlCl}_{3} \\
\mathrm{H}_{2} \mathrm{O}\end{array}$ & VIS $510 \mathrm{~nm}$ & $\begin{array}{l}\text { Ethanol, } \\
\text { methanol or } \\
\text { water }\end{array}$ & $\begin{array}{c}\text { Russula } \\
\text { vesca, } R . \\
\text { delica and } \\
\text { Termitomyce } \\
\text { s eurrhizus }\end{array}$ \\
\hline 106 & 2014 & $\begin{array}{l}\text { International } \\
\text { Journal of Food } \\
\text { Sciences and } \\
\text { Nutrition }\end{array}$ & 1.206 & $\begin{array}{l}\text { Karaman, M. } \\
\text { et al. }\end{array}$ & $\begin{array}{c}\text { Wild-growing } \\
\text { lignicolous mushroom specie } \\
\mathrm{s} \text { as sources of novel agents } \\
\text { with antioxidative and } \\
\text { antibacterial potentials. }\end{array}$ & $\begin{array}{c}65,3 \\
311-319\end{array}$ & $\begin{array}{c}\text { Total } \\
\text { flavonoids }\end{array}$ & Colorimetric & NF & NF & $\begin{array}{c}\text { Meripilus } \\
\text { giganteus, } A \text {. } \\
\text { aegerita, } F \text {. } \\
\text { fomentarius } \\
\text { and Xylaria } \\
\text { polymorpha }\end{array}$ \\
\hline 107 & 2014 & $\begin{array}{l}\text { Journal of } \\
\text { Agricultural and } \\
\text { Food Chemistry }\end{array}$ & 2.912 & $\begin{array}{l}\text { Sapozhnikov } \\
\text { a, Y. et al. }\end{array}$ & $\begin{array}{l}\text { Effects of UV-B radiation } \\
\text { levels on concentrations of } \\
\text { phytosterols, ergothioneine, } \\
\text { and polyphenolic compounds } \\
\text { in mushroom powders used } \\
\text { as dietary supplements. }\end{array}$ & $\begin{array}{l}62,14 \\
3034- \\
3042\end{array}$ & $\begin{array}{c}\text { Total } \\
\text { flavonoids }\end{array}$ & $\begin{array}{l}\text { LC-ESI- } \\
\text { MS/M }\end{array}$ & $\begin{array}{l}\text { Comparison } \\
\text { of mass } \\
\text { spectras } \\
\text { and } \\
\text { retention } \\
\text { times }\end{array}$ & $\begin{array}{c}80 \% \\
\text { Methanol }\end{array}$ & $\begin{array}{l}\text { A. bisporus, } \\
P . \text { ostreatus } \\
\text { and } L . \\
\text { edodes }\end{array}$ \\
\hline 108 & 2014 & $\begin{array}{l}\text { Journla of Food } \\
\text { Science }\end{array}$ & 1.696 & $\mathrm{Li}, \mathrm{H}$. et al. & $\begin{array}{l}\text { Antioxidant and anti- } \\
\text { inflammatory activities of } \\
\text { methanol extracts of } \\
\text { Tremella fuciformis and its } \\
\text { major phenolic acids. }\end{array}$ & $\begin{array}{l}79,4 \\
\text { C } 460- \\
\text { C468 }\end{array}$ & $\begin{array}{c}\text { Total } \\
\text { flavonoids }\end{array}$ & $\mathrm{AlCl}_{3}$ & VIS $640 \mathrm{~nm}$ & $\begin{array}{c}80 \% \\
\text { Methanol }\end{array}$ & $\begin{array}{l}\text { Tremella } \\
\text { fuciformis }\end{array}$ \\
\hline 109 & 2014 & $\begin{array}{l}\text { Journal of Food } \\
\text { Biochemistry }\end{array}$ & 0.741 & $\begin{array}{l}\text { Hasnat, MA. } \\
\text { et al. }\end{array}$ & $\begin{array}{l}\text { DNA protection, total } \\
\text { phenolics and antioxidant } \\
\text { potential of the mushroom } \\
\text { Russula virescens. }\end{array}$ & $\begin{array}{c}38,1,6- \\
17\end{array}$ & $\begin{array}{c}\text { Total } \\
\text { flavonoids }\end{array}$ & $\begin{array}{l}\mathrm{NaNO}_{2}+ \\
10 \% \mathrm{AlCl}_{3} \\
\mathrm{H}_{2} \mathrm{O}\end{array}$ & VIS 517 nm & $\begin{array}{c}75 \% \\
\text { Ethanol or } \\
\text { water }\end{array}$ & R. virescens \\
\hline
\end{tabular}




\section{Appendix-Supplementary Table 1}

\begin{tabular}{|c|c|c|c|c|c|c|c|c|c|c|c|}
\hline Number & Year & Journal & $\begin{array}{l}\text { Impact } \\
\text { factor }\end{array}$ & First author & Title & $\begin{array}{l}\text { Volumen, } \\
\text { Issue, } \\
\text { pages }\end{array}$ & $\begin{array}{c}\text { Compounds } \\
\text { found in } \\
\text { mushrooms }\end{array}$ & $\begin{array}{l}\text { Method } \\
\text { utilized to } \\
\text { measure } \\
\text { flavonoids }\end{array}$ & $\begin{array}{l}\text { Detection } \\
\text { device or } \\
\text { wavelength } \\
\text { used }\end{array}$ & $\begin{array}{l}\text { Solvents } \\
\text { used for } \\
\text { extraction }\end{array}$ & $\begin{array}{l}\text { Mushroom } \\
\text { specie } \\
\text { studied }\end{array}$ \\
\hline 110 & 2014 & $\begin{array}{l}\text { Food Analytical } \\
\text { Methods }\end{array}$ & 1.956 & $\begin{array}{l}\text { Cayan, F. et } \\
\text { al. }\end{array}$ & $\begin{array}{l}\text { Application of GC, GC-MSD, } \\
\text { ICP-MS and } \\
\text { spectrophotometric methods } \\
\text { for the determination of } \\
\text { chemical composition and in } \\
\text { vitro bioactivities of } \\
\text { Chroogomphus rutilus: the } \\
\text { edible mushroom species. }\end{array}$ & $\begin{array}{c}7,2,449- \\
458\end{array}$ & $\begin{array}{c}\text { Total } \\
\text { flavonoids }\end{array}$ & $10 \% \mathrm{AlNO}_{3}$ & $\begin{array}{c}\text { UV/VIS } 415 \\
n m\end{array}$ & $\begin{array}{l}\text { Ethaol, } \\
\text { hexane, } \\
\text { ethyl } \\
\text { acetate or } \\
\text { water }\end{array}$ & $\begin{array}{c}\text { Chroogomph } \\
\text { us rutilus }\end{array}$ \\
\hline 111 & 2014 & $\begin{array}{c}\text { Drying } \\
\text { Technologies }\end{array}$ & 1.518 & $\begin{array}{c}\text { Jaworska, G. } \\
\text { et al. }\end{array}$ & $\begin{array}{l}\text { Effect of different drying } \\
\text { methods and } 24 \text {-month } \\
\text { storage on water activity, } \\
\text { rehydration capacity, and } \\
\text { antioxidants in Boletus edulis } \\
\text { mushrooms. }\end{array}$ & $\begin{array}{c}32,3 \\
291-300\end{array}$ & $\begin{array}{c}\text { Total } \\
\text { flavonoids }\end{array}$ & Colorimetric & NF & NF & B. edulis \\
\hline 112 & 2014 & $\begin{array}{l}\text { Journal of Pure } \\
\text { and Applied } \\
\text { Microbiology }\end{array}$ & 0.073 & $\begin{array}{c}\text { Thakur, M. et } \\
\text { al. }\end{array}$ & $\begin{array}{l}\text { Qualitative phytochemical } \\
\text { screening, total phenolic } \\
\text { content, in vitro antioxidant } \\
\text { activity and antimicrobial } \\
\text { activities in methanolic } \\
\text { extracts of Lactarius } \\
\text { sanguifluus (Paulet) Fr. }\end{array}$ & $\begin{array}{c}8,6 \\
4735- \\
4741\end{array}$ & $\begin{array}{c}\text { Total } \\
\text { flavonoids }\end{array}$ & Colorimetric & NF & Methanol & L. sanguifluus \\
\hline 113 & 2014 & $\begin{array}{c}\text { Journal of Applied } \\
\text { Botany and Food } \\
\text { Quality }\end{array}$ & 0.758 & $\begin{array}{l}\text { Kruzselyi, D. } \\
\text { et al. }\end{array}$ & $\begin{array}{c}\text { Complex chemical evaluation } \\
\text { of the summer truffle (Tuber } \\
\text { aestivum Vittadini) fruit } \\
\text { bodies. }\end{array}$ & $\begin{array}{c}87,- \\
291-295\end{array}$ & $\begin{array}{c}\text { Total } \\
\text { flavonoids }\end{array}$ & $\mathrm{AlCl}_{3}$ & $\begin{array}{c}\text { UV/VIS } 415 \\
n m\end{array}$ & Methanol & $\begin{array}{l}\text { Tuber } \\
\text { aestivum } \\
\text { Vittadini }\end{array}$ \\
\hline 114 & 2014 & $\begin{array}{l}\text { Archives of } \\
\text { Biological } \\
\text { Sciences }\end{array}$ & 0.718 & $\begin{array}{l}\text { Milovanovic, } \\
\text { I. et al. }\end{array}$ & $\begin{array}{l}\text { Antioxidant, antigungal and } \\
\text { anticancer activities of Se- } \\
\text { enriched Pleurotus spp. } \\
\text { mycelium extracts. }\end{array}$ & $\begin{array}{l}66,4 \\
1379- \\
1388\end{array}$ & $\begin{array}{c}\text { Total } \\
\text { flavonoids }\end{array}$ & $10 \% \mathrm{Al}\left(\mathrm{NO}_{3}\right)_{3}$ & $\begin{array}{c}\text { UV/VIS } 415 \\
n m\end{array}$ & $\begin{array}{c}96 \% \\
\text { Ethanol }\end{array}$ & $\begin{array}{c}P \text {. eryngii, } P \text {. } \\
\text { ostreatus and } \\
P . \\
\text { pulmonarius }\end{array}$ \\
\hline
\end{tabular}




\section{Appendix-Supplementary Table 1}

\begin{tabular}{|c|c|c|c|c|c|c|c|c|c|c|c|}
\hline Number & Year & Journal & $\begin{array}{l}\text { Impact } \\
\text { factor }\end{array}$ & First author & Title & $\begin{array}{l}\text { Volumen, } \\
\text { Issue, } \\
\text { pages }\end{array}$ & $\begin{array}{l}\text { Compounds } \\
\text { found in } \\
\text { mushrooms }\end{array}$ & $\begin{array}{l}\text { Method } \\
\text { utilized to } \\
\text { measure } \\
\text { flavonoids }\end{array}$ & $\begin{array}{c}\text { Detection } \\
\text { device or } \\
\text { wavelength } \\
\text { used }\end{array}$ & $\begin{array}{l}\text { Solvents } \\
\text { used for } \\
\text { extraction }\end{array}$ & $\begin{array}{l}\text { Mushroom } \\
\text { specie } \\
\text { studied }\end{array}$ \\
\hline 115 & 2014 & $\begin{array}{l}\text { Scientific World } \\
\text { Journal }\end{array}$ & NF & $\begin{array}{l}\text { Phan, CW. et } \\
\text { al. }\end{array}$ & $\begin{array}{l}\text { Intrastrain comparison of the } \\
\text { chemical composition and } \\
\text { antioxidant activity of an } \\
\text { edible mushroom, Pleurotus } \\
\text { giganteus, and its potent } \\
\text { neuritogenic properties. }\end{array}$ & $\begin{array}{c}2014,- \\
111 \\
(\text { ID } 37865 \\
1)\end{array}$ & $\begin{array}{c}\text { Total } \\
\text { flavonoids }\end{array}$ & $\mathrm{AlCl}_{3}$ & VIS 435 nm & Ethanol & $\begin{array}{l}\text { Pleurotus } \\
\text { giganteus }\end{array}$ \\
\hline \multirow[t]{2}{*}{116} & \multirow[t]{2}{*}{2014} & \multirow{2}{*}{$\begin{array}{l}\text { Food Science and } \\
\text { Biotechnology }\end{array}$} & \multirow[t]{2}{*}{0.653} & \multirow{2}{*}{$\begin{array}{l}\text { Vamanu, E. } \\
\text { et al. }\end{array}$} & \multirow{2}{*}{$\begin{array}{l}\text { Biological activity of fluidized } \\
\text { bed ethanol extracts from } \\
\text { several edible mushrooms. }\end{array}$} & \multirow{2}{*}{$\begin{array}{l}23,5 \\
1483- \\
1490\end{array}$} & $\begin{array}{c}\text { Total } \\
\text { flavonoids }\end{array}$ & $\mathrm{AlCl}_{3}$ & $\begin{array}{c}\text { UV/VIS } 415 \\
n m\end{array}$ & \multirow{2}{*}{$\begin{array}{l}70 \% \\
\text { Ethanol }\end{array}$} & $\begin{array}{l}\text { P. ostreatus, } \\
\text { A. bisporus, } \\
\text { M. oreades, } \\
\text { C. } \\
\text { cornucopioide } \\
\text { s, and Tuber } \\
\text { melanosporu } \\
\text { m }\end{array}$ \\
\hline & & & & & & & $\begin{array}{l}\text { Rutin and } \\
\text { catechin }\end{array}$ & HPLC-DAD & $\begin{array}{l}\text { Comparison } \\
\text { of retention } \\
\text { times }\end{array}$ & & $\begin{array}{c}T . \\
\text { melanosporu } \\
m \text { and } P . \\
\text { ostreatus }\end{array}$ \\
\hline 117 & 2014 & $\begin{array}{l}\text { Food Science and } \\
\text { Technology }\end{array}$ & 0.393 & $\begin{array}{l}\text { Miao, QJ. et } \\
\text { al. }\end{array}$ & $\begin{array}{l}\text { Research on total flavonoids } \\
\text { bioactivity of edible fungus. }\end{array}$ & $\begin{array}{c}7,39 \\
206-209\end{array}$ & $\begin{array}{c}\text { Total } \\
\text { flavonoids }\end{array}$ & Colorimetric & NF & NF & $\begin{array}{l}\text { Pleurotus } \\
\text { citrinopileatus } \\
\text {, Pleurotus } \\
\text { geesteranus, } \\
\text { A. auricula } \\
\text { and } P \text {. } \\
\text { ostreatus }\end{array}$ \\
\hline 118 & 2014 & $\begin{array}{l}\text { LWT-Food } \\
\text { Sciences and } \\
\text { Technology }\end{array}$ & 2.416 & Lin, JT. et al. & $\begin{array}{c}\text { Chemical composition, } \\
\text { antioxidant and anti- } \\
\text { inflammatory properties for } \\
\text { Ethanolic extracts from } \\
\text { Pleurotus eryngii fruiting } \\
\text { bodies harvested at different } \\
\text { time. }\end{array}$ & $\begin{array}{c}55,1 \\
374-382\end{array}$ & $\begin{array}{c}\text { Total } \\
\text { flavonoids }\end{array}$ & HPLC-DAD & $\begin{array}{l}\text { UV } 220-450 \\
\text { nm and } \\
\text { comparison } \\
\text { of retention } \\
\text { times }\end{array}$ & Ethanol & P. eryngii \\
\hline
\end{tabular}




\section{Appendix-Supplementary Table 1}

\begin{tabular}{|c|c|c|c|c|c|c|c|c|c|c|c|}
\hline Number & Year & Journal & $\begin{array}{l}\text { Impact } \\
\text { factor }\end{array}$ & First author & Title & $\begin{array}{l}\text { Volumen, } \\
\text { Issue, } \\
\text { pages }\end{array}$ & $\begin{array}{c}\text { Compounds } \\
\text { found in } \\
\text { mushrooms }\end{array}$ & $\begin{array}{l}\text { Method } \\
\text { utilized to } \\
\text { measure } \\
\text { flavonoids }\end{array}$ & $\begin{array}{l}\text { Detection } \\
\text { device or } \\
\text { wavelength } \\
\text { used }\end{array}$ & $\begin{array}{l}\text { Solvents } \\
\text { used for } \\
\text { extraction }\end{array}$ & $\begin{array}{l}\text { Mushroom } \\
\text { specie } \\
\text { studied }\end{array}$ \\
\hline 119 & $2015^{*}$ & $\begin{array}{l}\text { Industrial Crops } \\
\text { and Products }\end{array}$ & 2.837 & $\begin{array}{l}\text { Tel-Cayan, } \\
\text { G. et al. }\end{array}$ & $\begin{array}{l}\text { Phytochemical investigation, } \\
\text { antioxidant and } \\
\text { anticholinesterase activities } \\
\text { of Ganoderma adspersum. }\end{array}$ & $\begin{array}{c}76,- \\
749-754\end{array}$ & $\begin{array}{c}\text { Total } \\
\text { flavonoids }\end{array}$ & $10 \% \mathrm{Al}\left(\mathrm{NO}_{3}\right)_{3}$ & $\begin{array}{c}\text { UV/VIS } 415 \\
n m\end{array}$ & Methanol & $\begin{array}{l}\text { Ganoderma } \\
\text { adspersum }\end{array}$ \\
\hline 120 & $2015^{\star}$ & Food Chemistry & 3.391 & $\begin{array}{l}\text { Jiang, T. et } \\
\text { al. }\end{array}$ & $\begin{array}{l}\text { Fumigation with essential oils } \\
\text { improves sensory quality and } \\
\text { enhanced antioxidant ability } \\
\text { of shiitake mushroom } \\
\text { (Lentinus edodes). }\end{array}$ & $\begin{array}{l}\text { 172, - } \\
692-698\end{array}$ & $\begin{array}{c}\text { Total } \\
\text { flavonoids }\end{array}$ & $\begin{array}{c}\mathrm{NaNO}_{2}+ \\
10 \% \mathrm{AlCl}_{3} . \\
\mathrm{H}_{2} \mathrm{O}\end{array}$ & VIS 510 nm & $\begin{array}{c}80 \% \\
\text { Ethanol }\end{array}$ & L. edodes \\
\hline 121 & $2015^{\star}$ & $\begin{array}{l}\text { International } \\
\text { Journal of } \\
\text { Medicinal } \\
\text { Mushrooms }\end{array}$ & 0.927 & $\begin{array}{c}\text { Ebrahimzade } \\
\text { h, MA. et al. }\end{array}$ & $\begin{array}{l}\text { Antioxidant activity of } \\
\text { different fractions of } \\
\text { methanolic extract of the } \\
\text { golden chanterelle } \\
\text { mushroom Cantharellus } \\
\text { cibarius (Higher } \\
\text { Basidiomycetes) from Iran. }\end{array}$ & $\begin{array}{c}17,6 \\
557-565\end{array}$ & $\begin{array}{c}\text { Total } \\
\text { flavonoids }\end{array}$ & Colorimetric & NF & $\begin{array}{l}\text { Metanol, } \\
\text { hexane, } \\
\text { choroform, } \\
\text { ethyl } \\
\text { acetate, } \mathrm{n} \text { - } \\
\text { butanol or } \\
\text { water }\end{array}$ & C. cibarius \\
\hline \multirow{2}{*}{122} & \multirow{2}{*}{$2015^{*}$} & \multirow{2}{*}{$\begin{array}{l}\text { BioMed Research } \\
\text { International }\end{array}$} & \multirow{2}{*}{1.579} & \multirow{2}{*}{$\begin{array}{l}\text { Sharma, SK. } \\
\text { et al. }\end{array}$} & \multirow{2}{*}{$\begin{array}{l}\text { Chemical, bioactive, and } \\
\text { antioxidant potential of } \\
\text { twenty wild } \\
\text { culinary mushroom species. }\end{array}$} & \multirow{2}{*}{$\begin{array}{c}2015,- \\
12 \text { (ID } \\
346508)\end{array}$} & $\begin{array}{c}\text { Total } \\
\text { flavonoids }\end{array}$ & $\begin{array}{l}\mathrm{NaNO}_{2}+ \\
10 \% \mathrm{AlCl}_{3} \\
\mathrm{H}_{2} \mathrm{O}\end{array}$ & VIS $510 \mathrm{~nm}$ & Water & \multirow{2}{*}{$\begin{array}{l}20 \text { culinary } \\
\text { mushroom } \\
\text { species }\end{array}$} \\
\hline & & & & & & & $\begin{array}{c}\text { Anthocyanidi } \\
\text { ns }\end{array}$ & Colorimetric & VIS 546 nm & $\begin{array}{c}\text { Ethyl } \\
\text { alcohol and } \\
\mathrm{ClH}\end{array}$ & \\
\hline 123 & $2015^{*}$ & $\begin{array}{l}\text { Food and } \\
\text { Function }\end{array}$ & 2.791 & $\begin{array}{l}\text { Kozarski, M. } \\
\text { et al. }\end{array}$ & $\begin{array}{c}\text { Nutraceutical properties of } \\
\text { the methanolic extract of } \\
\text { edible mushroom Cantharellu } \\
\text { s cibarius (Fries): primary } \\
\text { mechanisms. }\end{array}$ & $\begin{array}{c}6,6 \\
1875-86\end{array}$ & $\begin{array}{c}\text { Total } \\
\text { flavonoids }\end{array}$ & $\begin{array}{l}\mathrm{NaNO}_{2}+ \\
10 \% \mathrm{AlCl}_{3} \\
\quad \mathrm{H}_{2} \mathrm{O}\end{array}$ & VIS $510 \mathrm{~nm}$ & Methanol & C. cibarius \\
\hline 124 & $2015^{\star}$ & $\begin{array}{l}\text { International } \\
\text { Journal of } \\
\text { Medicinal } \\
\text { Mushrooms }\end{array}$ & 0.927 & $\begin{array}{l}\text { Khaund, P. et } \\
\text { al. }\end{array}$ & $\begin{array}{l}\text { Functional nutraceutical } \\
\text { profiling of wild edible and } \\
\text { medicinal mushrooms } \\
\text { consumed by ethnic tribes in } \\
\text { India. }\end{array}$ & $\begin{array}{c}17,2 \\
187-197\end{array}$ & $\begin{array}{c}\text { Total } \\
\text { flavonoids }\end{array}$ & Colorimetric & NF & Ethanol & $\begin{array}{l}10 \text { wild and } \\
\text { edible } \\
\text { mushrooms }\end{array}$ \\
\hline
\end{tabular}




\section{Appendix-Supplementary Table 1}

\begin{tabular}{|c|c|c|c|c|c|c|c|c|c|c|c|}
\hline Number & Year & Journal & $\begin{array}{l}\text { Impact } \\
\text { factor }\end{array}$ & First author & Title & $\begin{array}{l}\text { Volumen, } \\
\text { Issue, } \\
\text { pages }\end{array}$ & $\begin{array}{c}\text { Compounds } \\
\text { found in } \\
\text { mushrooms }\end{array}$ & $\begin{array}{l}\text { Method } \\
\text { utilized to } \\
\text { measure } \\
\text { flavonoids }\end{array}$ & $\begin{array}{l}\text { Detection } \\
\text { device or } \\
\text { wavelength } \\
\text { used }\end{array}$ & $\begin{array}{l}\text { Solvents } \\
\text { used for } \\
\text { extraction }\end{array}$ & $\begin{array}{l}\text { Mushroom } \\
\text { specie } \\
\text { studied }\end{array}$ \\
\hline 125 & $2015^{*}$ & $\begin{array}{l}\text { International } \\
\text { Journal of } \\
\text { Medicinal } \\
\text { Mushrooms }\end{array}$ & 0.927 & Wu, T. et al. & $\begin{array}{l}\text { Antidiabetic and antioxidant } \\
\text { activities of eight } \\
\text { medicinal mushroom species } \\
\text { from China. }\end{array}$ & $\begin{array}{c}17,2 \\
129-40\end{array}$ & $\begin{array}{c}\text { Total } \\
\text { flavonoids }\end{array}$ & Colorimetric & NF & NF & $\begin{array}{l}\text { G. lucidum } \\
\text { and } T \text {. } \\
\text { fuciformis }\end{array}$ \\
\hline 126 & $2015^{*}$ & $\begin{array}{l}\text { International } \\
\text { Journal of } \\
\text { Medicinal } \\
\text { Mushrooms }\end{array}$ & 0.927 & $\begin{array}{l}\text { Mishra ,KK. } \\
\text { et al. }\end{array}$ & $\begin{array}{l}\text { Antioxidant activities and } \\
\text { bioactive compound } \\
\text { determination from caps and } \\
\text { stipes of specialty medicinal } \\
\text { mushrooms Calocybe indica } \\
\text { and Pleurotus sajor-caju } \\
\text { (higher Basidiomycetes) from } \\
\text { India. }\end{array}$ & $\begin{array}{c}16,6 \\
555-67 .\end{array}$ & Tannins & Colorimetric & NF & $\begin{array}{c}\text { Methanol or } \\
\text { water }\end{array}$ & $\begin{array}{l}\text { C. indica and } \\
\text { P. sajor-caju }\end{array}$ \\
\hline \multirow[t]{2}{*}{127} & \multirow[t]{2}{*}{$2015^{\star}$} & \multirow{2}{*}{$\begin{array}{l}\text { Brazilian Journal } \\
\text { of Microbiology }\end{array}$} & \multirow[t]{2}{*}{0.592} & \multirow{2}{*}{$\begin{array}{c}\text { Tajalli, F. et } \\
\text { al. }\end{array}$} & \multirow{2}{*}{$\begin{array}{l}\text { Antioxidant capacity of } \\
\text { several Iranian, wild and } \\
\text { cultivated strains of the } \\
\text { button mushroom. }\end{array}$} & \multirow{2}{*}{$\begin{array}{c}46,3 \\
769-776\end{array}$} & $\begin{array}{c}\text { Total } \\
\text { flavonoids }\end{array}$ & $\begin{array}{c}\mathrm{NaNO}_{2}+ \\
10 \% \mathrm{AlCl}_{3} \\
\mathrm{H}_{2} \mathrm{O}\end{array}$ & VIS $510 \mathrm{~nm}$ & \multirow[t]{2}{*}{ Methanol } & \multirow[t]{2}{*}{ A. bisporus } \\
\hline & & & & & & & $\begin{array}{c}\text { Anthocyanidi } \\
\text { ns }\end{array}$ & $\mathrm{NaCH}_{3} \mathrm{Co}_{2}$ & $\begin{array}{c}\text { VIS } 510-700 \\
n m\end{array}$ & & \\
\hline 128 & $2015^{\star}$ & $\begin{array}{l}\text { Internatinal } \\
\text { Journal of Food } \\
\text { Science and } \\
\text { Technology }\end{array}$ & 1.384 & $\begin{array}{l}\text { Mokochinski, } \\
\text { JB. et al. }\end{array}$ & $\begin{array}{l}\text { Production of Agaricus } \\
\text { brasiliensis mycelium from } \\
\text { food industry residues as a } \\
\text { source of antioxidants and } \\
\text { essential fatty acids. }\end{array}$ & $\begin{array}{l}50,9 \\
2052- \\
2058\end{array}$ & $\begin{array}{c}\text { Total } \\
\text { flavonoids }\end{array}$ & $\mathrm{AlCl}_{3}$ & VIS 425 nm & Methanol & A. brasiliensis \\
\hline 129 & $2015^{\star}$ & $\begin{array}{l}\text { LWT-Food } \\
\text { Sciences and } \\
\text { Technology }\end{array}$ & 2.416 & $\begin{array}{l}\text { Gasecka, M. } \\
\text { et al. }\end{array}$ & $\begin{array}{l}\text { The effect of selenium on } \\
\text { phenolics and flavonoids in } \\
\text { selected edible white rot } \\
\text { fungi. }\end{array}$ & $\begin{array}{c}63,1 \\
726-731\end{array}$ & $\begin{array}{c}\text { Total } \\
\text { flavonoids }\end{array}$ & $\begin{array}{c}\mathrm{NaNO}_{2}+ \\
10 \% \mathrm{AlCl}_{3} \\
\mathrm{H}_{2} \mathrm{O}\end{array}$ & VIS $510 \mathrm{~nm}$ & Methanol & $\begin{array}{l}\text { Pholiota } \\
\text { nameko, } P \text {. } \\
\text { eryngii and } P \text {. } \\
\text { ostreatus }\end{array}$ \\
\hline 130 & $2015^{\star}$ & $\begin{array}{l}\text { Pharmaceutil } \\
\text { Biology }\end{array}$ & 1.241 & Tel, G. et al. & $\begin{array}{l}\text { Antioxidant and } \\
\text { anticholinesterase activities } \\
\text { of five } \\
\text { wild mushroom species with } \\
\text { total bioactive contents. }\end{array}$ & $\begin{array}{c}53,6 \\
824-830\end{array}$ & $\begin{array}{c}\text { Total } \\
\text { flavonoids }\end{array}$ & Colorimetric & NF & $\begin{array}{c}\text { Methanol or } \\
\text { ethyl } \\
\text { acetate }\end{array}$ & $\begin{array}{l}\text { G. Iucidum } \\
\text { and Funalia } \\
\text { trogii }\end{array}$ \\
\hline
\end{tabular}




\section{Appendix-Supplementary Table 1}

\begin{tabular}{|c|c|c|c|c|c|c|c|c|c|c|c|}
\hline Number & Year & Journal & $\begin{array}{l}\text { Impact } \\
\text { factor }\end{array}$ & First author & Title & $\begin{array}{l}\text { Volumen, } \\
\text { Issue, } \\
\text { pages }\end{array}$ & $\begin{array}{c}\text { Compounds } \\
\text { found in } \\
\text { mushrooms }\end{array}$ & $\begin{array}{l}\text { Method } \\
\text { utilized to } \\
\text { measure } \\
\text { flavonoids }\end{array}$ & $\begin{array}{l}\text { Detection } \\
\text { device or } \\
\text { wavelength } \\
\text { used }\end{array}$ & $\begin{array}{l}\text { Solvents } \\
\text { used for } \\
\text { extraction }\end{array}$ & $\begin{array}{l}\text { Mushroom } \\
\text { specie } \\
\text { studied }\end{array}$ \\
\hline 131 & $2015^{\star}$ & Food Chemistry & 3.391 & $\begin{array}{l}\text { Sarikurkcu, } \\
\text { C. et al. }\end{array}$ & $\begin{array}{l}\text { Metal concentration and } \\
\text { antioxidant activity of edible } \\
\text { mushrooms from Turkey. }\end{array}$ & $\begin{array}{c}175,- \\
549-555\end{array}$ & $\begin{array}{c}\text { Total } \\
\text { flavonoids }\end{array}$ & $\mathrm{AlCl}_{3}$ & $\begin{array}{c}\text { UV/VIS } 415 \\
n m\end{array}$ & $\begin{array}{l}\text { Methanol or } \\
\text { water }\end{array}$ & $\begin{array}{l}\text { Polyporus } \\
\text { sulphureus, } \\
\text { Macrolepiota } \\
\text { procera, L. } \\
\text { perlatum and } \\
\text { Gomphus } \\
\text { clavatus }\end{array}$ \\
\hline 132 & $2015^{\star}$ & $\begin{array}{l}\text { Pharmacognosy } \\
\text { Magazine }\end{array}$ & 1.256 & Sadi, G. et al. & $\begin{array}{l}\text { Cytotoxicity of some edible } \\
\text { mushrooms extracts over } \\
\text { liver hepatocellular } \\
\text { carcinoma cells in } \\
\text { conjunction with their } \\
\text { antioxidant and antibacterial } \\
\text { properties. }\end{array}$ & $\begin{array}{c}11,4 \\
\text { suppleme } \\
\text { nt, } 6-18\end{array}$ & $\begin{array}{c}\text { Total } \\
\text { flavonoids }\end{array}$ & Colorimetric & NF & $\begin{array}{l}\text { Methanol, } \\
\text { acetone, n- } \\
\text { hexane, } \\
\text { cloroform } \\
\text { or water }\end{array}$ & $\begin{array}{l}\text { C. comatus, } \\
\text { T. fracticum, } \\
\text { Rhizopogon } \\
\text { luteolus and } \\
\text { Lentinus } \\
\text { tigrinus }\end{array}$ \\
\hline 133 & $2015^{\star}$ & $\begin{array}{l}\text { Internatinal } \\
\text { Journal of Food } \\
\text { Science and } \\
\text { Technology }\end{array}$ & 1.384 & $\begin{array}{l}\text { Zhang, N. et } \\
\text { al. }\end{array}$ & $\begin{array}{c}\text { Chemical composition and } \\
\text { antioxidant properties of five } \\
\text { edible Hymenomycetes } \\
\text { mushrooms. }\end{array}$ & $\begin{array}{c}50,2 \\
465-471\end{array}$ & $\begin{array}{c}\text { Total } \\
\text { flavonoids }\end{array}$ & $\begin{array}{l}\mathrm{NaNO}_{2}+ \\
10 \% \mathrm{AlCl}_{3}\end{array}$ & VIS 510 nm & Ethanol & $\begin{array}{l}\text { L. edodes, } T \text {. } \\
\text { fuciformis, } A \text {. } \\
\text { polytricha, } G \text {. } \\
\text { lucidum and } I . \\
\text { obliquus }\end{array}$ \\
\hline 134 & $2015^{*}$ & $\begin{array}{l}\text { International } \\
\text { Journal of } \\
\text { Medicinal } \\
\text { Mushrooms }\end{array}$ & 0.927 & $\begin{array}{c}\text { Ganeshpurka } \\
\text { r, A. et al. }\end{array}$ & $\begin{array}{l}\text { Antioxidant potential of white } \\
\text { oyster culinary- } \\
\text { medicinal mushroom, } \\
\text { Pleurotus florida (Higher } \\
\text { Basidiomycetes). }\end{array}$ & $\begin{array}{c}17,5 \\
491-498\end{array}$ & $\begin{array}{c}\text { Total } \\
\text { flavonoids }\end{array}$ & Colorimetric & NF & $\begin{array}{l}50 \% \\
\text { Ethanol }\end{array}$ & P. florida \\
\hline 135 & $2015^{*}$ & $\begin{array}{l}\text { International } \\
\text { Journal of } \\
\text { Medicinal } \\
\text { Mushrooms }\end{array}$ & 0.927 & $\begin{array}{l}\text { Milovanovic, } \\
\text { I. et al. }\end{array}$ & $\begin{array}{l}\text { Effects of Selenium presence } \\
\text { in mycelia of Ganoderma } \\
\text { species (Higher } \\
\text { Basidiomycetes) on their } \\
\text { medicinal properties. }\end{array}$ & $\begin{array}{c}17,1,11- \\
20\end{array}$ & $\begin{array}{c}\text { Total } \\
\text { flavonoids }\end{array}$ & $10 \% \mathrm{Al}\left(\mathrm{NO}_{3}\right)_{3}$ & $\begin{array}{c}\text { UV/VIS } 415 \\
n m\end{array}$ & $\begin{array}{c}96 \% \\
\text { Ethanol }\end{array}$ & $\begin{array}{l}\text { G. } \\
\text { applanatum } \\
\text { and } G . \\
\text { lucidum }\end{array}$ \\
\hline 136 & $2015^{\star}$ & $\begin{array}{l}\text { Annals of Clinical } \\
\text { Microbiology and } \\
\text { Antimicrobials }\end{array}$ & 2.189 & $\begin{array}{l}\text { Chowdhury, } \\
\text { MMH. et al. }\end{array}$ & $\begin{array}{l}\text { Screening of antimicrobial, } \\
\text { antioxidant properties and } \\
\text { bioactive compounds of } \\
\text { some edible mushrooms } \\
\text { cultivated in Bangladesh. }\end{array}$ & $14,1,8$ & $\begin{array}{c}\text { Total } \\
\text { flavonoids }\end{array}$ & $10 \% \mathrm{Al}\left(\mathrm{NO}_{3}\right)_{3}$ & $\begin{array}{c}\text { UV/VIS } 415 \\
n m\end{array}$ & Methanol & $\begin{array}{l}\text { P. ostreatus, } \\
\text { L. edodes } \\
\text { and } H . \\
\text { tessulatus }\end{array}$ \\
\hline
\end{tabular}


Appendix-Supplementary Table 1 